Utah State University

DigitalCommons@USU

$5-1993$

\title{
The Impact of Nutrition Education on Dietary Behavior and Iron Status in Participants of the Supplemental Food Program for Women, Infants and Children, and the Expanded Food and Nutrition Education Program
}

Nedra K. Christensen

Utah State University

Follow this and additional works at: https://digitalcommons.usu.edu/etd

Part of the Human and Clinical Nutrition Commons, and the International and Community Nutrition Commons

\section{Recommended Citation}

Christensen, Nedra K., "The Impact of Nutrition Education on Dietary Behavior and Iron Status in Participants of the Supplemental Food Program for Women, Infants and Children, and the Expanded Food and Nutrition Education Program" (1993). All Graduate Theses and Dissertations. 5401.

https://digitalcommons.usu.edu/etd/5401

This Dissertation is brought to you for free and open access by the Graduate Studies at DigitalCommons@USU. It has been accepted for inclusion in All Graduate Theses and Dissertations by an authorized administrator of DigitalCommons@USU. For more information, please contact digitalcommons@usu.edu.

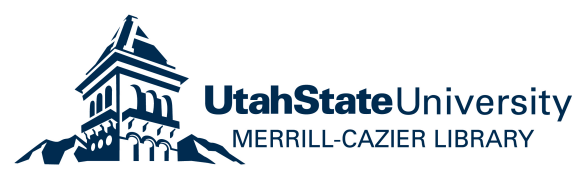


Copyright $\odot$ Nedra K. Christensen 1993

All Rights Reserved 
THE IMPACT OF NUTRITION EDUCATION ON DIETARY BEHAVIOR AND IRON STATUS IN PARTICIPANTS OF THE SUPPLEMENTAL FOOD PROGRAM FOR WOMEN, INFANTS AND CHILDREN, AND THE EXPANDED FOOD AND NUTRITION EDUCATION PROGRAM by

Nedra K. Christensen

A dissertation submitted in partial fulfillment of the requirements for the degree

of

DOCTOR OF PHILOSOPHY

in

Nutrition and Food Sciences

Approved :

UTAH STATE UNIVERSITY

Logan, Utah 


\section{ACKNOWLEDGMENTS}

This project is finally over, and I would like to acknowledge those who provided support and assistance to complete and polish this project.

I sincerely thank Dr. Georgia C. Lauritzen for her interest in this project, commitment to the data collection, and especially for her friendship and words of encouragement. I also thank Dr. Rodney J. Brown, Dr. Deloy G. Hendricks, Dr. Carol T. Windham, Dr. LeGrande C. Ellis, and Dr. Byron R. Burnham for their help in the study design as well as technical advice in the statistical and laboratory analysis. Roxane Pfister was very helpful with the statistical analysis. Becky Low and Eileen DeLeeuw provided valuable assistance in data collection and participant recruitment.

My family and friends provided a generous amount of encouragement and support. I express a special thanks and appreciation to my parents, Leo and Ethel Christensen.

I extend thanks to the participants who cooperated to make this study possible. I appreciated the help of the WIC County Clinic personnel and the Utah state University Extension EFNEP personnel.

Nedra K. Christensen 
CONTENTS

Page

ACKNOWLEDGMENTS . . . . . . . . . . . . . . . . ii

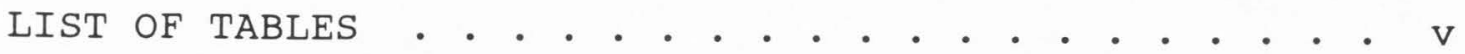

ABSTRACT . . . . . . . . . . . . . . . . . . . viii

CHAPTER

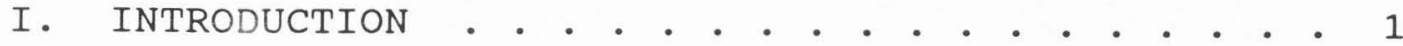

Background of the Problem . . . . . . . . . 1

Statement of the Problem . . . . . . . . . 4

Objectives . . . . . . . . . . . . . . 5

Research Design . . . . . . . . . . . 5

Significance . . . . . . . . . . . . . 10

Hypothesis . . . . . . . . . . . . . . 10

Working Hypothesis . . . . . . . . . . . 11

Delimitations of the study . . . . . . . . 11

II. REVIEW OF LITERATURE . . . . . . . . . . . . 12

Definition of Anemia . . . . . . . . . . . 12

Incidence and Diagnosis of Anemia . . . . . . 16

Iron Absorption . . . . . . . . . . . . . 24

Iron's Effect on Development . . . . . . . 27

Effectiveness of Nutrition Education . . . . 30

Evaluations of the WIC Program . . . . . . 34

Evaluations of the EFNEP Program . . . . . . 39

Summary of Literature Review

Relevance to This Study . . . . . . . . 44

III. METHODOLOGY . . . . . . . . . . . . . 48

Samples . . . . . . . . . . . . . . . 49

Description of the Instruments

Used to Obtain the Data . . . . . . . . 50

Protocol . . . . . . . . . . . . . . . 54

Analysis of Blood for Hematocrit

and Ferritin . . . . . . . . . . . 59

Statistical Analysis . . . . . . . . . 65

IV. RESULTS AND DISCUSSION . . . . . . . . . . 68

Description of the Study Population . . . . 68

Nutrition Knowledge Test Results . . . . . . 70

Paired T-Tests . . . . . . . . . . 75 
Percentage of the Study Population

That Did Not Meet $67 \%$ and $100 \%$

of the RDA for Several Nutrients . . . . . . 84

Mean Values and the Frequencies of

Hematocrit and Relative Ferritin . . . . . . 93

Correlation Analysis . . . . . . . . . . 96

Grouped T-Tests for Hematocrit,

Nutrition knowledge Scores and

Five Nutrients when separated

by the Discrete Variables of

"Taking Nutrition Classes" and

"Participating in Food Programs" . . . . . 100

Regression Analysis . . . . . . . . . 101

V. CONCLUSIONS AND RECOMMENDATIONS • . . . . . 107

Nutrition Knowledge . . . . . . . . . 107

Hematocrit Levels... . . . . . . . . 108

Dietary Nutrients . . . . . . . . . . . 109

Effect of Nutrition Education

Sessions in High School or

College and Income Level on

Dietary Intake and Nutrition

Knowledge Scores . . . . . . . . . . . . 111

Limitations . . . . . . . . . . . . . . 112

Recommendations . . . . . . . . . . . 112

REFERENCES • • • • . . . . . . . . . . . . . 114

APPENDICES . . . . . . . . . . . . . . . . . 120

APPENDIX A: Study Participant

Characteristics . . . . . . . . . . . . 121

APPENDIX B: Data Collection Forms
and Consent Form . . . . . . . . . . . . 127

APPENDIX C: Standards for Anemia
and Blood collection . . . . . . . . 140

APPENDIX D: Ferritin Double

Antibody Procedure . . . . . . . . . . . 157

APPENDIX E: Adjusted Ferritin

Double Antibody Procedure for

Small Samples... . . . . . . . . . 169

CURRICULUM VITAE • . . . . . . . . . . . . . 172 
LIST OF TABLES

Table

Page

1 California EFNEP participant characteristics

2 Adjustment in reagents for the Ferritin Double Antibody Method . . . . . . . . . 62

3 Ferritin levels for small amounts of serum using the altered Ferritin

Double Antibody procedure . . . . . . . . 64

4 Percent of study participants

answering each question correctly,

tallied by program... . . . . . . . . 71

5 Nutrition knowledge test scores,

tallied by program . . . . . . . . . . 72

6 Index of discrimination, efficiency

level, and difficulty level calculations

for the postprogram nutrition knowledge

test items...... . . . . . . . . 73

7 Index of discrimination, efficiency level, and difficulty level calculations for the preprogram nutrition knowledge test items

8 Paired t-tests on hematocrit, relative

ferritin, nutrition knowledge scores, and several nutrients for study participants . . . . 76

9 Paired t-tests on hematocrit, relative ferritin, nutrition knowledge scores, and several nutrients for study participants not taking vitamin supplements . . . . . . . . 79

10 Percentage of WIC study participants who were below $67 \%$ and $100 \%$ of the 1989 RDA for several vitamins and minerals . . . . . . . 85

11 Percentage of EFNEP study participants who were below $67 \%$ and $100 \%$ of the 1989 RDA for several vitamins and minerals . . . . 86

12 Percentage of WIC-Control study participants who were below $67 \%$ and $100 \%$ of the 1989

RDA for several vitamins and minerals 
13 Percentage of EFNEP-Control study participants who were below $67 \%$ and $100 \%$ of the 1989 RDA for several vitamins and minerals . . . . . . . 88

14 Percentage of the total study participants who were below $67 \%$ and $100 \%$ of the RDA for several vitamins and minerals

15 Analysis of variance calculated among the programs for several nutrients, hematocrit, and knowledge scores for participants not taking vitamin supplements . . . . . . . . . 91

16 Hematocrit values of study subjects, tallied by program. . . . . . . . . . . 94

17 Relative ferritin values of study subjects, tallied by program. . . . . . . . 95

18 Correlations of nutrition knowledge scores, iron intake, and hematocrit, reported by program . . . . . . . . . . . . . . . . 97

19 Correlations of independent variables . . . . . 98

20 Correlations for study participants with a hematocrit of 37 or less . . . . . . . . . . 99

21 Correlations for study participants not taking vitamin supplements and with a hematocrit of 37 or less . . . . . . . . . . 99

22 Grouped t-tests for hematocrit levels, nutrition knowledge scores and several nutrients when separated by the discrete variables "taking nutrition classes in high school," "taking nutrition classes in college," and "participating in other food programs".............. . 102

23 Regression analysis calculations showing significance . . . . . . . . . . . . . .

24 Regression analysis outlined with income level and nutrition classes as predictor variables . . . . . . . . . . .

A.1 Age distribution for WIC and WIC control study participants . . . . . . . .

A.2 Study participants categorized by family size and tailied by program 
A.3 Study participants categorized by monthly income and tallied by program . . . . 124

A.4 Study participants categorized by years of formal education and tallied by program . . . . . . . . . . . . 125

A.5 Percent of study participants who were taking vitamin supplements, participated in other federal food programs, or took a nutrition class in high school or college . . . . . . . . . 126

A. 6 Adjusted ferritin double antibody for small samples. . . . . . . . . 170 
viii

ABSTRACT

The Impact of Nutrition Education on Dietary Behavior and Iron Status in Participants of the Supplemental Food Program for Women, Infants and Children, and the Expanded Food and Nutrition Education Program

by

Nedra K. Christensen, Doctor of Philosophy

Utah State University, 1993

Major Professors: Dr. Georgia C. Lauritzen

Dr. Rodney J. Brown

Department: Nutrition and Food Sciences

This study was conducted to determine the impact of nutrition education on participants of the supplemental Food Program for Women, Infants and children (WIC) and the Expanded Food and Nutrition Education Program (EFNEP). The specific objectives were to: 1) determine the impact of participation in EFNEP on iron status as assessed by hematocrit (hct) and ferritin levels; 2) determine the effect of nutrition knowledge on het and ferritin values; and 3) determine the effect dietary behavior has on het and ferritin levels for both WIC and EFNEP participants.

Each study participant completed a 24-hour dietary recall record plus food frequency record, medical history, validated nutrition knowledge test, and finger stick blood sample prior to program enrollment or nutrition education, 
and again six months later. There were 42 WIC, 26 EFNEP, 23 WIC-control, and 23 EFNEP-control participants.

Paired t-tests were used to find differences between preprogram and postprogram evaluation scores for the variables of nutrition knowledge score, hematocrit level, ferritin level, and levels of several nutrients. Nutrition knowledge test scores increased significantly from preprogram to postprogram for both WIC and EFNEP participants $(14.2 \pm 3.27$ to $15.5 \pm 2.89$ for WIC, $14.2 \pm$ 3.77 to $15.6 \pm 2.79$ for EFNEP). EFNEP participants also increased significantly in het levels $(38.5 \% \pm 3.78$ to $40.7 \% \pm 2.13)$. Hematocrit levels did not change significantly for the wIC or control groups and nutrition knowledge did not increase for the control group between preprogram and postprogram evaluations.

Mean intakes of vitamin A, vitamin C, calcium, and protein were above the RDA at preprogram and postprogram evaluations, yet the percentage of individual participants who consumed less than $67 \%$ of the RDA in this study was higher than in the continuing Survey of Food Intake of Individuals - 1985. Improvement in nutrient intake at postprogram evaluations was encouraging.

Regression analysis indicated that nutrition education classes in college, income level, and level of formal education each had a positive effect on nutrient intake and nutrition knowledg $\epsilon$. 
CHAPTER I

INTRODUCTION

Problems involving food and nutrition and thus health are found throughout the world. Malnutrition or undernutrition can result in mild symptoms such as weakness, headaches, and irritability, or be severe such as kwashiorkor, or even death. Lack of food availability, lack of nutrition knowledge, an increasing number of unfamiliar foods with questionable nutritional content, an overabundance of unsound nutrition information, and misleading labeling or marketing information are a few reasons for suboptimal nutritional intake. Correcting these problems has been attempted by providing education programs. Nutrition education has had a positive effect on nutrition knowledge, attitude, and behavior according to a meta-analysis of 303 nutrition studies (Johnson and Johnson, 1985).

Background of the Problem

Undernutrition of iron and protein can produce irreversible health effects such as increased rates of infection, low growth rates in children, and delayed motor and cognitive development (Galler, 1987; Pollitt et al., 1985; Soemantri et al., 1985). The United States Congress has recognized this problem and has allocated money for nutrition programs to educa'e and to provide supplemental 
foods for those at highest risk, such as women and children.

One federally funded nutrition program is the Supplemental Food Program for Women, Infants, and Children (WIC). It provides nutrition education and nutrient dense foods (milk, cheese, eggs, beans, iron fortified cereals, and vitamin C fortified juices) for pregnant or lactating women, infants, and children under the age of five. WIC uses the hematocrit or hemoglobin finger stick blood value as one indicator of malnutrition. Hematocrit and hemoglobin values correlate with each other when correct techniques are used and indicate, when used interchangeably, similar iron status of the blood (Bull and Rittenbach, 1990; Yip et al., 1987b). They are inexpensive methods to screen for low iron stores, and either one may be used as a standard for screening for low iron status in the WIC program. Serum ferritin is a reliable indicator of tissue iron stores because it correlates with tissue ferritin. In the early stages of iron deficiency, ferritin stores decrease and are depleted before hematocrit or hemoglobin values indicate a deficiency (Lubin et al., 1980; Zeman, 1991).

The benefits of normal hematocrit levels (iron status) have been studied (Blot et al., 1981; Galler, 1987; Garn et al., 1981; Lubin et al., 1980; Stockman, 1987; WorthingtonRoberts, 1987). In a national collaborative perinatal 
project, the incidence of low birth weight and infant mortality correlated positively with low hemoglobin values (Garn et al., 1981). Children with malnutrition (specifically protein, kcalorie, and iron deficiency) exhibited significant delays in motor and cognitive development (Galler, 1987). Galler (1987) further summarized that behavioral impairment was the most permanent outcome of infant malnutrition. The cycle may continue with women who were low birth weight having low birth weight offspring.

Participation in the WIC program correlates positively with an increase in hematocrit or hemoglobin values as well as with other health indicators (Rush et al., 1988a). The authors emphasized that good long-term nutritional status is important by saying that the "behavioral and cognitive defects in children with iron deficiency anemia are not (fully) reversed by iron therapy. There were two logical explanations: either iron deficiency is not causally related to behavior, or if causally related, the deficits are the results of cumulative insult not easily reversible by rapid restoration of iron stores" (Rush et al., 1988a, p. 406$)$.

The WIC program provides foods high in nutritional quality compared to kcalorie level. The WIC food package has been designed to be high in iron, calcium, vitamin $C$, vitamin A, and protein. These are termed nutrient-dense 
foods. Providing vouchers for nutrient-dense foods has led to an increased proportion of household dollars spent on this type of foods (Rush et al., 1988a). The impact of early eating habits continuing through a lifetime has been reinforced by this practice (Rush et al., 1988a).

The Expanded Food and Nutrition Education Program (EFNEP) was developed to improve the nutrition and health of low income families by participant involvement in a series of nutrition education classes to improve nutritionrelated skills (shopping for and preparing nutritious foods). Eating behavior improved in EFNEP participants as assessed by improvement in dietary records (DelTredici et al., 1988; Torisky et al., 1987).

\section{Statement of the Problem}

Nutrition education has a positive effect on nutrition knowledge, attitude toward nutrition, and dietary behavior according to a meta-analysis of 303 nutrition studies (Johnson and Johnson, 1985). The next question to ask is "do the positive improvements in nutrition knowledge and dietary behavior improve health?" Two federally funded nutrition programs have helped untangle part of this question, but neither has collected all the data to answer this question. Participation in WIC results in improved hematocrit level (Rush et al., 1988a). The WIC program has not documented that an increased level of nutrition 
knowledge and dietary behavior correlates with the health assessment measurement of hematocrit. The EFNEP program has shown that eating behavior improves after nutrition education (Torisky, 1987, DelTredici et al., 1988). The EFNEP program lacks hematocrit measurements that would show whether improvements in nutrition knowledge improve iron status. A complete set of data from each of these programs would show whether improved nutrition knowledge improves dietary behavior and iron status.

objectives

The objectives of this study were to:

1) determine the impact participation in the Expanded Food and Nutrition Education Program has on iron status as assessed by hematocrit and ferritin values.

2) determine the effect of nutrition knowledge on hematocrit and ferritin values for both the WIC and EFNEP programs.

3) determine the effect of dietary behavior on hematocrit and ferritin values for both WIC and EFNEP participants.

Research Design

Forty-two participants who were first-time enrollees to the WIC program and 26 first-time enrollees to the EFNEP 
program were assessed for initial knowledge about nutrition by taking a validated nutrition test and by providing a 24hour dietary recall record and a food frequency record. Hematocrit and ferritin values were also obtained. The Human Subjects Committee of the Institutional Review Board at Utah State University reviewed all procedures required of study participants to ensure that safety and confidentiality were practiced. For the WIC group, a child in the family served as the study participant. A hematocrit and ferritin were drawn from the child, and the parent/guardian of the child took the knowledge test and provided the written documentation on the child's 24-hour dietary recall record and food frequency record. For the EFNEP group, the hematocrit level, ferritin level, nutrition score, and dietary behavior score were all assessed on the women participants. These knowledge test scores, dietary behavior scores, and blood values were taken at the initial appointment for enrollment in the program and repeated six months later.

Twenty-three women who received nutrition education and were in the same socioeconomic group as EFNEP participants served as the EFNEP control group. One child of each of the control women served as control subjects for the WIC program. The women in the control group were measured for hematocrit and ferritin levels, took the validated nutrition test, and provided a 24-hour dietary 
recall record and a food frequency record. The control children had hematocrit and ferritin levels measured, and their parent/guardian provided the written 24-hour dietary recall and food frequency for them. The parent/guardian's nutrition test score served as their assessment of nutrition knowledge. All tests and measurements were conducted initially and six months later for the control groups. Participants in WIC and EFNEP and control subjects signed informed consent documents outlining their involvement in the study, which included their right to withdraw. Data were collected and coded by identification numbers. Confidentiality was guarded for all study participants.

Hematocrit levels were collected by health department employees for the WIC program and by trained county employees for the EFNEP program. The hematocrit levels were collected according to health department policy. Four $0.5 \mathrm{~mm}$ hematocrit tubes were collected and spun according to protocol. The serum was saved and frozen to determine ferritin levels. Ferritin levels were determined using the method outlined by Diagnostic Products Corporation (Los Angeles, CA). Nutrition knowledge was assessed by administering the same validated nutrition test for both the WIC and EFNEP programs. Content validity was conducted to determine if the test matched the program's objectives. Construct validity was 
conducted to determine if the test required the participant to identify and analyze the information to get a correct answer. Content and construct validity were obtained from registered dietitians working in both programs. Face validity, the term used to describe whether the test takers feel the test is representative of the information learned in the program, was obtained by administering the test to graduate participants from the programs. The test was measured for internal consistency as calculated by the Kudar-Richardson method (Carmines and Zeller, 1987).

Dietary behavior was assessed by analyzing a 24-hour dietary recall record using the computrition software package (Computrition Inc., chatsworth, CA). The WIC program in Utah uses a 24-hour dietary recall record and a food frequency record to aid in assessing nutrient intake. The WIC dietary form was used for all participants in this study to obtain consistency in data collection. The food frequency record was used to help assess the 24-hour dietary recall record when there was a discrepancy between the 24-hour recall record (only 1 cup of milk was listed for the day) and the food frequency record (3 cups of milk per day were listed). This situation would result in further questioning by the nutritionist. Food intake records were analyzed for calcium, iron, protein, vitamin $A$, and vitamin $C$ since these are the nutrients WIC and 
EFNEP programs consider critical.

Group nutrition education classes and individual instruction were provided to WIC participants as usual. At least two nutrition education contacts must be offered to WIC participants every six months as stipulated by federal law. Frequent nutrition class topics include infant nutrition, cooking with dried beans, prenatal nutrition, iron, calcium, protein, and other specific nutrients. In-depth nutrition education, with practice sessions in the home, were provided for EFNEP participants as usual. Twelve nutrition education lessons are outlined for the EFNEP program, including topics such as menu planning, shopping basics, sanitation, supplementing meals with the foods in the home, nutrients, fruits, vegetables, and cooking with dried beans.

Group recruitment of EFNEP participants was initiated as well as recruitment for individual EFNEP contacts. No effort was made to control for various levels of information provided since the purpose of this study was to evaluate current nutrition education practices on dietary behavior and iron levels. Four different WIC clinics and two different EFNEP units in Weber, salt Lake, and Utah counties in Utah were involved in the data collection. The control group participants were recruited in Logan, Utah, a small university city. Control group participants had to meet the income guidelines for WIC and 
EFNEP.

A medical history questionnaire was collected on each participant by the health or county employees to rule out any disorders that would cause low hematocrit or ferritin values.

The data for the groups were analyzed separately to control for the effects of supplemental foods provided to those on the WIC program and to control for differences in the two programs.

\section{Significance}

This is a key time to conduct this research since EFNEP is charged with expanding its program in the most efficient yet effective manner possible. The Utah WIC program spent all allotted food money for the first time in fiscal year 1989 and exceeded program budget during fiscal year 1990. Conducting the research will help aid the Utah programs develop efficient nutrition education programs and also provide baseline data for future evaluations of the programs.

\section{Hypothesis}

Participation in the nutrition education programs of the federally funded WIC or EFNEP programs will result in an increase in nutrition knowledge. This increase of nutrition knowledge will correlate positively with an 
improved dietary intake and with improved health status (hematocrit and ferritin levels).

\section{Working Hypothesis}

1) Nutrition knowledge does not change after participation in the WIC or EFNEP programs.

2) Dietary behavior, as assessed by 24-hour dietary recall records and food frequency records, does not change after participation in the WIC or EFNEP programs.

3) A change in nutrition knowledge has no effect on dietary behaviors (as assessed by 24-hour dietary recall records and food frequency records), hematocrit levels, or ferritin levels.

\section{Delimitations of the study}

Food stamp recipients were not excluded in the study due to the regulations that nutrient-dense foods or foods of lesser quality may be purchased with food stamps. Food purchasing habits of persons using the Food stamp Program could represent those of the total population. 
CHAPTER II

REVIEW OF LITERATURE

Improvement in health is dependent on receiving the essentials of nutrition, immunization, and sanitation (Harper, 1987; Robinson and Lawler, 1982; Whitney et al., 1987). Nutrition has a major impact on health. Immunity against diseases, increased work output, and ability to concentrate are all dependent on adequate nutrition (Galler, 1987). To provide individuals with accurate nutrition facts, scientific information about nutrition must be communicated through nutrition education classes. This education provides individuals with tools to make correct decisions about foods and nutrition. The incidence and effects of anemia, nutrition education techniques, and the impact of federal food and nutrition programs have been studied in certain groups of people.

\section{Definition of Anemia}

The major functions of iron include transport of oxygen from the lungs to the tissues, transport of carbon dioxide from the cells to the lungs, and the process of cellular respiration. The transfer of oxygen and carbon dioxide is accomplished by hemoglobin in the erythrocyte and myoglobin in the muscle cell. The cytochromes, present in all cells, function in the respiratory chain by transferring electrons and storing energy through alternate 
oxidation and reduction of iron. Three forms of iron comprise 60-70\% of the total iron in the body and are classified as essential iron components (adult body contents average $2.5-3.0 \mathrm{gm}$ of hemoglobin, $150 \mathrm{mg}$ of myoglobin, and $300 \mathrm{mg}$ of iron in the respiratory enzymes).

The remaining $30-40 \%$ of iron in the body is classified as storage iron or transfer iron (adult body contents average 200-1500 $\mathrm{mg}$ of ferritin and hemosiderin, and 3-4 mg transferrin). Ferritin is the major storage form of iron. Up to $50 \mathrm{mg}$ per day can be mobilized from storage iron. Approximately $20 \mathrm{mg}$ of iron are used daily in hemoglobin synthesis, and if dietary intake does not meet this need, storage iron is mobilized. Conversely, when abnormally large amounts of iron are present, the apoferritin (which in the liver becomes ferritin when iron is added) becomes saturated and hemosiderin appears in large quantities. Hemosiderin is similar to ferritin, but contains more iron and is very insoluble.

Transferrin is responsible for the transfer of iron to the site-of-need or to storage. The rate at which iron is released from the mucosal cells in the intestinal wall into general circulation is regulated by the total amount and degree of saturation of transferrin. Transferrin is usually saturated to approximately one third of its total iron-binding capacity. If iron is not needed, transferrin remains saturated, and less iron is absorbed from the 
intestinal mucosa. If iron is needed, the transferrin is less saturated when it reaches the intestinal mucosal cells, and more iron passes from the mucosal cells to the transferrin.

The three main causes of iron depletion are: 1) chronic blood loss, such as from chronically bleeding peptic ulcers, hemorrhoids or parasites, or malignancy; 2) faulty iron intake or absorption; and 3) increased iron requirement for expansion of blood volume which occurs in infancy, puberty, pregnancy, and lactation.

Iron deficiency is often separated into three stages: 1) iron deficiency, which is characterized by the absence of iron stores; 2) iron-deficient erythropoiesis, which is a demonstrated insufficient supply of iron to the erythron; and 3) iron deficiency anemia, when an insufficient supply of iron to the erythron has reduced the hemoglobin concentration below two standard deviations of the normal hemoglobin distribution specific for age, sex, and altitude (Hallberg and Rossander-Hulten, 1991). To discriminate among the stages of iron deficiency, the hemoglobin (hbg) or hematocrit (hct) level must be combined with other biochemical tests. Since hematocrit and hemoglobin are affected late in the disease, they do not indicate the type of anemia. There is also a wide range of values in normal subjects, making anemia difficult to diagnose.

Serum ferritin is a simple a:ld reliable estimate of 
iron stores, provided inflammation, malignancies, infection, and liver disease have been excluded. In the normal adult, $1 \mathrm{mcg}$ of ferritin is roughly equivalent to 8 $\mathrm{mg}$ of storage iron. To express this relationship on a per kilogram basis, $1 \mathrm{mcg}$ serum ferritin is equivalent to approximately $120 \mathrm{mcg}$ storage iron per kilogram. Normal serum level of serum ferritin is greater than $20 \mathrm{ng} / \mathrm{ml}$ in the adult and greater than $12 \mathrm{ng} / \mathrm{ml}$ in the child (Finch and cook, 1984). In the early stages of iron store depletion, ferritin and hemosiderin are depleted.

Transferrin saturation is a gauge of iron supply to tissues. The total iron binding capacity (TIBC) of transferrin rises as iron stores in the bone marrow and the liver decrease. Values less than $16 \%$ in the adult and child suggest that iron deficiency is inhibiting normal erythropoiesis. Specifically, it is probable that the needs of the bone marrow for making hemoglobin and red blood cells are not being met. When the supply of iron to the developing red blood cell in the marrow is suboptimal, not all porphyrin can be used to make heme, so the levels of protoporphyrin in circulating red blood cells rise above normal. An increased red cell protoporphyrin greater than $3 \mathrm{mcg} / \mathrm{gm}$ hemoglobin in the adult or child indicates a deficient iron supply to the developing red blood cell (Finch and Cook, 1984).

These biochemical indices can be used to discriminate 
the iron replete person from those in one of the three stages of iron deficiency. The iron replete individuals have normal biochemical indices. Those with depleted iron stores have a low plasma ferritin. Those with iron deficiency, but no anemia, have low plasma ferritin, low transferrin saturation, and high red cell protoporphyrin. Those with iron deficiency anemia have low plasma ferritin, low transferrin saturation, high red cell protoporphyrin, and a low hemoglobin or hematocrit (Finch and Cook, 1984).

\section{Incidence and Diagnosis of Anemia}

Hallberg and Rossander-Hulten (1991) summarized several articles that indicated a low serum ferritin value is pathognomonic for iron deficiency because there are no other conditions that lead to low values. Disorders that result in inflammation, malignancies, infection or liver disease cause an increased ferritin level, which would lead to an underestimation of the prevalence of iron deficiency. A low serum ferritin would indicate a state of iron deficiency.

Low serum ferritin has been used in several studies to monitor incidence of iron deficiency and repletion of iron stores in iron deplete individuals. Milman and Kirchhoff (1992) conducted a population survey of serum ferritin values in 1359 nonpregnant Danish women in age cohorts in their $30^{\prime} \mathrm{s}, 40^{\prime} \mathrm{s}, 50^{\prime} \mathrm{s}$, and $60^{\prime} \mathrm{s}$. The results revealed a 
significant increase in serum ferritin in 50-year-old women from the 30- and 40-year-old women. There was another significant increase in ferritin in the 60-year-old women. In the 30- and 40-year-old women, median serum ferritin was $38 \mathrm{ug} / \mathrm{l}$ with $17.2 \%$ having values less than $15 \mathrm{ug} / 1$. In the 50-year-old women, median serum ferritin was $54 \mathrm{ug} / \mathrm{l}$, and 10.3\% had values less than $15 \mathrm{ug} / 1$. The 60-year-old women had a median serum ferritin of $84 \mathrm{ug} / \mathrm{l}$, and $1.6 \%$ had values less than $15 \mathrm{ug} / \mathrm{l}$. Blood donors had lower serum ferritin than nondonors. Hemoglobin levels were lower in those having serum ferritin less than 15 ug/l. Hemoglobin levels were lower in the 30- and 40-year-old women, which correlates with serum ferritin values and may be explained partly by menses.

Dienard et al. (1983) studied 4039 children between the ages of six months and 12 years to characterize developmental variations in serum ferritin and erythrocyte protoporphyrin. The mean serum ferritin value was found to rise through the first 12 years of life with the minus two standard deviation value of $12 \mathrm{ug} / 1 \mathrm{rising}$ to $21 \mathrm{ug} / \mathrm{l}$ by age 12 . The authors rationalized that the linear relationship observed between increasing hematocrit and serum ferritin with increasing age is associated with improved storage and availability of iron for heme synthesis.

other studies have further defined the role ferritin 
plays in detecting iron deficiency. Carriaga et al. (1991) studied the ferritin levels and iron retention in proteincalorie malnourished Mayan children with low hemoglobin production. Treatment consisted of a $4 \mathrm{gm} / \mathrm{kg}$ protein diet, $150 \mathrm{kcalories} / \mathrm{kg} / \mathrm{day}$, and $60 \mathrm{mg}$ of elemental iron plus vitamin and mineral supplements. The results showed that in the low ferritin-low hemoglobin group of 13 children (12 $\pm 8 \mathrm{ng}$ ferritin/dl and hemoglobin $<12 \mathrm{gm} / \mathrm{dl}$ ), iron retention was $9.3 \%$ of iron intake. The high ferritin-low hemoglobin group ( $86 \pm 32$ ng ferritin/dl and hemoglobin $<12$ $\mathrm{gm} / \mathrm{dl}$ ) retained $1.4 \%$ of iron intake. The recovery of biochemical and anthropometric indicators of nutritional status was similar in both groups. The authors suggested that the homeostatic regulation of intestinal iron absorption was the same in malnourished (protein calorie malnutrition) persons with adequate iron stores as in healthy persons with adequate iron storage pools. They also proposed that in the higher serum ferritin group with low hemoglobin, the low hemoglobin concentration was mainly dependent on an adaptive adjustment to the decreased lean body mass. They suggested that during nutritional repletion, when there is an increase in lean body mass and thus an increased demand of oxygen carrying capacity, that therapeutic doses of iron be given. The high rate of hemoglobin synthesis could be supported either by exogenous iron supply or by normal or high iron reserves. 
The incidence of childhood iron deficiency anemia has declined steadily since 1975 or before. Anemia declined from $7.8 \%$ in 1975 to $2.9 \%$ in 1985 as reported by the Centers for Disease Control Pediatric Nutrition Surveillance system (Yip et al., 1987b). Hematologic measurements were obtained on children ages six to 60 months that were enrolled in public health programs in six states. The prevalence of anemia declined at preenrollment screening visits as well as those seen at follow-up visits, suggesting a generalized improvement in childhood iron nutritional status. To determine if the decline in anemia was a function of change in the population observed, the Tennessee records were further analyzed through linkage to birth records to obtain detailed socioeconomic status information. The socioeconomic status remained stable and the prevalence of anemia declined significantly within each socioeconomic group (20\% of the children in 1975 and $22 \%$ in 1984 were in the lowest socioeconomic group, and 8\% in 1975 and 9\% in 1984 were in the highest socioeconomic group). Yip et al. (1987b) suggested that since the preenrollment prevalence of anemia had declined in WIC children, the improved iron nutritional status was due in part to the changes in infant and child feeding practices. There was greater frequency and duration of breast feeding, substitution of iron-fortified formulas for unfortified 
formulas and cow's milk, a trend toward the longer duration of use of iron-fortified formulas, and increased use of iron-fortified infant cereal.

The 1985 Nationwide Food Consumption Survey (NFCS) documented a significantly higher daily intake of iron among children ages one to five years, living in the United States, compared to the 1977 NFCS. Yip et al. (1987b) attributed some of the NFCS changes to the concerted nutrition education efforts of pediatric health care providers.

To determine the incidence of anemia in middle-class children, Yip et al. (1987a) studied a population of children between nine months and six years at a private pediatric clinic in Minneapolis from 1969 through 1986. To ensure they were studying a low-risk group, the sample was restricted to children from households that had never received public assistance and at least one parent worked. They further excluded children from households headed by never-married women, black children (to avoid confusion of sickle cell anemia), and children with a history of chronic disease. The overall age-adjusted rate of anemia decreased from $6.2 \%$ in 1969 through 1973, to 5.8\% in 1974 through 1977, to $3.8 \%$ in 1978 through 1981 , and to $2.7 \%$ in 1982 through 1986. The prevalence of anemia from 1982 to 1986 was relatively low: $2.8 \%$ among nine- to 23-month-old children, 2.4\% among 24- to 47-month-old children, and $2.7 \%$ 
among 48- to 83-month-old children. The authors attributed improved childhood iron nutritional status to heightened awareness of nutritional issues.

Stockman (1987) reviewed the changes in type of iron in fortified products since 1940. Most dry food cereals produced in the $1940^{\prime} \mathrm{s}$ and $1950^{\prime} \mathrm{s}$ contained sodium iron pyrophosphate, which was poorly absorbed. Since 1972, dry infant cereals have been fortified with electrolytically reduced iron of small particle size. Absorption of this form of iron is approximately $4 \%$, which is equivalent to the absorption of ferrous sulfate added to cereal. Stockman (1987) also attributed some of the improvement in childhood nutritional status to identification of high-risk children through participation in the Women, Infants, and Children Supplemental Food Program (WIC). The author cautioned that only 25-30\% of the eligible women and children were participating in WIC, and there is no good understanding of the prevalence of iron deficiency in those who would qualify for WIC but are not participating.

Iron deficiency anemia in women has also been documented. Pregnancy is considered a high-risk period to develop iron deficiency anemia. Kennedy and Gershoff (1982) monitored the incidence of anemia in pregnant women to evaluate the effectiveness of the WIC program. Hematocrit values for 134 WIC and 77 non-WIC women were used to monitor change from initial visit to final visit. 
Anemia was defined as a het $<34 \%$ during pregnancy. The mean initial het was $35.8 \%$ for WIC and $35.6 \%$ for non-WIC women. Final mean hot levels were $36.7 \%$ for WIC and $35.1 \%$ for non-WIC women. There was no significant change for the total group of women. When conducting a separate analysis for the women with anemia, the 39 WIC women with anemia had an initial het value of $31.9 \%$ and a final value of $35.7 \%$. The 26 non-WIC women with anemia had an initial value of $32.2 \%$ and a final value of $34.8 \%$. There was no significant difference between initial and final hct levels for the women with anemia, yet there was a trend for improvement. Iron deficiency anemia in the athlete, especially the female athlete, has also been documented (Kris-Etherton, 1986; Singh et al., 1989). The term "sports anemia" was described as an increased destruction of erythrocytes and a drop in hemoglobin in response to acute exercise-induced stress. The causes have not been well defined, but contributing factors could include inadequate iron intake, decreased iron absorption, increased iron losses (sweat, gastrointestinal tract), expansion of blood volume, intravascular hemolysis due to increased red blood cell destruction, decreased red blood cell production, and inadequate dietary protein. The present recommendation is to monitor all athletes for iron deficiency anemia and to advise iron supplementation when indicated.

Farley et al. (1987) reported on characteristics 
affecting dietary iron intake in the adult. The authors obtained food frequency information from 762 Utahns, ages 24 to 80 , and divided them into categories of iron intake of $9 \mathrm{mg}$ iron/1000 kcalories, $6-8.9 \mathrm{mg}$ iron/1000 kcalories, and less than $6 \mathrm{mg}$ iron/1000 kcalories. Twentyseven percent of the women and $16 \%$ of the men reported consumption of more than $9 \mathrm{mg}$ iron/1000 kcalories. Six percent of the women consumed $18 \mathrm{mg}$ iron daily. Individuals in the high-iron intake category consumed greater proportions of their iron and energy from vegetable, fruit, and cereal products. The individuals in the low-iron intake category consumed more pastries, beverages, sweets, and added fats. When fortified breakfast cereals were removed from the diets, only $14 \%$ of the women and $6 \%$ of the men consumed diets that provided 9 mg/1000 kcalories. The authors provided the following outline for women as a guideline to meet the $9 \mathrm{mg}$ iron/1000 kcalories: distribution of kcalories should be $14-16 \%$ as cereals, at least $11 \%$ as vegetables, 16-18\% as meat, fish, poultry or eggs, $13-18 \%$ as fruits and juices, $15 \%$ as dairy products, and 21-31\% to be used as beverages and other foods. (The authors further advised increased dairy consumption, and little to no added sugar and fat.) Tilgner and Schiller (1990) added supporting data that iron consumption in women was lower than the recommended guidelines. They reported that women who were concerned 
with nutrient intake to improve their athletic performance did not meet the recommended dietary allowance for iron. The 19 swimmers in the study reported an average of $13.2 \pm$ $4 \mathrm{mg}$ iron/day; the 8 field hockey players reported $10.5 \pm$ $3.3 \mathrm{mg}$ iron/day; and the 17 non-athlete controls reported $11.2 \pm 4.7 \mathrm{mg}$ iron/day.

\section{Iron Absorption}

Recommendations for dietary iron intake to prevent or correct iron deficiency anemia are influenced by body stores as well as by a variety of dietary factors that increase or decrease the availability of iron for absorption. The healthy adult male has an average loss of $1 \mathrm{mg}$ iron per day (Green et al., 1968). The adult female loses an additional $0.5 \mathrm{mg}$ iron per day, which accounts for menstrual blood loss averaged over one month (Hallberg et al., 1966; Hallberg and Rossander-Hulten, 1991). To cover for the loss of iron, intake is recommended at $10 \mathrm{mg}$ per day for adult men and $15 \mathrm{mg}$ for women. The $15 \mathrm{mg}$ value was agreed upon by the National Research Council (1989) when they evaluated the data of "some impairment of iron status" in $9.6 \%$ to $14.2 \%$ of nonpregnant women 15 to 44 years of age with an average dietary iron intake of 10 to $11 \mathrm{mg}$ per day. They gathered their survey reports from the U.S. Department of Agriculture, the National Center of Health Statistics, and the Food and Jrug Administration. Dietary iron intake 
of $10 \mathrm{mg}$ per day was associated with an adequate iron status in $86 \%$ of the women ages 15-44. Meyers et al. (1983) reported that those women with high menstrual losses compensated by increased absorption of iron since the prevalence of iron deficiency in this group was low.

Iron absorption is dependent on the form of the iron and on the presence of enhancers and inhibitors of nonheme iron. About $40 \%$ of the total iron in animal tissues is heme iron although it varies in certain tissues. The remaining $60 \%$ of iron in animal tissues, and all the iron in vegetables and grains, is nonheme iron (National

Research Council, 1989). Bezwoda et al. (1983) reported that $20 \%$ of heme iron is absorbed and is a function of heme iron in the meal. The total heme iron absorption ranged from $6.4 \%$ to $18 \%$ when varying proportions of heme to nonheme iron were eaten by study participants. The test meal consisted of $120 \mathrm{gm}$ mashed potato with $6 \mathrm{mg}$ of total iron (4 test meals had nonheme iron contents of $5.72 \% \mathrm{mg}$, $4.88 \mathrm{mg}, 3.76 \mathrm{mg}$, and $1.52 \mathrm{mg})$. The percentage of absorption of nonheme iron was $7 \%$ for $5.72 \mathrm{mg}, 9 \%$ for $4.88 \%$ $\mathrm{mg}, 6.4 \%$ for $3.76 \mathrm{mg}$, and $18 \%$ for the $1.52 \%$ nonheme iron preparations, respectively.

Gillooley et al. (1983) studied the effects of organic acids, phytates, and polyphenols on the absorption of iron from vegetables. The authors reported that the geometric mean iron absorption increased from 0.028 to 0.085 with $1 \mathrm{~g}$ 
citric acid, from 0.031 to 0.081 with $15 \mathrm{mg}$ ascorbic acid, from 0.048 to 0.095 with $1 \mathrm{gm}$ L-malic acid, from 0.041 to 0.096 with $1 \mathrm{gm}$ tartaric acid. The only exception was the addition of $1 \mathrm{gm}$ oxalic acid, which resulted in a depressed iron absorption of 0.320 to 0.195 .

Gillooley et al. (1983) also added $3 \mathrm{mg}$ ferrous sulfate to different vegetables to determine bioavailability of their iron content. Vegetables with low iron bioavailability were wheat germ, aubergine, butter beans, spinach, brown lentils, green lentils, and beet greens. Vegetables with moderate to high bioavailability were carrot, potato, beet root, pumpkin, broccoli, tomato, cauliflower, cabbage, turnip, and sauerkraut. All vegetables associated with moderate or good iron bioavailability contained appreciable amounts of one or more of the organic acids: malic, citric, and ascorbic acids. Poor iron bioavailability was noted in vegetables with high phytate contents (wheat germ, butter beans, brown lentils, and green lentils).

To monitor the iron absorption of nuts, which are used as a dietary protein source, Macfarlane et al. (1988)

compared iron absorption of a bread-alone meal to a meal of bread plus nut paste. Walnuts displayed a potent inhibitory effect on iron absorption with values of $5.9 \%$ iron absorption on the bread-alone meal, compared to $0.7 \%$ for the bread and walnut meal. Almonds, peanuts, and 
hazelnuts also proved to be powerful iron inhibitors with absorption decreasing from $11.1 \%$ to $1.7 \%$ for almonds, $8.1 \%$ to $2.2 \%$ for peanuts, and $4.4 \%$ to $2.3 \%$ for hazelnuts when they were added to the bread meals. When ascorbic acid was added to overcome the inhibitory effects of certain nuts, $25 \mathrm{mg}$ of ascorbic acid improved the absorption of the peanut plus bread meal from $2.2 \%$ to $3.5 \%$. Fifty milligrams of ascorbic acid improved iron absorption in the peanut meal and restored it to the bread-alone meal value of $8.1 \%$. With Brazil nuts, $25 \mathrm{mg}$ of ascorbic acid returned the iron absorption to the bread-alone meal. Ascorbic acid was not as effective in reversing the inhibitory effects on iron absorption in soy proteins.

Iron's Effect on Development

Recovering from the effects of iron malnutrition has been studied in various situations while testing for several different performance criteria. Pollitt et al. (1985) conducted a study in a semiurban community in Egypt to associate iron status with problem solving. of the original 203 children 28 were defined as iron deficient $(\mathrm{hbg}<11.5 \mathrm{gm} / \mathrm{dl}$, and either a transferrin saturation of < $25 \%$ or a serum ferritin $<20 \mathrm{ng} / \mathrm{ml})$, and 40 children were defined as iron replete $(\mathrm{hbg}>13 \mathrm{~g} / \mathrm{dl}$ and either a transferrin saturation $>25 \%$ or a serum ferritin $>20$ ng/dl). For four months, 18 iron depleted and 18 iron 
replete children received $50 \mathrm{mg}$ ferrous sulfate. The remaining subjects received a placebo. A test for "matching familiar figures" was administered, and the time required to make a first response plus the error rate were recorded. The efficiency of correct matching of the nonanemic children before treatment was significantly greater than for the anemic children. After treatment, the efficiency of the iron-treated anemic children was greater than that of the anemic children treated with a placebo. Soemantri et al. (1985) used a nonverbal I.Q. test (testing biology, social science, and language) to study the effect of iron deficiency on learning performance in Indonesian children. The preselection criteria for the study were extensive and included a height and weight above the 80 th percentile, mid-arm circumference above the 85th percentile, and negative parasite egg count in a stool examination; the children also had to be negative for thalassemia and malaria. Forty-one children were defined as iron deficient ( $\mathrm{hbg}<11 \mathrm{gm} / \mathrm{dl}$ and transferrin saturation $<15 \%)$, and 43 were defined as iron replete (hbg >12 gm/dl and transferrin saturation $>20 \%$. A $10 \mathrm{mg} / \mathrm{kg} / \mathrm{day}$ oral treatment of ferrous sulfate was given the 43 anemic children and to 16 of the nonanemic children.

The results of the study conducted by soemantri et al. (1985) showed there was no significant difference between the groups for age or socioeconomic characteristics. The 
nonanemic group was slightly heavier and taller than the anemic group. The results of the school achievement tests showed a significant difference on pretest scores between the anemic and nonanemic children. Once the influence of the pretest had been removed, the iron-treated children had significantly higher increases in test scores as compared to children given the placebo treatment. The authors suggested that although the iron deficit was fully reversed, the deficits in achievement were not overcome. Although iron repletion might help the learning process, it would not compensate for the deficits accrued over a period of time.

Galler (1987) summarized her own studies and studies of others regarding the effects of severe undernutrition, including protein kcalorie and iron undernutrition. Her animal model consisted of rats that were fed a low protein diet for 25 generations. A parallel colony of rats was fed adequate protein for the same length of time. A third group of rats was derived from the protein deprived and were cross-fostered at birth to healthy mothers and provided adequate nutrition for four generations.

The results of the Galler (1987) rat-model study showed that after 25 generations of malnutrition, the malnourished rats were half the size of the well-nourished rats. However, within one generation of consuming an adequate diet, the rats' physical growth quickly returned 
to normal. Deficits on behavioral tasks were seen in the animals after one generation of malnutrition. Following rehabilitation on the adequate protein diet, there was some recovery of behavioral function, but this was incomplete among animals with a prior history of intergenerational malnutrition. Some behaviors were aberrant up to four generations following rehabilitation.

Galler (1987) also presented human studies that were similar to the animal model described above (e.g., women who were low birth weight having low birth weight infants, and the "new morbidity" in children refers to attention deficit problems such as impaired attention, easy distractibility, poor school performance, and poor memory associated with poor nutritional status). The author concluded that malnutrition resulted in a permanent impairment of behavioral functions.

\section{Effectiveness of Nutrition Education}

Many leading causes of mortality and morbidity in the United states could be affected by dietary improvements (U.S. Senate Select Committee on Nutrition and Human Needs, 1977). In addition, benefits of consistent dietary management could reduce the need for long-term use of medication for hypertension, diabetes, and hyperlipidemia (Cohon and Zimmet, 1983; Trevisan et al., 1983). The goal of nutrition education for persons with diet-related 
diseases or for the general population to prevent dietrelated diseases would be implementation of lifelong dietary changes. This would be achieved through voluntary cooperation of the individual.

Glanz (1985), in a review article, summarized the basic components for effective nutrition education used in treatment of diseases (cancer, diabetes mellitus, renal disease, cardiac disease, hypertension, and weight reduction). Based on the review of literature, the author recommended the following principles for consideration in the design of all educational efforts: a) tailoring of both dietary regimens and educational strategies; b) use of social support within and outside the health-care setting; c) provision of skills training in addition to information; d) effective patient-provider communication; and e) attention to follow-up, monitoring, and reinforcement. The author placed a strong emphasis on individualized tailoring of diet prescriptions, as well as a major focus on educational and behavioral diagnosis prior to the intervention phase. This diagnosis could be used to determine what educational role would be best for family and friends and which individual or group approaches would be most suitable. Another observation was that the nutrition educator needs to understand both behavioral issues and principles of nutrition management to be effective. 
To establish the current state of knowledge about the effectiveness of nutrition education, Johnson and Johnson (1985) conducted a meta-analysis of published and unpublished nutrition education studies. They reviewed 607 studies and identified 303 that had usable research findings. A coding procedure was applied, and three methods of meta-analysis were used: the voting method, the effect-size method, and the $z$ score method. The voting method considered the findings of the original author. The findings were categorized as positive findings (meaning nutrition education had a positive, statistically significant impact), negative findings (meaning nutrition education had significant, but negative impact), or findings of no difference (meaning nutrition education had no statistically significant impact). The authors recognized the limitations of the voting method (ignoring sample size and disregarding the importance of information about the strength among variables).

The effect-size method used by Johnson and Johnson (1985) was a calculation of the differences between the means of pairs of treatment conditions divided by the within group standard deviation of the treatment conditions. This yielded a standardized mean difference. The $\mathrm{z}$ score method was a calculation to describe the likelihood that the overall pattern of results was generated by chance. 
The results of the meta-analysis indicated nutrition education affects nutrition knowledge, nutrition attitude, and nutrition behavior positively. The voting method for published journal articles resulted in 244 positive findings, five negative findings, and 139 no difference findings for nutrition knowledge; 88 positive findings, eight negative findings, and 101 no difference findings for nutrition attitudes; and 810 positive findings, 37 negative findings, and 596 no difference findings for nutrition behavior. (Several studies had numerous findings, so the total number of findings varied.) The effect-size method indicated that the average participants' scores toward good nutrition were higher than the control group for nutrition knowledge, nutrition attitude, and nutrition behavior. The $z$ score method indicated the probability that the superiority of nutrition education that was due to chance was less than 0.001 for all three categories.

Johnson and Johnson (1985) also calculated some correlations in the studies when they contained more than one dependent variable. In 38 studies and collected data on behavior and knowledge, the correlation coefficient was 0.50 between behavior and knowledge using the effect-size method and 0.32 using the $z$ score method. Nutrition attitude and nutrition behavior had a correlation coefficient of 0.20 using the effect size-method and 0.47 using the $z$ score method. 
Evaluations of the WIC Program

The primary purpose of the Women, Infants, and Children Supplemental Food Program (WIC) is to enhance the health of expectant and lactating women, infants, and children under the age of five who are nutritionally at risk. The program attempts to achieve this objective by providing nutrition education and supplemental foods that are rich in calcium, iron, protein, vitamin A, and vitamin C. Several studies have been published reporting favorable outcomes of improved iron status, dietary intake, and infant birth weight that have been attributed to participation in the WIC program (Kennedy and Gershoff, 1982; Miller et al., 1985; Smith et al., 1986; Stockbauer, 1987; Stockbauer, 1986; Weiler et al., 1979; Yip et al., $1987 b)$

Smith et al. (1986) conducted a study on 25 WIC children and 25 control children in the Los Angeles area. The results were reported as the experimental group having a mean hbg level of $10.1 \pm 0.76 \mathrm{gm} / \mathrm{dl}$ at initial enrollment and a mean $\mathrm{hbg}$ of $11.8 \pm 0.88 \mathrm{gm} / \mathrm{dl}$ at the end of the study. The control group had a mean hbg of $10.0 \pm 0.7$ $\mathrm{gm} / \mathrm{dl}$ at the initial visit and $10.0 \pm 0.8$ at the end of the study. They used a one-way analysis of variance to compute the difference between the experimental and control groups and found a significant difference at the 0.05 level. A 24-hour dietary recall conducted at the beginning of the 
study showed the following percent of children did not meet the RDA for specific vitamins: $44 \%$ for vitamin $A, 22 \%$ for vitamin C, $40 \%$ for calcium, $44 \%$ for iron, $32 \%$ for protein, and $1 \%$ for folacin. No dietary assessments were made for the experimental group at the end of the study. No dietary evaluations were conducted on the control group.

Miller et al. (1985) conducted a study on wIC children to consider the contribution of WIC participation in limiting development of iron depletion or iron deficiency anemia. A comparison of the hematologic status of infants from pre-WIC program era to infant participants of the WIC program was conducted using medical charts at the Children and Youth Project Clinic, Minneapolis Health Department. Subjects were matched for age, initial trimester of prenatal care, age of mother at enrollment, marital status of parent, maternal education status, number of months between pregnancies, number of prior pregnancies, and employment status. Ferritin and hematocrit values were taken on the 362 pre-WIC era infants and 478 WIC participant infants. The statistical analysis (chi square) showed ferritin concentration differences were statistically significant at the 0.005 level. The analysis on the hematocrit levels revealed no significant differences between the two groups.

Rush and the team from the Research Triangle Institute were contracted by the office of Analysis and Evaluation, 
Food and Nutrition Service, U.S. Department of Agriculture, to conduct a comprehensive evaluation of the WIC program called the National WIC Evaluation (NWE). The first step of this evaluation process was to conduct a comprehensive review of literature on the WIC program (Rush et al., 1988a). The research team reported the results as well as the problems comparing data when different methodologies were used. They specified certain strengths and weakness of studies such as the one by Smith et al. (1986), which did not account for initial disparity (mean values were calculated and evaluated and a paired t-test was not conducted) .

The NWE research team then conducted four studies to evaluate the effects of participation in the WIC program on nutrition and health during pregnancy and early childhood. The first of the four studies conducted by Rush and the Triangle Research Team (Rush et al., 1988b) was the Historical study of Pregnancy outcomes. A total of 6563 women (5205 WIC and 1358 non-WIC women) was randomly selected from the 48 contiguous states and the District of Columbia. The authors reported that during pregnancy, the women in WIC had significantly higher intakes of protein, iron, calcium, vitamin C, energy, magnesium, phosphorus, thiamin, riboflavin, niacin, vitamin B6, and vitamin B12 than control women. The WIC participants also showed a reversal of low weight gain in early pregnancy and smaller 
fat stores in later pregnancy than control women. The authors suggested that weight gain and less fat stores may have been a nutrient to fetus shuttle rather than a kcalorie to fat storage shuttle. The data also showed larger infant head circumference, but not an increased birth weight of WIC infants (the WIC infants were $23 \mathrm{gm}$ heavier than the control infants which was not significant, yet there was significance when the woman was associated with a WIC program of "high quality"). There was also a trend for lower infant mortality (although not of significant magnitude) in the WIC participants over the control group.

The study of infants and children (Rush et al., 1988e) included 711 current enrollees in the WIC program, 637 children past WIC participants, and 763 control children that had never been in the WIC program. The WIC children had significantly better intakes for iron, vitamin A, and vitamin $C$ than the control group or past WIC participants (no residual benefits of past WIC enrollment was shown). The WIC children were short in stature, suggesting effective targeting for children of nutritional risk. The WIC children also had kept their immunizations updated at a better rate and had more frequent use of health care than control children. The WIC children scored higher on vocabulary tests if WIC participation started while the fetus was in utero. The WIC children exhibited better 
digit memory if infants started the WIC program after 12 months of age (significance occurred only after statistical adjustments were made for sociodemographic factors).

The historical study of pregnancy outcomes (Rush et al., 1988b) was an extensive study to relate the WIC benefits for pregnant women to perinatal outcome. Birth certificates, death records, WIC medical records, WIC participation rates, and U.S. Census and Area Resources Files were all utilized to match data for $11,154,673$ births in 1392 counties in 19 states and the District of Columbia. WIC participation was associated with increased first trimester prenatal care, longer duration of gestation, decreased preterm delivery, increased birth weight (a positive $23 \mathrm{gm}$ for WIC infants), and decreased fetal mortality (a decrease of $2.3 / 1,000$ ).

The last of the four studies was the Food Expenditure Study (Rush et al., 1988f) that was designed to assess the impact of the WIC program on family food purchasing practices. Recalls of monthly family food expenditures were taken from the women in the Longitudinal study of Pregnant Women (Rush et al., 1988c). Records were taken at enrollment in WIC and after the women ended their participation in WIC. Records were collected from 4219 WIC women and 785 control women. WIC benefits to pregnant women were strongly associated with larger amounts of WIC food (high nutrient density food) entering the household, 
but effects on grocery spending were unclear.

Evaluations of the EFNEP Program

The Expanded Food and Nutrition Education Program (EFNEP) has a defined goal of helping low income families and youth acquire the knowledge, skills, attitudes, and changed behavior necessary for nutritionally sound diets, and to contribute to their personal development and to the improvement of the total family diet and nutritional welfare (United States Code 3175,1988 ). EFNEP is a federally funded food and nutrition education program that is directed at the state government level. Evaluations of such programs are mandated since they prove important in demonstrating program effectiveness, determining to what degree the target population is being served, and in providing feedback to those involved in all stages of planning and implementing the program.

Torisky et al. (1989) conducted a study on the Virginia EFNEP program to assess the long-term impact of the program on graduated participants. Dietary intake was assessed using a 24-hour food recall record in a sample of 180 program participants who had completed six to 18 months of instruction in the Virginia EFNEP program. The food recall records were scored at program entry, at graduation, and six to 18 months after graduation. Perceived program benefit was assessed by a questionnaire addressing 
consumption of "junk" food with frequency of illness, consumption of fruits, vegetables and milk, variety in family menu, willingness of family to try new foods, finding food specials and bargains, stretching food money further, help in reading labels, feeding baby, safe food storage, and finding other food resources. Participant characteristics included: 53\% were single-headed families, $70 \%$ had at least one child less than five years of age, average age was $31,69 \%$ of the families earned less than $\$ 519$ per month, $71 \%$ participated in the Food stamp Program, $68 \%$ participated in the WIC program, and $42 \%$ received public assistance.

Results of Torisky's et al. (1989) study showed that by program completion, $37 \%$ of the participants obtained a perfect score of $100 \%$ in obtaining a diet pattern of two milk, two meat, four fruit/vegetable, and four grain servings per day. Average diet scores of 65.5 at entry to the program rose to 88 at program completion. Those who had the lowest scores at entry to the program dropped in diet score by $17 \%$. Increases in servings from the milk, fruit/vegetable, and bread/cereal groups were responsible for the improved diet score in the total study population. A statistically significant but small decline in average diet score occurred from 88.0 at program exit to 83.8 at the follow-up visit six to 18 months later. The average follow-up score remained significantly higher than entry 
score suggesting dietary improvement was retained.

The highest perceived learning skills of the Virginia EFNEP participants were learning how to get better food buys and what foods were in the basic four food groups. The area of least perceived knowledge gain was finding other food resources (some families were already enrolled in WIC [68\%] and Food stamp [71\%] Programs).

The California EFNEP program was evaluated (DelTredici et al., 1988) to determine if the program had an impact on dietary intake. Study participants were recruited into the study if they met the income guidelines and were then assigned to either the EFNEP group (received EFNEP instruction immediately) or to the control group (received no EFNEP instruction during the study). There were 355 EFNEP participants and 328 control participants with the demographic characteristics outlined in Table 1.

The results revealed no difference in food recall scores at the beginning of the study $(66 \pm 23$ vs. $66 \pm 24$ for EFNEP and control groups, respectively). After six months of instruction in the EFNEP group, there was a significant increase in food recall score for the EFNEP group and no change in the control group ( $77 \pm 23$ for the EFNEP group vs. $66 \pm 25$ for the control group). The improvements observed in the EFNEP group resulted from increased intakes from the milk, protein, and fruit/vegetable groups. The program characteristics that 
Table 1. California EFNEP participant characteristics.

\begin{tabular}{lrrrr}
\hline Variable & \multicolumn{5}{c}{ EFNEP } & \multicolumn{1}{c}{ Control } \\
\hline Age & $28.7 \pm$ & 8.3 & $29.9 \pm$ & 9.0 \\
Monthly income & $567.0 \pm$ & 186.0 & $581.0 \pm$ & 209.0 \\
Food stamp income & $91.0 \pm$ & 62.0 & $88.0 \pm$ & 65.0 \\
Amount spent on food & $172.0 \pm$ & 97.0 & $192.0 \pm$ & 111.0 \\
Family size with father & $4.5 \pm$ & 1.5 & $4.7 \pm$ & 2.0 \\
Family size-no father & $3.4 \pm$ & 1.4 & $3.1 \pm$ & 1.2 \\
White & $23.8 \%$ & & $23.9 \%$ & \\
Black & $18.4 \%$ & & $21.8 \%$ & \\
Hispanic & $54.1 \%$ & & $51.8 \%$ & \\
American Indian & $0.6 \%$ & & $0.9 \%$ & \\
Asian/Pacific Islander & $3.1 \%$ & & & \\
\end{tabular}

led to those changes were determined to be in the length of the EFNEP visit (mean of $80.5 \pm 24.3$ minutes), the number of EFNEP visits (mean of $7.8 \pm 3.9$ visits), and EFNEP instruction topics (cooking practices, food economics, and food safety).

Chipman and Kendall (1989) reviewed the national changes and challenges of the EFNEP program since it started in 1968. They reported the program has always served those at greatest nutritional need. In $1969,33 \%$ of the enrollees were on welfare assistance and $15 \%$ used food stamps. Welfare assistance jumped to $45 \%$ and food stamp use to $61 \%$ by 1979 . In $1987,31 \%$ reported annual incomes under $\$ 3,780,67 \%$ reported incomes under $\$ 6,228$, and $94 \%$ reported incomes under $\$ 11,000$, which was poverty level for a family of four at the time. Food stamps were used by $66 \%$ of EFNEP participants and 30\% were enrolled in WIC in 1987. The authors assessed that the EFNEP participants enrolled 
in 1987 were less isolated, more sophisticated, better educated, and more discriminating than earlier participants. They also appeared to be more selfmotivated (temporary victims of unemployment) than earlier participants.

Evaluating the most effective methods to instruct the participants was also reviewed by Chipman and Kendall (1989), and they suggested small group sessions with telephone follow-up sessions as an effective and cost efficient method for improving nutrition knowledge and nutrition practices. Combining five one-on-one sessions with seven mailed lessons was also considered cost-effective and timeefficient. The advantages of teaching in groups were larger caseload per paraprofessional, lower lesson cost per individual, increased number of program graduates, and the benefits of increased enthusiasm, friendships, and group cohesiveness.

Randall et al. (1989) added that the philosophy of using low income paraprofessionals as teachers leads to employment and provides personal growth and career development for the paraprofessional. Paraprofessionals have increased their self-esteem, been able to leave the welfare rolls, found better jobs, and improved their own and their families' nutritional status. 


\section{Summary of Literature Review \\ Relevance to This study}

Serum ferritin is a simple and reliable estimate of iron stores as long as inflammation, malignancies, infection, and liver disease have been excluded (Finch and Cook, 1984). Hematocrit level should be combined with ferritin level to determine iron status since hematocrit levels are affected late in the disease process, and there is a wide scatter of values in normal subjects (making anemia difficult to diagnose) .

Physiological changes in normal individuals have an affect on iron status. Milman and Kirchhoff (1992) reported increased serum ferritin in postmenopausal women. Hemoglobin levels in this group were lower in women with serum ferritin less than $15 \mathrm{ug} / 1$. The Centers for Disease Control (1989) have also outlined normal values for hematocrit and hemoglobin that are adjusted for age, altitude, pregnancy, and smoking status. Normal physiological variability should be considered before completing a study design to avoid unwanted variability in data.

The incidence of childhood iron deficiency declined steadily since before 1975 (Yip et al., 1987b). This improvement was attributed to WIC participation, heightened awareness of nutritional issues, and improved quality of iron in fortified products (Stockman, 1987; Yip et al., 
1987b). Stockman (1987) cautioned that only $25-30 \%$ of eligible women and children participate in WIC, and there is no good understanding of the prevalence of iron deficiency in those who would qualify for WIC but are not participating.

Dietary iron intake has been reported to be low in normal, athletic women and women who reported they were concerned about nutritional issues (Farley et al., 1987; Kris-Etherton, 1986; Singh et al., 1989; Tilgner and Schiller, 1990). The National Research Council (1989) recommended $15 \mathrm{mg}$ of dietary iron be consumed daily by women ages 15-44 to maintain iron stores. Farley et al. (1987) provided an outline to obtain $9 \mathrm{mg} / 1000 \mathrm{kcalories}$ and summarized that those most successful in meeting this goal consumed a higher proportion of their kcalories from vegetables, fruit, and iron-fortified cereal products.

The effect of enhancers and inhibitors of iron absorption has been studied (Bezwoda et al., 1983; Gillooley et al., 1983; Macfarlane et al., 1988). Foods with phytates and polyphenols decreased iron absorption while foods with ascorbic acid, malic acid, and tartaric acid increased iron absorption. Monitoring specific foods high in these substances on a dietary history form that is specifically designated to capture these data would help unscramble iron status data.

The importance of iron status on intellectual 
development, growth, and behavioral development has been studied (Galler, 1987; Pollitt et al., 1985; Soemantri et al., 1985). The common finding was that iron repletion after a prolonged iron deficit did not overcome the intellectual and behavioral deficits accrued over time. The importance of good iron status has a dramatic impact for generations, a good reason for further research.

Nutrition education has been shown to have a positive effect on nutrition knowledge, nutrition behavior, and nutrition attitude (Johnson and Johnson, 1985). Glanz (1985) summarized basic components shown to be effective in treating diseases with dietary prescriptions (diabetes mellitus, renal disease, cardiac disease, hypertension, cancer, and weight reduction). WIC and EFNEP have incorporated nutrition education into their programs to improve the health of their program participants. Both have reported success in accomplishing certain goals of their programs. The WIC program has shown improvement in hematocrit (Kennedy and Gershoff, 1982; Miller et al., 1985; Rush et al., 1988a-e; Smith et al., 1986; Stockbauer, 1987; Stockbauer, 1986; Weiler et al., 1979; Yip et al., 1987b) and EFNEP has shown improvement in dietary nutrients (Chipman and Kendall, 1989; DelTredici et al., 1988; Torisky et al., 1989). EFNEP studies have not reported on iron status as has been done with WIC (through hematocrit levels). WIC and EFNEP have not used knowledge tests to 
monitor nutrition knowledge gain. 
CHAPTER III

METHODOLOGY

This study was conducted on children between the ages of one and five years, and on adult women between the ages of 20 and 45 years. The purpose of this study was to evaluate the impact of participation in the Expanded Food and Nutrition Education Program (EFNEP) and the Supplemental Food Program for Women, Infants, and Children (WIC) through monitoring iron status, nutrition knowledge, and dietary behavior. The specific objectives of the study were 1) determine the impact of participation in EFNEP on iron status as assessed by hematocrit and ferritin values; 2) determine the effect of nutrition knowledge on hematocrit and ferritin values for both the WIC and EFNEP program participants; and 3) determine the effect of dietary behavior (as measured by 24-hour dietary recall record checked against a food frequency record) on henatocrit and ferritin values for both WIC and EFNEP participants.

It was hypothesized that participation in the nutrition education sessions of the federally funded WIC or EFNEP programs would result in an increase in nutrition knowledge. The increase in nutrition knowledge was expected to correlate positively with improved dietary intake and improved iron status (hematocrit and ferritin). 
Samples

The persons who participated in the study were 1) first-time WIC program children ages one to five years and their legal guardians; 2) women enrolled in the EFNEP program for the first time; and 3) children between the ages of one and five and their legal guardians who were not enrolled in either the WIC or EFNEP programs, yet would have been eligible for the WIC or EFNEP programs based on income criteria.

The WIC participants were recruited from clinics in Utah, Salt Lake, Weber, and Morgan counties in Utah. The EFNEP participants were recruited from two units that covered the same geographical area as the WIC participants. The control children and control women (the mothers or guardians of the control children) were recruited by posting flyers in trailer courts, laundromats, the Utah State University Extension campus field office, and student housing units in Logan, Utah. The control participants met the income criteria to participate in the WIC and EFNEP programs, yet were not enrolled in either program. All program and control participants were free of chronic disease and any condition that would cause a low hematocrit, hemoglobin, or ferritin level (thalassemia, inflammation, malignancies, or liver disease).

To obtain a statistical association between nutrition knowledge, dietary behavior, and hematocrit and ferritin 
levels, children were chosen as the study participants for the WIC program. The physiological changes in hematocrit levels for the child have been documented, and the normal values have been outlined by the Centers of Disease Control (Appendix C). Infants enrolled in the WIC program were excluded from the study due to high neonatal reserves of storage iron (Filer, 1989) and the impact that ironfortified formulas (which are the required formula for use if the infant is not breast fed) would have on the hematocrit levels of infants. Pregnant women enrolled in the WIC program were also excluded from the study due to the physiological variability of normal hematocrits for different trimesters of pregnancy. Another problem would be that the follow-up hematocrit level reading for pregnant women would be taken postpartum (WIC protocol). A postpartum hematocrit level would be elevated above pregnancy level and impossible to interpret.

Nonpregnant women who enrolled in the EFNEP program served as the study participants representing the EFNEP group. The control groups consisted of children of the same ages as the WIC children and their parent/guardian who were not enrolled in WIC or EFNEP.

\section{Description of the Instruments Used to Obtain the Data}

The first step in obtaining information about the 
nutrition knowledge and behavior of WIC and EFNEP participants was to develop a useful and cost-effective nutrition knowledge test. The test was validated according to the Cangelosi method (1989). Cangelosi defined the usefulness/cost effectiveness of a test as one that is usable and valid. He then described a test's validity. It is based on its relevance (including construct validity and content validity) and reliability (including internal consistency, test-retest validity, and scorer reliability). A 30-point test was constructed to test if WIC and EFNEP participants were meeting the nutrition education goals of the program. To obtain content and construct validity, eight registered dietitians with master's degrees and who worked for the public health department were asked to evaluate a 30-question nutrition test. They were asked to review each question for content validity by deciding whether each question matched the program objective of "improving health and nutritional status through teaching nutrition knowledge and skills that result in the purchase and consumption of nutrient dense foods."

To determine construct validity the public health dietitians were asked to agree or disagree with the author's assessment of whether the question met the stated learning objective and to agree or disagree with classification of objectives into level of cognition (e.g., question \#5's objective [Protein is impurtant to the human 
body because:] was to identify the functions of target nutrients in the body, with a cognition classification of simple knowledge. Question \#13's objective [Which of the following foods would provide the most protein for your money?] was to analyze food labels and choose the food with the most nutrients for the same amount of money. It has a cognition classification of intellectual knowledge involving analysis and application). This process resulted in a revision of the test into a 21-question test that met content and construct validity.

The 21-question test was then administered to 10 recent graduates of each program to determine face validity (did those taking the test feel it was representative of what they were taught in the program?).

Internal consistency was measured on the tests administered to 10 recent program graduates by conducting a split-half reliability. The procedure checks on whether the same number of correct responses was scored on the oddnumbered questions as on the even-numbered questions. All test items were written in multiple choice format to assure intra- and inter-scorer reliability. Calculations of difficulty level, index of discrimination, and efficiency level were calculated on each nutrition test item (Cangelosi, 1982).

The nutrition knowledge test was administered to the study participants at the beginning of the study before 
education sessions had begun. Six months later (the time frame for reapplying to the WIC program) the same test was readministered to each program participant. The exception to this was, of the 42 WIC participants in the study, 24 took the nutrition knowledge test as a posttest and 18 took the nutrition knowledge test as both a pretest and as a posttest. This was done to determine if there was a learning effect from taking the test. The 26 EFNEP and 23 control women took the nutrition knowledge test as both a pretest and a posttest. The nutrition knowledge tests taken by the control women were scored for them and for the control children.

Dietary behavior was analyzed by computer using the Computrition Nutrition Software Library (1989). Each study participant completed a dietary questionnaire that included a 24-hour dietary recall record for a typical day (if the previous day was atypical) and a food frequency record. If there was a discrepancy between the 24-hour dietary recall record and food frequency record, a registered dietitian further questioned the participant regarding her usual dietary intake.

Each participant completed the dietary records at enrollment in the study and six months later. A typical dietary intake was then analyzed by computrition for vitamin A, vitamin C, iron, calcium, and protein. Paired t-tests were calculated on the nutrients to compare dietary 
intake prior to study enrollment and dietary intake at the six month evaluation. Total amount of each nutrient consumed was recorded in grams or milligrams for each participant. A record of whether they met $67 \%$ or greater of the Recommended Dietary Allowance (RDA) for each nutrient was also kept.

A medical history form used by the WIC program was completed by each study participant. It was used to screen out any study participant who could have had a low hematocrit level for reasons other than iron deficiency. Demographic data were collected at the initial visit. These data included information on age, gender of child participant, type of vitamin/mineral supplement, if any, educational level of parent/guardian, income level of family, family size, income level of family divided by number of members in family, hours of nutrition education while participating in the WIC or EFNEP programs, and if transportation to the grocery store was a problem.

\section{Protocol}

The WIC participants were enrolled in this study in the following manner:

1) First-time WIC participants who had an eligible child participant between the ages of one and five years were told about the study on their initial visit to the WIC clinic. They could not have participated in 
the WIC or EFNEP programs previously. The purpose of the study, what the involvement included, who was responsible for the study, and the benefits of the study were explained to the parent/guardian of the WIC child.

2) The parent/guardian of the WIC child read and signed a written consent form that was approved by the Utah State University Human Subjects Committee Institutional Review Board and the salt Lake county Advocacy Board (Appendix B) .

3) A WIC dietary history form (including a 24-hour dietary recall record and a food frequency record) and medical history form were completed for each WIC child by the parent/guardian (Appendix B).

4) A nutrition knowledge test was taken by 24 of the 42 parents/guardians of the WIC children. A form detailing demographic data was also completed.

5) Four micro capillary tubes of blood were drawn on each WIC child with the hematocrit value read immediately, and the serum portion was frozen for later ferritin analysis.

6) The WIC clients participated in the WIC program as usual. No attempt was made to alter the education sessions from their normal routine. Participants had an individual consultation with a registered dietitian and two group nutrition classes that were 
approximately 20 minutes in length.

7) Six months after the initial WIC enrollment visit, the WIC program requires another dietary and hematocrit analysis to enable the participant to continue to receive program benefits. At this time the dietary form, medical history form, and the nutrition knowledge test were administered to the parent/ guardian as the postprogram evaluation. Four micro capillary tubes of blood were drawn on each child for the postprogram evaluation of hematocrit and ferritin. The EFNEP participants were enrolled in this study in the following manner:

1) Women who were interested in participating in the EFNEP program, or were referred to the EFNEP program, were told about the study on their initial contact. They could not have participated in the WIC or EFNEP programs previously. The purpose of the study, what the involvement included, who was responsible for the study, and the benefits of the study were explained to the women at that time.

2) The EFNEP participants read and signed the approved written consent form.

3) The WIC dietary history form and WIC medical history form were completed by each EFNEP participant. The dietary information required by the EFNEP program was transferred from the WIC forms for official EFNEP 
records.

4) A nutrition knowledge test was given to each EFNEP woman at the initial visit. A form detailing demographic data was also completed.

5) Four micro capillary tubes of blood were drawn on each EFNEP woman with the hematocrit value read immediately, and the serum portion frozen for later ferritin analysis.

6) The EFNEP clients participated in the EFNEP program as usual. Individual as well as group nutrition education sessions were provided for them, as outlined in the Utah EFNEP program. Each EFNEP client received between six and 12 hours of nutrition education before "graduating" from the program.

7) Six months after the initial enrollment in EFNEP, the EFNEP client completed the WIC nutrition history form, the WIC medical history form, and the nutrition knowledge test for the postprogram evaluation. Four micro capillary tubes of blood were drawn on each EFNEP client for postprogram evaluation of hematocrit and ferritin. The six month time schedule was enforced to coincide with the WIC program time frames. The control subjects were enrolled in this study in the following manner:

1) Flyers announcing the study were posted in housing units, laundromats, tre Utah state University 
Extension campus field office, and local neighborhoods near Utah State University. The purpose of the study, what the involvement included, who was responsible for the study, and the benefits of the study were all outlined. An incentive voucher for Utah State University premium ice cream was also offered to the control participants.

2) Women with children between the ages of one and five who were interested in the study called the Utah state University Extension campus field office to obtain more information. The women were screened to rule out those that had been or were currently enrolled in the WIC or EFNEP programs. The screening included verification of income guidelines that met the WIC and EFNEP income guidelines.

3) The woman and one of her children between the ages of one and five came to the Utah state University Extension campus field office, the Nutrition and Food Sciences building, or a local resident's home to enroll in this study. The control woman read and signed a written consent form for herself and another form for her child (control child).

4) The WIC dietary history form and WIC medical history form were completed by the woman for herself and another set was completed for her child.

5) A nutrition knowledge test anc a form detailing the 
family's demographic data were completed by each woman. The nutrition knowledge test and demographic data served as the control data for both the control woman and control child.

6) Four micro capillary tubes of blood were drawn on each control woman and each control child. The hematocrit was read immediately, and the serum portion was frozen for later ferritin analysis.

7) The control subjects did not receive any nutrition education for the next six months. They were excluded from the study if they enrolled in the WIC or EFNEP programs.

8) Six months after their enrollment in the study, the control woman completed the WIC dietary history form and the WIC medical history form for herself and her "control child." The control woman completed a nutrition knowledge test that served as the postevaluation for herself and her child. Both the control woman and control child had four micro capillary tubes of blood drawn for postprogram evaluation of hematocrit and ferritin. The six month time schedule was enforced to coincide with the WIC program time frames.

Analysis of Blood for Hematocrit and Ferritin

Each study participant had a finger stick blood sample 
drawn to determine hematocrit and ferritin levels at the beginning of enrollment into the study and six months later. An Autolance (Becton Dickinson, Franklin Lakes, NJ) finger-pricking device with disposable lancets was used to prick the finger for blood drawing. Aseptic methods as outlined by the Utah state Health Department were used by the county personnel who drew the blood. Four heparinized micro capillary tubes with an inside diameter of 0.5 to 0.6 $\mathrm{mm}$ and length of $75 \mathrm{~mm}$ were filled with blood for each of their two scheduled blood analysis days.

The hematocrit levels were determined by averaging the readings of the four micro capillary tubes spun for three minutes at $3,000 \mathrm{rpm}$ in a HematasTAT model c-70 centrifuge (Separation Technology, Inc., Salt Lake City, UT). The HemataSTAT model C-70 centrifuge has been approved as an accurate hematocrit reading device by the Utah state WIC program.

To determine the ferritin levels, the four capillary tubes were separated at the serum:packed-red-blood-cell dividing line by mechanically scratching the tube with a file at that point and breaking the tube. The serum portion of the blood was blown from the four capillary tubes into a plastic bullet labeled with the participants' identification numbers. The labeled plastic bullets with serum were frozen at -20 degrees centigrade until all samples were collected and were analyzed at the same time. 
The Ferritin Double Antibody Method (Diagnostic Products Corporation) was used to measure ferritin levels. The principle of this procedure is that $125 \mathrm{I}-\mathrm{labeled}$ ferritin added to the blood sample competes with ferritin in the patient sample for sites on ferritin-specific antibody. After incubation for a fixed time, separation of bound from free ferritin is achieved, and the tube is counted in a gamma counter. The counts are inversely related to the amount of ferritin present in the patient sample. The procedure calls for $100 \mu l$ of serum per assay tube. The WIC county health departments refused to allow venous blood draws and limited the blood sample volume to four micro hematocrit capillary tubes. The amount of serum obtained from the participants was 5-35 $\mu 1$ instead of the recommended $100 \mu \mathrm{l}$. To adjust the Ferritin Double Antibody method to the reduced amount of serum, a trial on the blood with equal reduction in all reagents equal to the volume of serum was conducted. A procedure to adjust for the reduced serum volume by concentrating the calibration solutions to be more sensitive at a higher percent binding of the radioactive ferritin was also conducted. This second procedure was chosen because the first method did not result in a precipitate large enough to react in the gamma counter.

Adjustments were made in reagents $A$ and $B$ to enable a more discriminatory reading of a high percent binding of 
radioactive ferritin. This was necessary since more of the radioactive ferritin would be bound because the volume of serum ferritin was reduced. Table 2 contains the adjustments made to the procedures on page 5 of the "Ferritin Double Antibody" instructions (Appendix D).

Table 2. Adjustments in reagents for the Ferritin Double Antibody Method.

\begin{tabular}{lcr}
\hline TUBE & PERCENT BOUND & FERRITIN $\mathrm{ng} / \mathrm{ml}$ \\
\hline $\mathrm{A}$ & 100 & 0 \\
32/4A, 1/4B & 91.4 & 2.5 \\
1/2A, 1/2B & 88.2 & 5.0 \\
1/4A, 3/4B & 87.0 & 7.5 \\
$\mathrm{~B} 2$ & 86.4 & 10.0 \\
$\mathrm{C}$ & 76.4 & 25.0 \\
$\mathrm{D}$ & 39.4 & 100.0 \\
$\mathrm{E}$ & 19.4 & 200.0 \\
$\mathrm{~F}$ & 8.2 & 500.0 \\
\end{tabular}

The "altered" (concentrating the calibration solution for the small amount of serum samples and using small serum samples) ferritin procedure was conducted on two different samples of blood to check the feasibility of obtaining accurate ferritin levels from small samples of serum. The following procedures were taken:

1) The "radioimmunoassay" procedure of the Ferritin Double Antibody instructions (Appendix D) was adjusted in step 1 of page 4 as outlined in Table 2 .

2) Step 2 of page 4 in the Ferritin Double Antibody instructions was altered by adding different amounts of one patient's serum to the tubes. One patient's 
blood was separated into 24 tubes (three tubes each of $5,10,15,20,25,30,35$, and $100 \mu 1$ of serum). This was repeated for a second patient's blood.

3) Steps 3-9 on page 4 of the Ferritin Double Antibody instructions were conducted on the serum samples with no alterations.

4) The "Net CPM" (counts per minute) was calculated by subtracting 450 (the NSB [non-specific binding] count) from the "Average CPM." This calculation is outlined on page 5 of the Ferritin Double Antibody instructions.

5) The "percent bound" was calculated by dividing the Net CPM by the "Net MB" (maximum binding) counts and multiplying by 100. The Net MB count was 113.79 . This calculation is outlined on page 5 of the Ferritin Double Antibody instructions.

6) A logarithm curvilinear line was established to calculate the patients' sample using the results of the adjusted calibrator solutions as outlined in Table 2. The equation generated was the $\log$ of $X=Y-88.51 /-$ 14.32 .

7) The value of $\mathrm{X}$ was calculated by taking the antilog of $\mathrm{X}$.

8) The percent bound value was multiplied by the dilution factor (100 divided by the amount of patient serum [e.g., if the serum sample was $5 \mu$, the equation was: 
$100 / 5 \mu 1=20])$.

9) The value of $x$ was plotted against the new percent bound value calculated in step 8 to obtain the amount of ferritin in the sample.

Table 3 contains the results of the above procedure on two blood samples. Averages for the three tubes with the same amount of patient's serum were calculated and placed in Table 3. If the value for one of the three tubes varied widely from the other two values, the two similar values were averaged. If there was no similar reading for the triplicate tubes, the word "erratic" was reported in the table. Appendix E contains the raw data of these calculations.

Table 3. Ferritin levels for small amounts of serum using the altered Ferritin Double Antibody procedure.

\begin{tabular}{rll}
\hline Amount & Sample \#1 & Sample \#2 \\
\hline $5 \mu 1$ & $16.3 \mathrm{ng} / \mathrm{ml}$ & erratic \\
$10 \mu 1$ & erratic & $22.7 \mathrm{ng} / \mathrm{ml}$ \\
$15 \mu 1$ & $13.5 \mathrm{ng} / \mathrm{ml}$ & $22.6 \mathrm{ng} / \mathrm{ml}$ \\
$20 \mu 1$ & $12.8 \mathrm{ng} / \mathrm{ml}$ & $25.4 \mathrm{ng} / \mathrm{ml}$ \\
$25 \mu 1$ & $22.4 \mathrm{ng} / \mathrm{ml}$ & erratic \\
$30 \mu 1$ & $23.6 \mathrm{ng} / \mathrm{ml}$ & erratic \\
$35 \mu 1$ & $17.2 \mathrm{ng} / \mathrm{ml}$ & $36.8 \mathrm{ng} / \mathrm{ml}$ \\
\hline
\end{tabular}

The ferritin values for the study participants were calculated using the same procedure above. The blood analysis was conducted at a separate time with a different calibration kit, so a separate logarithm curvilinear line was calculated $(Y=X-98 /-14.5)$. Y represented the new 
ferritin level and $\mathrm{x}$ represented the percent bound value. The results in Table 3 indicated that the ferritin values were not exact; however, regardless of sample size the results obtained were similar to the actual values.

\section{Statistical Analysis}

The following statistical tests were conducted for each program separately and for the total group collectively.

1) Paired t-tests were conducted between the scores on nutrition knowledge tests taken at the beginning to the study (program enrollment) and the nutrition knowledge test taken six months later.

2) Paired t-tests were conducted between dietary components (protein, calcium, iron, vitamin C, and vitamin A) consumed prior to study enrollment and dietary components consumed six months later.

3) Paired t-tests were conducted between hematocrit levels taken prior to study enrollment and hematocrit levels six months later.

4) Paired t-tests were conducted between ferritin levels taken prior to study enrollment and ferritin levels six months later.

5) Correlation of nutrition knowledge scores with each of the five dietary components (protein, calcium, iron, vitamin C, and vitamin A) were conducted. 
6) Correlation of nutrition knowledge scores with hematocrit levels were conducted.

7) Correlation of nutrition knowledge scores with relative ferritin levels were conducted.

8) Correlation of each of the dietary components (protein, calcium, iron, vitamin C, and vitamin A) with hematocrit levels were conducted.

9) Correlation of each of the dietary components (protein, calcium, iron, vitamin C, and vitamin A) with relative ferritin levels were conducted.

10) Group t-tests for hematocrit levels, knowledge scores, and dietary components when separated by the discrete variables "taking nutrition classes in high school," "taking nutrition classes in college," and "participating in other food programs" were conducted.

11) Group t-tests between the nutrition knowledge postprogram scores for those receiving a preprogram test versus those that received a postprogram test only were conducted.

12) Correlations of demographic data (age, income, family size, previous nutrition education sessions, and individual income [income divided by family size]) with the dependent variables of hematocrit levels, ferritin levels, dietary components, and nutrition knowledge scores were conducted.

13) Regression analyses using nutrition knowledge scores, 
hematocrit levels, relative ferritin levels, and dietary intake components as the dependent variables, and nutrition knowledge scores, hematocrit levels, relative ferritin levels, dietary components, family size, income, individual income, vitamin supplementation, years of education, participating in food programs, and taking nutrition classes in high school or college as the independent variables were conducted on each other.

14) One-way analysis of variance was calculated among the EFNEP, WIC, and control groups for several nutrients, hematocrit, and nutrition knowledge scores.

15) An analysis of covariance was conducted with "years of formal education" as a covariate with "nutrition knowledge score."

16) Item analysis, item discrimination, item difficulty, and item effectiveness were calculated on each test question of the nutrition knowledge test. 
CHAPTER IV

\section{RESULTS AND DISCUSSION}

Undernutrition of iron and protein can have irreversible health effects such as increased rates of infection, low growth rates in children, and delayed motor and cognitive development (Galler, 1987; Soemantri et al., 1985). The purpose of this study was to determine the impact of participation in the Expanded Food and Nutrition Education Program (EFNEP) and Women, Infants, and Children Supplemental Food Program (WIC) by iron status, nutrition knowledge, and dietary behavior. The specific objectives were to: 1) determine the impact of participation in the EFNEP program on iron status as assessed by hematocrit and ferritin values; 2) determine the effect of nutrition knowledge on hematocrit and ferritin values for both WIC and EFNEP program participants; and 3) determine the effect of dietary behavior on hematocrit and ferritin values for both WIC and EFNEP participants.

\section{Description of the Study Population}

All study participants were enrolled in the study between December 1989 and June 1991. The WIC population had a high dropout rate, with 42 of the original 155 participants completing the study. All 26 EFNEP participants and 23 of the 28 control families completed tre study. 
The characteristics of the study population served as independent variables in the research. Nutrition knowledge test scores, hematocrit levels, relative ferritin levels, and the five nutrients also served as independent variables when used as predictive variables on each other as dependent variables. The results presented in Appendix A describe the population according to age distribution for the children, usage of vitamin and mineral supplements, family size, income level, and years of formal education. The results have been separated by program participation. The control participants had a higher mean education level. The EFNEP participants had higher mean family size.

The characteristics of this study population differ somewhat from other data reported in the literature. DelTredici et al. (1988) reported the mean income for a California EFNEP group as $\$ 567 \pm 186$ per month. The EFNEP participants in this study had a \$1045 \pm 332 monthly income (and a mean individual income [income/family size] of $\$ 225)$. The authors also reported a family size of $4.5 \pm$ 1.6 if the father was present or $3.4 \pm 1.4$ if the father was not present compared to $5.0 \pm 1.44$ for the EFNEP participants in this study. Chipman and Kendall (1989) reported the mean income for a Colorado EFNEP group as $\$ 315$ per month, and that $66 \%$ were participants in the Food stamp Program, and $30 \%$ also participated in the WIC program. Torisky et al. (1989) reported $71 \%$ participated in the Food 
Stamp Program and $68 \%$ in the WIC program, with an average monthly income of $\$ 579$. Twelve percent of the EFNEP participants in this study were participants in the Food Stamp Program and none were participating in the WIC program due to the study design. The participants in this study had a higher income, slightly larger family size, and participated less frequently in other food programs than did those in other reported studies.

\section{Nutrition knowledge Test Results}

Each study participant or guardian of the study participant took a 21-question multiple-choice nutrition knowledge test at preprogram enrollment and six months later. Internal consistency of the test was calculated prior to this study on ten graduates of the programs with a split-half reliability. A similar number of correct responses were scored on the odd-numbered questions as on the even-numbered questions. The test contained face validity, as program graduates felt the test covered material that was taught, even if they missed questions.

The number and percentage of study participants who answered questions correctly were tallied by program and by question in Table 4 . The results of separating the test scores into ranges of correct responses (Table 5) revealed that the WIC participants had a high proportion scoring less than $52 \%$ correctly on the pre. and posttests, the 
Table 4. Percent of study participants answering each question correctly, tallied by program.

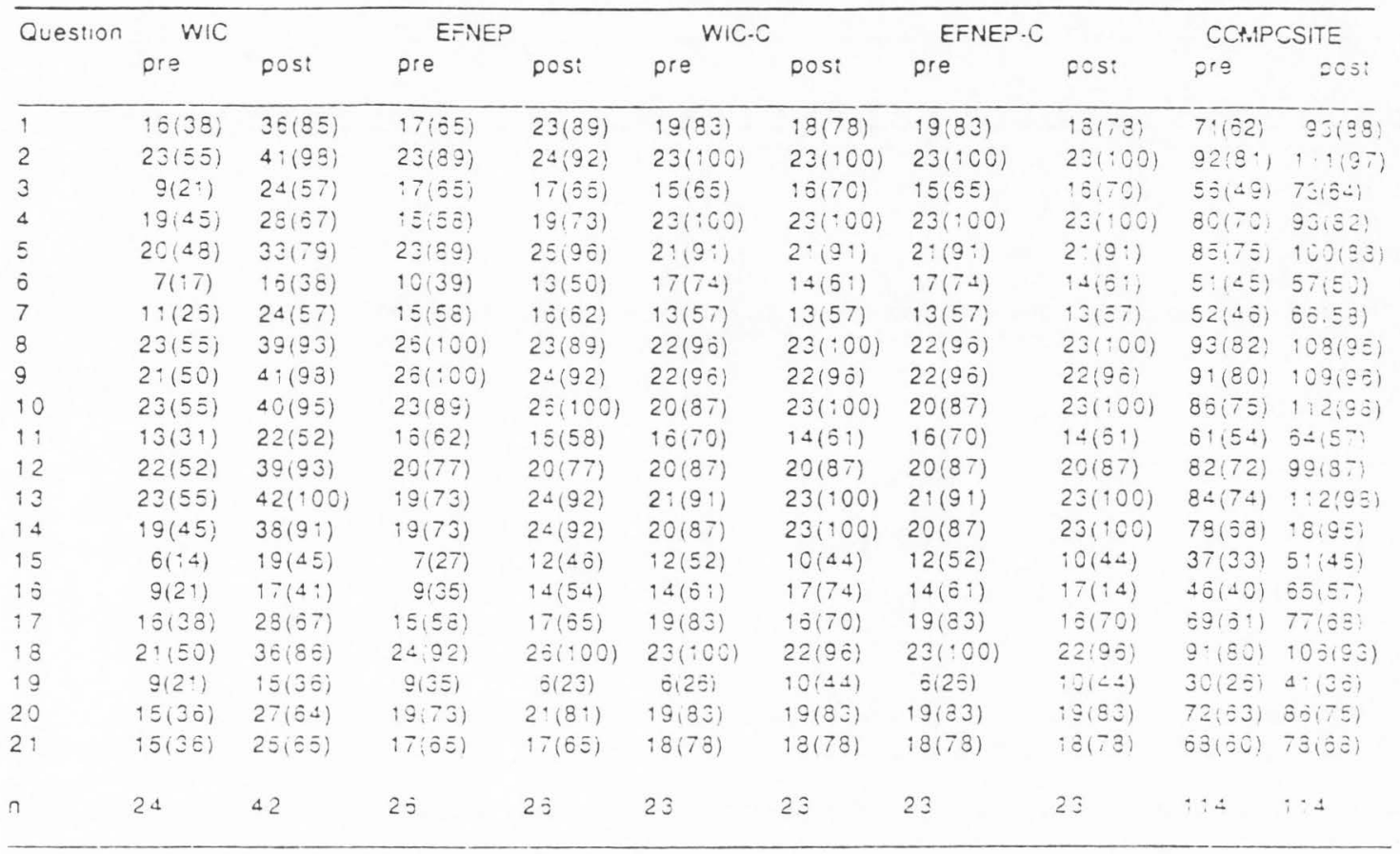

Note: Numcers in parentheses () are percentages

EFNEP participants had a high proportion scoring less than $52 \%$ correctly on the pretest with most of the participants scoring between $52 \%$ and $76 \%$ on the posttest, and the control participants had a higher proportion scoring higher than $76 \%$ correctly on both the pretest and posttest. To determine if taking a pretest had an effect on posttest scores, approximately half of the WIC participants were administerod both o hr tect and posttest whi'f the other half received only a posttest. There was no significant difference un $\ldots=$ pustest score between the $<4$ WIC participants that took both a pretest and posttest and the 18 WIC participants taking only a post:est. This was 
Table 5. Nutrition knowledge test scores, tallied by program.

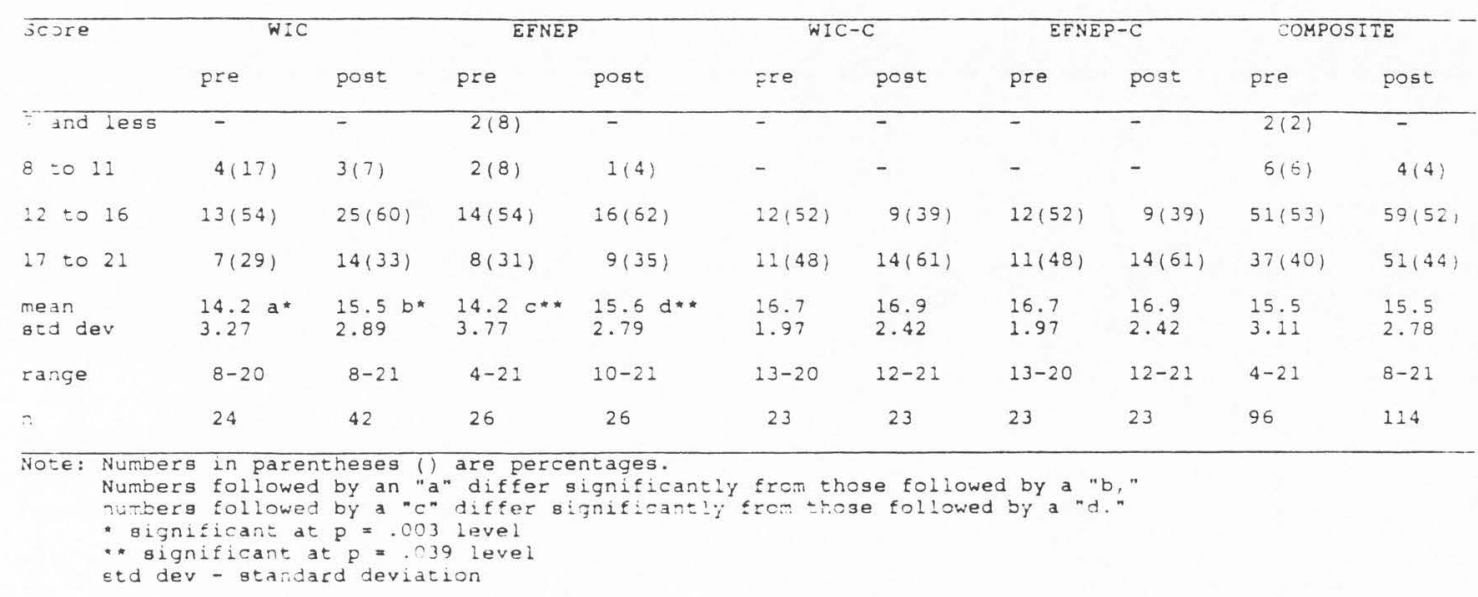

assessed by a significance of $p=0.20$ when a group $t$-test was conducted. When years of formal education (control groups with 12.8 years, WIC with 12.02 , and EFNEP with 12.00 years) were considered as a covariate with nutrition knowledge scores, there were no significant differences among the groups observed with an analysis of covariance. The calculations of difficulty level, index of discrimination, and efficiency level on postnutrition knowledge scores ('rable 6) indicated questions 3, 6, 11 , $15,16,17,19,20$, and $2:$ were the best discriminators of

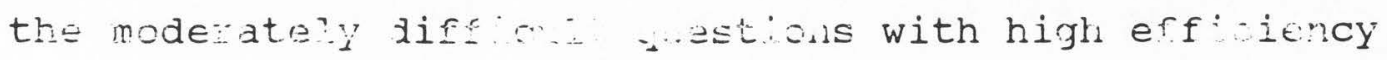
scores. The pretest calculations (Table 7) indicated questions $4,11,14,15, \ldots, 17,20$, and 21 were the best discriminators of the moderately difficult questions with high efficiency scores. The difficulty index indivated 
Table 6. Index of discrimination, efficiency level, and difficulty level calculations for the postprogram nutrition knowledge test items.

\begin{tabular}{lllllllll}
\hline Question & $\mathrm{CH}$ & $\mathrm{CL}$ & $\mathrm{PH}$ & $\mathrm{PL}$ & $\mathrm{D}$ & $\mathrm{P}$ & $\begin{array}{l}\text { Maximum } \\
\text { Level }\end{array}$ & $\mathrm{E}$
\end{tabular}

\begin{tabular}{|c|c|c|c|c|c|c|c|c|c|}
\hline 1 & 20 & 15 & 0.91 & 0.68 & 0.23 & 0.73 & $\mathrm{~m}$ & 0.54 & 0.42 \\
\hline 2 & 22 & 22 & 1.00 & 1.00 & 0.00 & 0.92 & e & 0.16 & 0.00 \\
\hline 3 & 19 & 4 & 0.86 & 0.18 & $0.68 *$ & 0.48 & $\mathrm{~m}$ & 0.96 & 0.71 \\
\hline 4 & 22 & 11 & 1.00 & 0.50 & 0.50 & 0.69 & $\mathrm{~m}$ & 0.62 & 0.81 \\
\hline 5 & 22 & 19 & 1.00 & 0.86 & 0.14 & 0.85 & e & 0.30 & 0.47 \\
\hline 6 & 20 & 7 & 0.91 & 0.32 & 0.59 * & 0.56 & $\mathrm{~m}$ & 0.88 & 0.67 \\
\hline 7 & 16 & 10 & 0.73 & 0.45 & 0.28 & 0.54 & $\mathrm{~m}$ & 0.92 & $0.30 r$ \\
\hline 8 & 22 & 19 & 1.00 & 0.86 & 0.14 & 0.85 & e & 0.30 & 0.47 \\
\hline 9 & 22 & 18 & 1.00 & 0.82 & 0.18 & 0.83 & e & 0.34 & 0.53 \\
\hline 10 & 22 & 22 & 1.00 & 1.00 & 0.00 & 0.92 & e & 0.16 & $0.00 \mathrm{r}$ \\
\hline 11 & 22 & 8 & 1.00 & 0.36 & 0.64 * & 0.63 & $\mathrm{~m}$ & 0.74 & 0.86 \\
\hline 12 & 19 & 20 & 0.86 & 0.91 & -0.05 & 0.81 & e & 0.38 & $0.00 r$ \\
\hline 13 & 22 & 21 & 1.00 & 0.95 & 0.05 & 0.89 & e & 0.22 & $0.23 r$ \\
\hline 14 & 22 & 17 & 1.00 & 0.77 & 0.23 & 0.81 & e & 0.38 & 0.61 \\
\hline 15 & 21 & 3 & 0.95 & 0.14 & $0.81 *$ & 0.50 & $\mathrm{~m}$ & 1.00 & 0.81 \\
\hline 16 & 22 & 4 & 1.00 & 0.18 & 0.82 * & 0.54 & $\mathrm{~m}$ & 0.92 & 0.89 \\
\hline 17 & 21 & 8 & 0.95 & 0.36 & 0.59 * & 0.60 & $\mathrm{~m}$ & 0.80 & 0.74 \\
\hline 18 & 22 & 15 & 1.00 & 0.68 & 0.32 & 0.77 & $\mathrm{~m}$ & 0.46 & 0.69 \\
\hline 19 & 17 & 5 & 0.77 & 0.23 & $0.54 *$ & 0.46 & $\mathrm{~m}$ & 0.92 & 0.59 \\
\hline 20 & 22 & 7 & 1.00 & 0.32 & $0.68 *$ & 0.61 & $\mathrm{~m}$ & 0.78 & 0.87 \\
\hline 21 & 18 & 5 & 0.82 & 0.23 & 0.59 * & 0.48 & $\mathrm{~m}$ & 0.96 & 0.61 \\
\hline
\end{tabular}

Note: 22 were in the high scoring group, 22 were in the low scoring group, $\mathrm{CH}=$ correct responses for the high scoring group, $C L=$ correct responses for the low scoring group, $\mathrm{PH}=$ proportion of correct responses for the high scoring group, $\mathrm{PL}=$ proportion of correct responses for the low scoring group, $D=$ index of discrimination, $P=$ difficulty level, $m=$ moderate difficulty ( $p$ between 2 \& 8 ), $e=$ easy difficulty level $(p>8), *=$ best discriminating questions, $r=$ refining needed, $E=$ efficiency of item. Question \#12 had the only negative index of discrimination.

that 13 of the questions were moderately difficult

(approximately two thirds of the questions) and 8 were 
Table 7. Index of discrimination, efficiency level, and difficulty level calculations for the preprogram nutrition knowledge test items.

\begin{tabular}{lllllllll}
\hline Question & $\mathrm{CH}$ & $\mathrm{CL}$ & $\mathrm{PH}$ & $\mathrm{PL}$ & $\mathrm{D}$ & $\mathrm{P}$ & $\begin{array}{l}\text { Maximum } \\
\text { Level }\end{array}$ & $\mathrm{E}$
\end{tabular}

\begin{tabular}{lrrlllllll}
\hline 1 & 17 & 17 & 0.77 & 0.65 & 0.12 & 0.71 & $\mathrm{~m}$ & 0.58 & $0.21 \mathrm{r}$ \\
2 & 22 & 19 & 1.00 & 0.73 & 0.27 & 0.85 & $\mathrm{e}$ & 0.30 & 0.90 \\
3 & 16 & 6 & 0.73 & 0.23 & 0.50 & 0.45 & $\mathrm{~m}$ & 0.90 & 0.56 \\
4 & 21 & 13 & 0.95 & 0.50 & $0.45 *$ & 0.71 & $\mathrm{~m}$ & 0.58 & 0.78 \\
5 & 22 & 18 & 1.00 & 0.69 & 0.31 & 0.83 & $\mathrm{e}$ & 0.34 & 0.91 \\
6 & 21 & 6 & 0.95 & 0.23 & 0.72 & 0.56 & $\mathrm{~m}$ & 0.88 & 0.82 \\
7 & 16 & 6 & 0.73 & 0.23 & 0.50 & 0.45 & $\mathrm{~m}$ & 0.90 & 0.56 \\
8 & 22 & 20 & 1.00 & 0.77 & 0.23 & 0.88 & $\mathrm{e}$ & 0.24 & 0.96 \\
9 & 22 & 21 & 1.00 & 0.81 & 0.19 & 0.89 & $\mathrm{e}$ & 0.22 & 0.86 \\
10 & 22 & 23 & 1.00 & 0.88 & 0.12 & 0.94 & $\mathrm{e}$ & 0.12 & 1.00 \\
11 & 20 & 8 & 0.91 & 0.31 & $0.60 *$ & 0.58 & $\mathrm{~m}$ & 0.84 & 0.71 \\
12 & 22 & 21 & 1.00 & 0.81 & 0.19 & 0.89 & $\mathrm{e}$ & 0.22 & 0.86 \\
13 & 22 & 18 & 1.00 & 0.69 & 0.31 & 0.83 & $\mathrm{e}$ & 0.34 & 0.91 \\
14 & 22 & 14 & 1.00 & 0.54 & $0.46 *$ & 0.75 & $\mathrm{~m}$ & 0.50 & 0.92 \\
15 & 15 & 5 & 0.68 & 0.19 & $0.49 *$ & 0.42 & $\mathrm{~m}$ & 0.16 & 3.06 \\
16 & 20 & 5 & 0.91 & 0.19 & $0.72 *$ & 0.52 & $\mathrm{~m}$ & 0.96 & 0.75 \\
17 & 21 & 14 & 0.95 & 0.54 & $0.41 *$ & 0.73 & $\mathrm{~m}$ & 0.54 & 0.76 \\
18 & 22 & 22 & 1.00 & 0.85 & 0.15 & 0.92 & $\mathrm{e}$ & 0.16 & 0.94 \\
19 & 11 & 5 & 0.50 & 0.19 & 0.31 & 0.33 & $\mathrm{~m}$ & 0.66 & 0.51 \\
20 & 22 & 15 & 1.00 & 0.58 & $0.42 *$ & 0.77 & $\mathrm{~m}$ & 0.46 & 0.91 \\
21 & 21 & 13 & 0.95 & 0.50 & $0.45 *$ & 0.71 & $\mathrm{~m}$ & 0.58 & 0.78
\end{tabular}

\begin{tabular}{ll}
\hline Note: & 22 were in the high scoring group, 26 were in the \\
low scoring group, $\mathrm{CH}=$ correct responses for the \\
high scoring group, $\mathrm{CL}=$ correct responses for the \\
low scoring group, $\mathrm{PH}=$ proportion of correct \\
responses for the high scoring group, PL = \\
proportion of correct responses for the low scoring \\
group, D = index of discrimination, $*=$ best \\
discriminating question, $\mathrm{P}=$ difficulty level, $\mathrm{m}=$ \\
moderate difficulty $(\mathrm{p}$ between 2 \& 8$), \mathrm{e}=$ easy \\
difficulty level $(\mathrm{p}<8), \mathrm{r}=$ refinement needed, $\mathrm{E}=$ \\
efficiency of item.
\end{tabular}

rated as easy questions. The easy questions did not prove to be good discriminators between low and high scoring groups. 
The efficiency of several test questions (efficiency = index of discrimination divided by the maximum value of the index of discrimination) was calculated. The ability to consider both the index of discrimination (the proportion correctly responding to a question from a low scoring group subtracted from the proportion of correct responses from the high scoring group) and the difficulty level (maximum index of discrimination) revealed that questions \#1, 7, 10, 12, and 13 need revising if the test is used again.

\section{Paired T-Tests}

Paired t-tests were calculated for all study participants and for a subgroup of participants not taking vitamin supplements on hematocrit level, relative ferritin levels, nutritional knowledge scores, and several nutrient components. The paired t-tests were separated by program and tallied in Tables 8 and 9. When the paired t-tests for all study participants were calculated, the WIC participants had a significant increase in nutrition knowledge score $(14.2 \pm 3.27$ to $15.5 \pm 2.89)$ and protein intake (274 $\pm 121 \% \mathrm{RDA}$ to $343 \pm 125 \% \mathrm{RDA})$ at the follow-up visit. The EFNEP participants had a significant increase in nutrition knowledge score $(14.2 \pm 3.77$ to $15.6 \pm 2.79)$ and hematocrit level $(38.5 \pm 3.78 \%$ to $40.7 \% \pm 2.13)$. The WIC control group had a significant decrease in relative ferritin (209 $\pm 36 \mu \mathrm{g} / 1$ to $85 \pm 81 \mu \mathrm{g} / \mathrm{l})$, and the EFNEP 
Table 8. Paired t-tests on hematocrit, relative ferritin, nutrition knowledge scores, and several nutrients for study participants.

\begin{tabular}{lllll}
\hline Program Variable & Mean & $N$ & $\mathrm{p}$ & $\begin{array}{l}\text { Ave } \% \text { pt. } \\
\text { change }\end{array}$
\end{tabular}

\begin{tabular}{|c|c|c|c|c|c|c|}
\hline WIC & $\begin{array}{l}\text { pre vit } A \\
\text { post vit } A\end{array}$ & $\begin{array}{l}226 \pm 230 \% \\
240 \pm 236 \%\end{array}$ & $\begin{array}{l}\text { RDA } \\
\% \text { RDA }\end{array}$ & 42 & 0.809 & 0.686 \\
\hline EFNEP & $\begin{array}{l}\text { pre vit } A \\
\text { post vit } A\end{array}$ & $\begin{array}{l}253 \pm 206 \% \\
280 \pm 203 \%\end{array}$ & $\begin{array}{ll}\circ & \text { RDA } \\
\circ & \text { RDA }\end{array}$ & 26 & 0.606 & 1.070 \\
\hline WIC-C & $\begin{array}{l}\text { pre vit } A \\
\text { post vit } A\end{array}$ & $\begin{array}{l}188 \pm 160 \% \\
135 \pm 136 \%\end{array}$ & $\begin{array}{ll}\circ & \text { RDA } \\
0 & \text { RDA }\end{array}$ & 23 & 0.234 & 0.206 \\
\hline EFNEP-C & $\begin{array}{l}\text { pre vit } A \\
\text { post vit } A\end{array}$ & $\begin{array}{l}195 \pm 225 \% \\
203 \pm 163 \%\end{array}$ & $\begin{array}{ll} & \text { RDA } \\
0 & \text { RDA }\end{array}$ & 23 & 0.877 & 1.110 \\
\hline Composite & $\begin{array}{l}\text { pre vit } A \\
\text { post vit } A\end{array}$ & $\begin{array}{l}218 \pm 210 \% \\
220 \pm 201 \%\end{array}$ & $\begin{array}{ll}\circ & \text { RDA } \\
0 & \text { RDA }\end{array}$ & 114 & 0.944 & 0.762 \\
\hline WIC & $\begin{array}{l}\text { pre calc } \\
\text { post calc }\end{array}$ & $\begin{array}{l}105 \pm 47 \% \\
122 \pm 49 \%\end{array}$ & $\begin{array}{l}\text { RDA } \\
\text { RDA }\end{array}$ & 42 & 0.074 * & 0.384 \\
\hline EFNEP & $\begin{array}{l}\text { pre calc } \\
\text { post calc }\end{array}$ & $\begin{array}{l}107 \pm 59 \% \\
142 \pm 96\end{array}$ & $\mathrm{RDA}$ & 26 & $0.036 * *$ & 0.401 \\
\hline WIC-C & $\begin{array}{l}\text { pre calc } \\
\text { post calc }\end{array}$ & $\begin{array}{r}106 \pm 52 \% \\
96 \pm 48 \%\end{array}$ & $\begin{array}{l}\text { RDA } \\
\text { RDA }\end{array}$ & 23 & 0.377 & 0.148 \\
\hline EFNEP-C & $\begin{array}{l}\text { pre calc } \\
\text { post calc }\end{array}$ & $\begin{array}{l}102 \pm 49 \% \\
106 \pm 55 \%\end{array}$ & $\mathrm{RDA}$ & 23 & 0.740 & 0.233 \\
\hline Composite & $\begin{array}{l}\text { pre calc } \\
\text { post calc }\end{array}$ & $\begin{array}{l}105 \pm 50 \% \\
118 \pm 65 \%\end{array}$ & $\begin{array}{l}\text { RDA } \\
\text { RDA }\end{array}$ & 114 & $0.037 * *$ & 0.310 \\
\hline WIC & $\begin{array}{l}\text { pre prot } \\
\text { post prot }\end{array}$ & $\begin{array}{l}274 \pm 121 \% \\
343 \pm 125 \%\end{array}$ & $\begin{array}{l}\text { RDA } \\
\text { RDA }\end{array}$ & 42 & $0.010 * \star *$ & 0.543 \\
\hline EFNEP & $\begin{array}{l}\text { pre prot } \\
\text { post prot }\end{array}$ & $\begin{array}{l}131 \pm 41 \% \\
156 \pm 46 \%\end{array}$ & $\begin{array}{l}\text { RDA } \\
\text { RDA }\end{array}$ & 26 & $0.023 * *$ & 0.317 \\
\hline WIC-C & $\begin{array}{l}\text { pre prot } \\
\text { post prot }\end{array}$ & $\begin{array}{l}132 \pm 72 \% \\
115 \pm 32\end{array}$ & RDA & 23 & 0.273 & 0.049 \\
\hline EFNEP-C & $\begin{array}{l}\text { pre prot } \\
\text { post prot }\end{array}$ & $\begin{array}{l}257 \pm 112 \% \\
296 \pm 111 \%\end{array}$ & $\begin{array}{ll}6 & \text { RDA } \\
6 & \text { RDA }\end{array}$ & 23 & 0.151 & 0.348 \\
\hline Composite & pre prot & $209 \pm 117 \%$ & RDA & 114 & $0.003 * * *$ & 0.352 \\
\hline
\end{tabular}


Table 8 continued

\begin{tabular}{lllll}
\hline Program Variable & Mean & $\mathrm{N}$ & $\mathrm{p}$ & $\begin{array}{l}\text { Ave } \% \text { pt. } \\
\text { change }\end{array}$
\end{tabular}

\begin{tabular}{|c|c|c|c|c|c|}
\hline WIC & $\begin{array}{l}\text { pre iron } \\
\text { post iron }\end{array}$ & $\begin{array}{c}74 \pm 42 \% \mathrm{RDA} \\
115 \pm 145 \% \mathrm{RDA}\end{array}$ & 42 & $0.070 *$ & 0.654 \\
\hline EFNEP & $\begin{array}{l}\text { pre iron } \\
\text { post iron }\end{array}$ & $\begin{array}{ll}63 \pm 26 \% & \text { RDA } \\
77 \pm 32 \% & \text { RDA }\end{array}$ & 26 & $0.068 *$ & 0.468 \\
\hline WIC-C & $\begin{array}{l}\text { pre iron } \\
\text { post iron }\end{array}$ & $\begin{array}{ll}58 \pm 19 \% & R D A \\
60 \pm 20 \% & R D A\end{array}$ & 23 & 0.846 & 0.125 \\
\hline EFNEP-C & $\begin{array}{l}\text { pre iron } \\
\text { post iron }\end{array}$ & $\begin{array}{ll}59 \pm 20 \% & \text { RDA } \\
77 \pm 25 \% & \text { RDA }\end{array}$ & 23 & $0.001 * \star \star *$ & 0.447 \\
\hline Composite & $\begin{array}{l}\text { pre iron } \\
\text { post iron }\end{array}$ & $\begin{array}{ll}65 \pm 31 \% & \text { RDA } \\
82 \pm 92 \% & \text { RDA }\end{array}$ & 114 & $0.010 * * *$ & 0.463 \\
\hline WIC & $\begin{array}{l}\text { pre vit } C \\
\text { post vit } C\end{array}$ & $\begin{array}{ll}147 \pm 124 \% & \text { RDA } \\
184 \pm 142 \% & \text { RDA }\end{array}$ & 42 & 0.224 & 1.500 \\
\hline EFNEP & $\begin{array}{l}\text { pre vit } C \\
\text { post vit } C\end{array}$ & $\begin{array}{ll}202 \pm 156 \% & \text { RDA } \\
245 \pm 149 \% & \text { RDA }\end{array}$ & 26 & 0.327 & 2.580 \\
\hline WIC-C & $\begin{array}{l}\text { pre vit } C \\
\text { post vit } C\end{array}$ & $\begin{array}{ll}151 \pm 177 \% & \text { RDA } \\
177 \pm 162 \% & \text { RDA }\end{array}$ & 23 & 0.540 & 1.000 \\
\hline EFNEP-C & $\begin{array}{l}\text { pre vit } C \\
\text { post vit } C\end{array}$ & $\begin{array}{l}115 \pm 84 \% \text { RDA } \\
201 \pm 155 \% \text { RDA }\end{array}$ & 23 & $0.030 * *$ & 2.340 \\
\hline Composite & $\begin{array}{l}\text { pre vit C } \\
\text { post vit } C\end{array}$ & $\begin{array}{ll}154 \pm 139 \% & \mathrm{RDA} \\
200 \pm 150 \% & \mathrm{RDA}\end{array}$ & 114 & $0.014 * *$ & 1.818 \\
\hline WIC & $\begin{array}{l}\text { pre Hct } \\
\text { post Hct }\end{array}$ & $\begin{array}{l}36.4 \pm 2.2 \% \\
37.1 \pm 2.3 \%\end{array}$ & 42 & 0.149 & 0.019 \\
\hline EFNEP & $\begin{array}{l}\text { pre Hct } \\
\text { post Hct }\end{array}$ & $\begin{array}{l}38.5 \pm 3.5 \% \\
40.7 \pm 2.2 \%\end{array}$ & 26 & $0.001 * * *$ & 0.064 \\
\hline WIC-C & $\begin{array}{l}\text { pre Hct } \\
\text { post Hct }\end{array}$ & $\begin{array}{l}40.2 \pm 2.3 \% \\
40.3 \pm 2.4 \%\end{array}$ & 23 & 0.937 & 0.000 \\
\hline EFNEP-C & $\begin{array}{l}\text { pre Hct } \\
\text { post Hct }\end{array}$ & $\begin{array}{l}37.1 \pm 2.1 \% \\
37.0 \pm 2.4 \%\end{array}$ & 23 & 0.817 & 0.002 \\
\hline Composite & $\begin{array}{l}\text { pre Hct } \\
\text { post Hct }\end{array}$ & $\begin{array}{l}38.1 \pm 3.0 \% \\
38.8 \pm 2.4 \%\end{array}$ & 144 & 0.006 & 0.021 \\
\hline
\end{tabular}


Table 8 continued

\begin{tabular}{|c|c|c|c|c|c|}
\hline Program & Variable & Mean & $\mathrm{N}$ & $\begin{array}{l}\text { A) } \\
\text { ch }\end{array}$ & $\begin{array}{l}\text { le } \% \text { pt. } \\
\text { lange }\end{array}$ \\
\hline WIC & $\begin{array}{l}\text { pre know sc } \\
\text { post know sc }\end{array}$ & $\begin{array}{l}14 \cdot 2 \pm 3.3 \\
15 \cdot 5 \pm 2.7\end{array}$ & 24 & $0.003 * *$ & 0.114 \\
\hline EFNEP & $\begin{array}{l}\text { pre know sc } \\
\text { post know sc }\end{array}$ & $\begin{array}{l}14.2 \pm 3.8 \\
15.6 \pm 2.8\end{array}$ & 26 & $0.039 * *$ & 0.211 \\
\hline WIC-C & $\begin{array}{l}\text { pre know sc } \\
\text { post know sc }\end{array}$ & $\begin{array}{l}16.7 \pm 2.0 \\
16.9 \pm 2.4\end{array}$ & 23 & 0.611 & 0.017 \\
\hline EFNEP-C & $\begin{array}{l}\text { pre know sc } \\
\text { post know sc }\end{array}$ & $\begin{array}{l}16 \cdot 7 \pm 2 \cdot 0 \\
16 \cdot 9 \pm 2 \cdot 4\end{array}$ & 23 & 0.611 & 0.017 \\
\hline Composite & $\begin{array}{l}\text { pre know sc } \\
\text { post know sc }\end{array}$ & $\begin{array}{l}15 \cdot 3 \pm 3.1 \\
16.2 \pm 1.8\end{array}$ & 96 & $0.002 * \star \star \star$ & 0.094 \\
\hline WIC & $\begin{array}{l}\text { pre rel fer } \\
\text { post rel fer }\end{array}$ & $\begin{array}{ll}76 \pm 58 & \mu \mathrm{g} / \mathrm{l} \\
85 \pm 49 & \mu \mathrm{g} / \mathrm{l}\end{array}$ & 13 & 0.716 & 0.956 \\
\hline EFNEP & $\begin{array}{l}\text { pre rel fer } \\
\text { post rel fer }\end{array}$ & $\begin{array}{l}128 \pm 121 \mathrm{\mu g} / \mathrm{l} \\
114 \pm 88 \mathrm{\mu g} / 1\end{array}$ & 23 & 0.644 & 0.511 \\
\hline WIC-C & $\begin{array}{l}\text { pre rel fer } \\
\text { post rel fer }\end{array}$ & $\begin{array}{l}209 \pm 223 \mu \mathrm{g} / 1 \\
85 \pm 81 \mu \mathrm{g} / 1\end{array}$ & 16 & $0.023 * *$ & 0.235 \\
\hline EFNEP-C & $\begin{array}{l}\text { pre rel fer } \\
\text { post rel fer }\end{array}$ & $\begin{array}{l}124 \pm 135 \mu \mathrm{g} / 1 \\
104 \pm 91 \mu \mathrm{g} / \mathrm{l}\end{array}$ & 35 & 0.576 & 0.470 \\
\hline Composite & $\begin{array}{l}\text { pre rel fer } \\
\text { post rel fer }\end{array}$ & $\begin{array}{l}136 \pm 151 \mu \mathrm{g} / 1 \\
99 \pm 81 \mu \mathrm{g} / \mathrm{I}\end{array}$ & 87 & 0.494 & 0.487 \\
\hline
\end{tabular}

Note: vit $\mathrm{C}=$ vitamin $\mathrm{C}$ intake, vit $\mathrm{A}=$ vitamin $\mathrm{A}$ intake, calc $=$ calcium intake, prot $=$ protein intake, rel fer $=$ relative ferritin, $*=$ significant at $\mathrm{p}=.10$ level, $* *=$ significant at $\mathrm{p}=.05$ level, $* * *=$ significant at $\mathrm{p}=.01$ level, Ave \% pt change $=$ Average percent point change 
Table 9. Paired t-tests on hematocrit, relative ferritin, nutrition knowledge scores, and several nutrients for study participants not taking vitamin supplements.

\begin{tabular}{|c|c|c|c|c|c|c|}
\hline Program & Variable & Mean & & $\mathrm{N}$ & $\begin{array}{l}\text { Av } \\
\mathrm{Ch}\end{array}$ & $\begin{array}{l}\text { le } \% \mathrm{pt} \\
\text { lange }\end{array}$ \\
\hline WIC & $\begin{array}{l}\text { pre vit } A \\
\text { post vit } A\end{array}$ & $\begin{array}{l}219 \pm 230 \% \\
260 \pm 256\end{array}$ & RDA & 34 & 0.506 & 0.863 \\
\hline EFNEP & $\begin{array}{l}\text { pre vit } A \\
\text { post vit } A\end{array}$ & $\begin{array}{l}289 \pm 215 \% \\
257 \pm 193 \%\end{array}$ & $\begin{array}{l}\text { RDA } \\
\text { RDA }\end{array}$ & 20 & 0.575 & 0.818 \\
\hline WIC-C & $\begin{array}{l}\text { pre vit } A \\
\text { post vit } A\end{array}$ & $\begin{array}{l}201 \pm 167 \% \\
145 \pm 144 \%\end{array}$ & $\begin{array}{l}\text { RDA } \\
\text { RDA }\end{array}$ & 20 & 0.272 & 0.209 \\
\hline EFNEP-C & $\begin{array}{l}\text { pre vit } A \\
\text { post vit } A\end{array}$ & $\begin{array}{l}218 \pm 241 \% \\
200 \pm 151 \%\end{array}$ & $\begin{array}{l}\text { RDA } \\
\text { RDA }\end{array}$ & 19 & 0.776 & 0.766 \\
\hline Composite & $\begin{array}{l}\text { pre vit } A \\
\text { post vit } A\end{array}$ & $\begin{array}{l}230 \pm 216 \% \\
223 \pm 205 \%\end{array}$ & $\begin{array}{l}\text { RDA } \\
\text { RDA }\end{array}$ & 93 & 0.797 & 0.693 \\
\hline WIC & $\begin{array}{l}\text { pre calc } \\
\text { post calc }\end{array}$ & $\begin{array}{l}102 \pm 44 \% \\
124 \pm 45 \%\end{array}$ & $\begin{array}{l}\text { RDA } \\
\text { RDA }\end{array}$ & 34 & $0.035 * *$ & 0.453 \\
\hline EFNEP & $\begin{array}{l}\text { pre calc } \\
\text { post calc }\end{array}$ & $\begin{array}{l}102 \pm 60 \% \\
139 \pm 104 \%\end{array}$ & $\begin{array}{l}\text { RDA } \\
\text { RDA }\end{array}$ & 20 & $0.089 *$ & 0.448 \\
\hline WIC-C & $\begin{array}{l}\text { pre calc } \\
\text { post calc }\end{array}$ & $\begin{array}{l}112 \pm 51 \% \\
101 \pm 47 \%\end{array}$ & $\begin{array}{l}\mathrm{RDA} \\
\mathrm{RDA}\end{array}$ & 20 & 0.340 & 0.150 \\
\hline EFNEP-C & $\begin{array}{l}\text { pre calc } \\
\text { post calc }\end{array}$ & $\begin{array}{l}105 \pm 51 \% \\
109 \pm 60 \%\end{array}$ & $\begin{array}{l}\mathrm{RDA} \\
\mathrm{RDA}\end{array}$ & 19 & 0.797 & 0.245 \\
\hline Composite & $\begin{array}{l}\text { pre calc } \\
\text { post calc }\end{array}$ & $\begin{array}{l}105 \pm 50 \% \\
119 \pm 66 \%\end{array}$ & $\begin{array}{l}\text { RDA } \\
\text { RDA }\end{array}$ & 93 & 0.052 * & 0.344 \\
\hline WIC & $\begin{array}{l}\text { pre prot } \\
\text { post prot }\end{array}$ & $\begin{array}{l}268 \pm 116 \% \\
348 \pm 115 \%\end{array}$ & $\begin{array}{l}\text { RDA } \\
\text { RDA }\end{array}$ & 34 & $0.005 * * *$ & 0.612 \\
\hline EFNEP & $\begin{array}{l}\text { pre prot } \\
\text { post prot }\end{array}$ & $\begin{array}{l}123 \pm 39 \% \\
151 \pm 45 \%\end{array}$ & $\begin{array}{l}\text { RDA } \\
\text { RDA }\end{array}$ & 20 & $0.031 * *$ & 0.368 \\
\hline WIC-C & $\begin{array}{l}\text { pre prot } \\
\text { post prot }\end{array}$ & $\begin{array}{l}140 \pm 73 \% \\
115 \pm 34 \%\end{array}$ & $\begin{array}{l}\mathrm{RDA} \\
\mathrm{RDA}\end{array}$ & 20 & 0.158 & 0.039 \\
\hline EFNEP-C & $\begin{array}{l}\text { pre prot } \\
\text { post prot }\end{array}$ & $\begin{array}{l}272 \pm 109 \% \\
296 \pm 122 \%\end{array}$ & $\begin{array}{l}\mathrm{RDA} \\
\mathrm{RDA}\end{array}$ & 19 & 0.402 & 0.166 \\
\hline Composite & pre prot & $210 \pm 116 \%$ & $\mathrm{RDA}$ & 93 & $0.007 * * *$ & 0.328 \\
\hline
\end{tabular}


Table 9 continued

\begin{tabular}{|c|c|c|c|c|c|}
\hline Program & Variable & Mean & $\mathrm{N}$ & $\begin{array}{l}\text { Ay } \\
\text { Ch }\end{array}$ & $\begin{array}{l}\text { ve \% pt. } \\
\text { lange }\end{array}$ \\
\hline WIC & $\begin{array}{l}\text { pre iron } \\
\text { post iron }\end{array}$ & $\begin{array}{c}80 \pm 44 \% \mathrm{RDA} \\
124 \pm 158 \% \mathrm{RDA}\end{array}$ & 34 & 0.105 & 0.689 \\
\hline EFNEP & $\begin{array}{l}\text { pre iron } \\
\text { post iron }\end{array}$ & $\begin{array}{ll}62 \pm 27 \% & \mathrm{RDA} \\
78 \pm 34 \% & \mathrm{RDA}\end{array}$ & 20 & $0.056 *$ & 0.543 \\
\hline WIC-C & $\begin{array}{l}\text { pre iron } \\
\text { post iron }\end{array}$ & $\begin{array}{ll}59 \pm 16 \% & \mathrm{RDA} \\
59 \pm 21 \% & \mathrm{RDA}\end{array}$ & 20 & 1.0 & 0.053 \\
\hline EFNEP-C & $\begin{array}{l}\text { pre iron } \\
\text { post iron }\end{array}$ & $\begin{array}{ll}62 \pm 17 \% & R D A \\
80 \pm 25 \% & R D A\end{array}$ & 19 & $0.005 * * *$ & 0.371 \\
\hline Composite & $\begin{array}{l}\text { pre iron } \\
\text { post iron }\end{array}$ & $\begin{array}{l}68 \pm 32 \% \mathrm{RDA} \\
91 \pm 101 \% \mathrm{RDA}\end{array}$ & 93 & $0.022 * *$ & 1.583 \\
\hline WIC & $\begin{array}{l}\text { pre vit } C \\
\text { post vit } C\end{array}$ & $\begin{array}{ll}160 \pm 129 \% & R D A \\
200 \pm 149 \% & R D A\end{array}$ & 34 & 0.286 & 1.583 \\
\hline EFNEP & $\begin{array}{l}\text { pre vit } C \\
\text { post vit } C\end{array}$ & $\begin{array}{ll}204 \pm 146 \% & \text { RDA } \\
238 \pm 125 \% & \text { RDA }\end{array}$ & 20 & 0.421 & 1.616 \\
\hline WIC-C & $\begin{array}{l}\text { pre vit } C \\
\text { post vit } C\end{array}$ & $\begin{array}{ll}153 \pm 188 \% & \text { RDA } \\
155 \pm 115 \% & \text { RDA }\end{array}$ & 20 & 0.979 & 0.999 \\
\hline EFNEP-C & $\begin{array}{l}\text { pre vit } C \\
\text { post vit } C\end{array}$ & $\begin{array}{l}129 \pm 86 \% \mathrm{RDA} \\
187 \pm 142 \% \mathrm{RDA}\end{array}$ & 19 & 0.132 & 1.830 \\
\hline Composite & $\begin{array}{l}\text { pre vit C } \\
\text { post vit } C\end{array}$ & $\begin{array}{ll}162 \pm 140 \% & \mathrm{RDA} \\
196 \pm 137 \% & \mathrm{RDA}\end{array}$ & 93 & 0.090 & 1.515 \\
\hline WIC & $\begin{array}{l}\text { pre Hct } \\
\text { post Hct }\end{array}$ & $\begin{array}{l}36.5 \pm 2.2 \% \\
37.1 \pm 2.3 \%\end{array}$ & 34 & 0.182 & 0.016 \\
\hline EFNEP & $\begin{array}{l}\text { pre Hct } \\
\text { post Hct }\end{array}$ & $\begin{array}{l}38.5 \pm 3.8 \% \\
40.4 \pm 2.1 \%\end{array}$ & 20 & $0.006 * \star *$ & 0.058 \\
\hline WIC-C & $\begin{array}{l}\text { pre Hct } \\
\text { post Hct }\end{array}$ & $\begin{array}{l}40 \cdot 5 \pm 2.3 \% \\
40 \cdot 5 \pm 2.5 \%\end{array}$ & 20 & 0.969 & 0.001 \\
\hline EFNEP-C & $\begin{array}{l}\text { pre Hct } \\
\text { post Hct }\end{array}$ & $\begin{array}{l}37.0 \pm 1.6 \% \\
37.5 \pm 2.1 \%\end{array}$ & 19 & 0.272 & 0.015 \\
\hline Composite & $\begin{array}{l}\text { pre Hct } \\
\text { post Hct }\end{array}$ & $\begin{array}{l}37.9 \pm 2.9 \% \\
38.6 \pm 2.8 \%\end{array}$ & 93 & $0.005 * * *$ & 0.022 \\
\hline
\end{tabular}


Table 9 continued

\begin{tabular}{|c|c|c|c|c|c|}
\hline Program & Variable & Mean & $\mathrm{N}$ & $\begin{array}{l}\mathrm{A} \\
\mathrm{Cl}\end{array}$ & $\begin{array}{l}\text { ve } \% \text { pt. } \\
\text { hange }\end{array}$ \\
\hline WIC & $\begin{array}{l}\text { pre know sc } \\
\text { post know sc }\end{array}$ & $\begin{array}{l}14.0 \pm 3.1 \\
15.2 \pm 2.5\end{array}$ & 19 & $0.016 * *$ & 0.110 \\
\hline EFNEP & $\begin{array}{l}\text { pre know sc } \\
\text { post know sc }\end{array}$ & $\begin{array}{l}14.6 \pm 3.3 \\
15.7 \pm 2.6\end{array}$ & 20 & 0.052 * & 0.122 \\
\hline WIC-C & $\begin{array}{l}\text { pre know sc } \\
\text { post know sc }\end{array}$ & $\begin{array}{l}16.7 \pm 2.1 \\
16.9 \pm 2.6\end{array}$ & 20 & 0.750 & 0.013 \\
\hline EFNEP-C & $\begin{array}{l}\text { pre know sc } \\
\text { post know sc }\end{array}$ & $\begin{array}{l}16.8 \pm 2.1 \\
17.0 \pm 2.4\end{array}$ & 19 & 0.640 & 0.017 \\
\hline Composite & $\begin{array}{l}\text { pre know sc } \\
\text { post know sc }\end{array}$ & $\begin{array}{l}15 \cdot 5 \pm 2 \cdot 9 \\
16 \cdot 9 \pm 2 \cdot 4\end{array}$ & 78 & $0.007 * * *$ & 0.066 \\
\hline WIC & $\begin{array}{l}\text { pre rel fer } \\
\text { post rel fer }\end{array}$ & $\begin{array}{l}75 \pm 50 \mu \mathrm{g} / 1 \\
68 \pm 49 \mu \mathrm{g} / 1\end{array}$ & 18 & 0.720 & 1.200 \\
\hline EFNEP & $\begin{array}{l}\text { pre rel fer } \\
\text { post rel fer }\end{array}$ & $\begin{array}{l}129 \pm 138 \mu \mathrm{g} / \mathrm{l} \\
97 \pm 58 \mu \mathrm{g} / \mathrm{l}\end{array}$ & 17 & 0.355 & 0.485 \\
\hline WIC-C & $\begin{array}{l}\text { pre rel fer } \\
\text { post rel fer }\end{array}$ & $\begin{array}{l}240 \pm 236 \mu \mathrm{g} / 1 \\
73 \pm 81 \mu \mathrm{g} / \mathrm{l}\end{array}$ & 13 & $0.009 * * *$ & 0.632 \\
\hline EFNEP-C & $\begin{array}{l}\text { pre rel fer } \\
\text { post rel fer }\end{array}$ & $\begin{array}{l}142 \pm 154 \mu \mathrm{g} / \mathrm{l} \\
112 \pm 98 \mu \mathrm{g} / \mathrm{l}\end{array}$ & 11 & 0.530 & 0.402 \\
\hline Composite & $\begin{array}{l}\text { pre rel fer } \\
\text { post rel fer }\end{array}$ & $\begin{array}{l}139 \pm 159 \mu \mathrm{g} / \mathrm{l} \\
95 \pm 71 \mu \mathrm{g} / \mathrm{l}\end{array}$ & 59 & $0.008 * * *$ & 0.442 \\
\hline
\end{tabular}

Note: vit $\mathrm{C}=$ vitamin $\mathrm{C}$ intake, $\mathrm{vit} \mathrm{A}=$ vitamin $\mathrm{A}$ intake, calc $=$ calcium intake, prot $=$ protein intake, rel fer $=$ relative ferritin, $*=$ significant at $\mathrm{p}=.10$, ** = significant at $\mathrm{p}=.05$ level, $* * *=$ significant at $\mathrm{p}=.01$ level. Ave $\%$ pt change $=$ Average percent point change. 
control group had a significant increase in dietary iron intakes ( $59 \pm 20 \%$ of $\mathrm{RDA}$ to $77 \pm 25 \%$ of $\mathrm{RDA})$. The paired t-test calculations for the subgroup of participants not taking vitamin supplements, which could be a subgroup with a different emphasis on nutrition, indicated the WIC participants had a significant increase in dietary protein intake (268 $\pm 116 \%$ of $\mathrm{RDA}$ to $348 \pm 115 \%$ of $\mathrm{RDA})$, and EFNEP participants had a significant increase in hematocrit (38.5 $\pm 3.8 \%$ to $40.4 \pm 2.1 \%)$. The preprogram value of $38.5 \pm$ 3.78 was above the CDC cut-off value for low hematocrit ("low normal"), and an increase within an already normal range is impressive. The WIC-control participants had a significant decrease in relative ferritin $(240 \pm 236 \mu \mathrm{g} / \mathrm{l}$ to $73 \pm 81 \mu \mathrm{g} / 1)$, and the EFNEP-control group had a significant increase in dietary iron intake (62 $\pm 17 \%$ of $\mathrm{RDA}$ to $80 \pm 25 \%$ of $\mathrm{RDA})$.

In this study, the WIC participants did not have a significant increase in hematocrit level at the postprogram evaluation above the preprogram hematocrit level (36.4 \pm 2.17 at preprogram and $37.1 \pm 2.34$ at postprogram evaluation). Rush et al. (1988a) in the "Review of Past Studies" of the WIC program summarized that most evidence indicated that the WIC program had led to a decreased incidence of anemia in late infancy and early childhood. "However, the issue warrants a great deal more attention" (Rush et al., 1988a, p. 409). 
EFNEP has previously evaluated its effectiveness by reporting changes in dietary behavior. Torisky et al. (1989) reported that by the end of the study on Virginia EFNEP participants, they scored $100 \%$ on meeting the basic four food group dietary guidelines. DelTredici et al. (1988) reported a significant improvement in dietary behavior which was attributed to increased intakes of milk, protein, and fruit/vegetable groups.

In this study there were only a few significant differences in nutrient intake before and after study participation. At the $\mathrm{p}=0.05$ level there were significant differences between preprogram and postprogram levels for calcium and protein in the EFNEP program. This study did not make dietary comparisons to food groupings, as in previous studies; yet differences between nutrient intakes would be similar to improvements in consuming the basic four food groups. The increase in nutrition knowledge scores indicates the nutrition education components of the Utah EFNEP program are effective. The increase in hematocrit levels indicates an improved iron status (indicative of health/nutritional status) for EFNEP participants.

The significant differences noted from the paired $t-$ test calculations for the control groups were 1) the WICcontrol children had a decrease in relative ferritin $(p=0.023) ;$ and 2$)$ the EFNEP-control women had a significant 
increase in dietary iron $(p=0.001)$. There was no increase for either control group in nutrition knowledge score, which may be due to their higher initial test scores, or to the lack of their participation in nutrition education sessions during this study period. The increase in dietary iron might have been influenced positively due to study involvement; yet, the children of the study participants (WIC-control participants) did not show a similar increase.

\section{Percentage of the study Population That \\ Did Not Meet $67 \%$ and $100 \%$ of the \\ RDA for Several Nutrients}

The frequency of study participants consuming less than $67 \%$ and less than $100 \%$ of the RDA for vitamin A, vitamin C, calcium, iron, and protein were tallied for each separate program in Tables $10,11,12,13$, and 14 . The frequency of dietary iron intake at less than $67 \%$ and $100 \%$ of the RDA for all participants was the highest of all nutrients ( $62 \%$ preprogram and $42 \%$ postprogram were below $67 \%$ of the RDA and $91 \%$ preprogram, and $80 \%$ postprogram were below $100 \%$ of the RDA). The frequency of dietary protein intake for the total population that was below $67 \%$ and $100 \%$ of the RDA was the lowest of all the nutrients studied (5\% preprogram and $4 \%$ postprogram were below $67 \%$ of the RDA, and $18 \%$ preprogram and $10 \%$ postprogram below $100 \%$ of the RDA). The mean intake of nutrients for this study 
Table 10. Percentage of WIC study participants who were below $67 \%$ and $100 \%$ of the 1989 RDA for several vitamins and minerals.

\begin{tabular}{|c|c|c|c|c|c|c|c|c|}
\hline Nutrient & $<67$ & $\% \mathrm{RDA}$ & $<1$ & $0 \%$ RDA & $\begin{array}{l}\text { mea } \\
\text { int }\end{array}$ & $\begin{array}{l}\text { in } \\
\text { ake }\end{array}$ & $\begin{array}{l}\text { mean } \\
\text { intake } \\
\% \text { RDA }\end{array}$ & $\begin{array}{l}\text { range } \\
\text { intake } \\
\% \text { RDA }\end{array}$ \\
\hline Vitamin A & & & & & & & & \\
\hline preprogram & 3 & (7) & 7 & (17) & 904 & R.E. & 226 & $30-999$ \\
\hline postprogram & 3 & (7) & 10 & $(24)$ & 960 & R.E. & 240 & $21-997$ \\
\hline Vitamin C & & & & & & & & \\
\hline preprogram & 16 & (38) & 21 & $(50)$ & 59 & $\mathrm{mg}$ & 147 & $20-587$ \\
\hline postprogram & 6 & $(14)$ & 15 & $(36)$ & 74 & $\mathrm{mg}$ & 184 & $36-601$ \\
\hline Calcium & & & & & & & & \\
\hline preprogram & 11 & $(24)$ & 21 & $(50)$ & 840 & $\mathrm{mg}$ & 105 & $24-218$ \\
\hline postprogram & 5 & $(12)$ & 10 & (24) & 976 & $\mathrm{mg}$ & 122 & $39-271$ \\
\hline Iron & & & & & & & & \\
\hline preprogram & 22 & $(57)$ & 36 & $(86)$ & 7.4 & $\mathrm{mg}$ & 74 & $22-217$ \\
\hline postprogram & 13 & (33) & 27 & (64) & 11.5 & $\mathrm{mg}$ & 115 & $30-806$ \\
\hline Protein & & & & & & & & \\
\hline preprogram & 1 & (2) & 2 & (5) & 44 & gm & 274 & $41-554$ \\
\hline postprogram & 1 & (2) & 1 & (2) & 55 & $g m$ & 343 & $61-713$ \\
\hline
\end{tabular}

Note: Numbers in parentheses ( ) are percentages

R.E. = Retinol Equivalent 
Table 11. Percentage of EFNEP study participants who were below $67 \%$ and $100 \%$ of the 1989 RDA for several vitamins and minerals.

\begin{tabular}{|c|c|c|c|c|c|c|c|c|}
\hline Nutrient & $<67$ & RDA & $<10$ & $0 \% \mathrm{RDA}$ & & ake & $\begin{array}{l}\text { mean } \\
\text { intake } \\
\% \mathrm{RDA}\end{array}$ & $\begin{array}{l}\text { range } \\
\text { intake } \\
\% \text { RDA }\end{array}$ \\
\hline Vitamin A & & & & & & & & \\
\hline preprogram & 5 & (19) & 9 & (35) & 2024 & R.E. & 253 & $23-648$ \\
\hline postprogram & 4 & (15) & 5 & (19) & 2240 & R.E. & 280 & $8-616$ \\
\hline Vitamin C & & & & & & & & \\
\hline preprogram & 8 & (31) & 8 & (31) & 121 & $\mathrm{mg}$ & 202 & $7-496$ \\
\hline postprogram & 3 & (12) & 3 & (12) & 147 & $\mathrm{mg}$ & 245 & $58-674$ \\
\hline Calcium & & & & & & & & \\
\hline preprogram & 7 & (27) & 13 & $(50)$ & 856 & $\mathrm{mg}$ & 107 & $27-276$ \\
\hline postprogram & 7 & (27) & 8 & (31) & 1136 & $\mathrm{mg}$ & 142 & $23-459$ \\
\hline Iron & & & & & & & & \\
\hline preprogram & 13 & (50) & 23 & (89) & 9.5 & $\mathrm{mg}$ & 63 & $16-107$ \\
\hline postprogram & 11 & $(42)$ & 22 & (85) & 11.6 & $\mathrm{mg}$ & 77 & $40-195$ \\
\hline Protein & & & & & & & & \\
\hline preprogram & 1 & (4) & 5 & (19) & 65 & gm & 131 & $33-231$ \\
\hline postprogram & 1 & (4) & 1 & (4) & 78 & $\mathrm{gm}$ & 156 & $60-260$ \\
\hline
\end{tabular}

Note: Numbers in parentheses ( ) are percentages

R.E. = Retinol Equivalent 
Table 12. Percentage of WIC-Control study participants who were below $67 \%$ and $100 \%$ of the 1989 RDA for several vitamins and minerals.

\begin{tabular}{|c|c|c|c|c|c|c|c|c|}
\hline Nutrient & $<67$ & $\%$ RDA & $<1$ & $0 \%$ RDA & $\begin{array}{l}\text { me } \\
\text { in }\end{array}$ & in & $\begin{array}{l}\text { mean } \\
\text { intake } \\
\% \text { RDA }\end{array}$ & $\begin{array}{l}\text { range } \\
\text { intake } \\
\% \text { RDA }\end{array}$ \\
\hline Vitamin A & & & & & & & & \\
\hline preprogram & 5 & (22) & 7 & $(30)$ & 752 & R.E. & 188 & $37-587$ \\
\hline postprogram & 7 & $(30)$ & 13 & $(57)$ & 540 & R.E. & 135 & $26-687$ \\
\hline Vitamin C & & & & & & & & \\
\hline preprogram & 10 & $(44)$ & 14 & (61) & 60 & $\mathrm{mg}$ & 151 & $10-683$ \\
\hline postprogram & 6 & (26) & 9 & (39) & 71 & $\mathrm{mg}$ & 177 & $10-727$ \\
\hline Calcium & & & & & & & & \\
\hline preprogram & 6 & (26) & 10 & $(44)$ & 848 & $\mathrm{mg}$ & 106 & $17-247$ \\
\hline postprogram & 8 & (35) & 12 & $(52)$ & 768 & $\mathrm{mg}$ & 96 & $28-183$ \\
\hline Iron & & & & & & & & \\
\hline preprogram & 17 & (74) & 22 & $(96)$ & 5.8 & mg & 58 & $31-105$ \\
\hline postprogram & 15 & (65) & 23 & $(100)$ & 6.0 & $\mathrm{mg}$ & 60 & $10-98$ \\
\hline Protein & & & & & & & & \\
\hline pre program & 3 & (13) & 7 & $(30)$ & 21 & gm & 132 & $42-401$ \\
\hline postprogram & 2 & (9) & 6 & (26) & 128 & $g m$ & 115 & $44-174$ \\
\hline
\end{tabular}

Note: Numbers in parentheses ( ) are percentages R.E. = Retinol Equivalent 
Table 13. Percentage of EFNEP-Control study participants who were below $67 \%$ and $100 \%$ of the 1989 RDA for several vitamins and minerals.

\begin{tabular}{|c|c|c|c|c|c|c|c|}
\hline Nutrient & $<67 \%$ RDA & $<1$ & $0 \% \mathrm{RDA}$ & & $\begin{array}{l}\text { an } \\
\text { cake }\end{array}$ & $\begin{array}{l}\text { mean } \\
\text { intake } \\
\% \text { RDA }\end{array}$ & $\begin{array}{l}\text { range } \\
\text { intake } \\
\% \text { RDA }\end{array}$ \\
\hline Vitamin A & & & & & & & \\
\hline preprogram & $5 \quad(22)$ & 6 & $(26)$ & 1560 & R.E. & 195 & $23-942$ \\
\hline postprogram & $3(13)$ & 7 & $(30)$ & 1624 & R.E. & 203 & $23-942$ \\
\hline Vitamin C & & & & & & & \\
\hline preprogram & $(30)$ & 13 & $(56)$ & 69 & $\mathrm{mg}$ & 115 & $9-280$ \\
\hline postprogram & $3(13)$ & 8 & (39) & 121 & $\mathrm{mg}$ & 201 & $40-618$ \\
\hline Calcium & & & & & & & \\
\hline preprogram & $6(26)$ & 12 & $(52)$ & 816 & $\mathrm{mg}$ & 102 & $37-231$ \\
\hline postprogram & $3(13)$ & 13 & $(57)$ & 848 & $\mathrm{mg}$ & 106 & $30-256$ \\
\hline Iron & & & & & & & \\
\hline preprogram & $15(65)$ & 23 & $(100)$ & 8.9 & $\mathrm{mg}$ & 59 & $19-98$ \\
\hline postprogram & $8(35)$ & 19 & (83) & 11.6 & $\mathrm{mg}$ & 77 & $38-131$ \\
\hline Protein & & & & & & & \\
\hline preprogram & 1 (4) & 1 & (4) & 129 & gm & 257 & $81-512$ \\
\hline postprogram & - & & - & 148 & $\mathrm{gm}$ & 296 & $148-590$ \\
\hline
\end{tabular}

Note: Numbers in parentheses ( ) are percentages R.E. = Retinol Equivalent 
Table 14. Percentage of the total study participants who were below $67 \%$ and $100 \%$ of the RDA for several vitamins and minerals.

\begin{tabular}{|c|c|c|c|c|c|c|c|c|}
\hline \multirow{2}{*}{$\begin{array}{l}\text { Nutrient } \\
\text { Vitamin A }\end{array}$} & \multicolumn{2}{|c|}{$<67 \%$ RDA } & \multicolumn{2}{|c|}{$<100 \%$ RDA } & \multicolumn{2}{|c|}{$\begin{array}{l}\text { mean } \\
\text { intake }\end{array}$} & \multirow[t]{2}{*}{$\begin{array}{l}\text { mean } \\
\text { intake } \\
\% \mathrm{RDA}\end{array}$} & \multirow[t]{2}{*}{$\begin{array}{l}\text { range } \\
\text { intake } \\
\% \mathrm{RDA}\end{array}$} \\
\hline & & & & & & & & \\
\hline preprogram & 18 & (16) & 28 & $(25)$ & 774 & R.E. & 129 & $23-999$ \\
\hline postprogram & 14 & $(12)$ & 39 & $(34)$ & 876 & R.E. & 146 & $8-997$ \\
\hline \multicolumn{9}{|l|}{ Vitamin C } \\
\hline preprogram & 38 & (33) & 56 & $(49)$ & 51 & $\mathrm{mg}$ & 101 & $7-683$ \\
\hline postprogram & 17 & (15) & 35 & $(31)$ & 77 & $\mathrm{mg}$ & 153 & $10-727$ \\
\hline \multicolumn{9}{|l|}{ Calcium } \\
\hline preprogram & 29 & (25) & 56 & $(49)$ & 768 & $\mathrm{mg}$ & 96 & $17-276$ \\
\hline postprogram & 22 & (19) & 43 & $(38)$ & 856 & $\mathrm{mg}$ & 107 & $23-459$ \\
\hline \multicolumn{9}{|l|}{ Iron } \\
\hline preprogram & 71 & (62) & 104 & (91) & 7.2 & $\mathrm{mg}$ & 58 & $16-217$ \\
\hline postprogram & 48 & $(42)$ & 91 & $(80)$ & 9.1 & $\mathrm{mg}$ & 73 & $10-806$ \\
\hline \multicolumn{9}{|l|}{ Protein } \\
\hline preprogram & 6 & (5) & 18 & $(16)$ & & gm & 195 & $33-554$ \\
\hline postprogram & 4 & (4) & 10 & (9) & 77 & gm & 232 & $44-713$ \\
\hline
\end{tabular}

Note: Numbers in parentheses ( ) are percentages R.E. = Retinol Equivalent 
population was compared to the Nationwide Food Consumption Survey - Continuing Survey of Food Intake by Individuals (CSFII) (USDA, 1985). The CSFII 1985 data were compared to the 1980 Recommended Dietary Allowances (RDAs), but were adjusted to the 1989 RDAs for comparison purposes for this study .

The WIC children in this study had higher dietary intakes of vitamin A and protein, lower dietary intakes of vitamin C, and similar dietary intakes of calcium and iron when compared to the children in the CSFII. The EFNEP women in this study had higher dietary intakes of vitamin A, vitamin C, and calcium, and similar dietary intakes of iron and protein when compared to the women in the CSFII. This comparison and the analysis of variance calculations to determine differences between programs in hematocrit, nutrition knowledge scores, years of education, family size, relative ferritin levels, and dietary nutrients are summarized in Table 15. There was no significant difference between programs for preprogram and postprogram nutrition knowledge scores when the covariates of "years of formal education" and "nutrition knowledge scores" were entered into an analysis of covariance.

When comparing the data of WIC participants to previous literature on dietary intake, there were differences for each nutrient, yet the trends for low dietary intakes are similar. Smith et al. (1986) reported 
Table 15. Analysis of variance calculated among the programs for several nutrients, hematocrit, and knowledge scores for participants not taking vitamin supplements.

\begin{tabular}{|c|c|c|c|c|c|c|}
\hline Variable & WIC & EFNEP & WIC-C & EFNEP-C & TOTAL & CSFII \\
\hline $\begin{array}{l}\text { years } \\
\text { education }\end{array}$ & $\begin{array}{l}12.02 a \\
\pm 1.58 \\
(7-16)\end{array}$ & $\begin{array}{l}12.0 \text { a } \\
\pm 1.57 \\
(6-13)\end{array}$ & $\begin{array}{l}13.8 \mathrm{~b} \\
\pm 1.51 \\
(12-16)\end{array}$ & $\begin{array}{l}13.8 b \\
\pm 1.51 \\
(12-16)\end{array}$ & $\begin{array}{l}12.73 \\
\pm 1.76 \\
(6-16)\end{array}$ & \\
\hline $\begin{array}{l}\text { family } \\
\text { size }\end{array}$ & $\begin{array}{l}3.95 b \\
\pm 1.03 \\
(2-6)\end{array}$ & $\begin{array}{l}5.0 \text { a } \\
\pm 1.44 \\
(3-8)\end{array}$ & $\begin{array}{l}3.96 b \\
\pm 1.02 \\
(2-5)\end{array}$ & $\begin{array}{l}3.96 b \\
\pm 1.02 \\
(2-5)\end{array}$ & $\begin{array}{l}4.19 \\
\pm 1.20 \\
(2-8)\end{array}$ & \\
\hline $\begin{array}{l}\text { pre nutr } \\
\text { know sc }\end{array}$ & $\begin{array}{l}14.2 \text { a } \\
\pm 3.27 \\
(8-20)\end{array}$ & $\begin{array}{l}14.2 \text { a } \\
\pm 3.77 \\
(4-21)\end{array}$ & $\begin{array}{l}16.7 \mathrm{~b} \\
\pm 1.97 \\
(13-20)\end{array}$ & $\begin{array}{l}16.7 \mathrm{~b} \\
\pm 1.97 \\
(13-20)\end{array}$ & $\begin{array}{l}15.5 \\
\pm 3.11 \\
(4-21)\end{array}$ & \\
\hline $\begin{array}{l}\text { post nutr } \\
\text { know sc }\end{array}$ & $\begin{array}{l}15.5 \text { a } \\
\pm 2.89 \\
(8-21)\end{array}$ & $\begin{array}{l}15.6 \\
\pm 2.79 \\
(10-21)\end{array}$ & $\begin{array}{l}16.9 \mathrm{~b} \\
\pm 2.42 \\
(12-21)\end{array}$ & $\begin{array}{l}16.9 \mathrm{~b} \\
\pm 2.42 \\
(12-21)\end{array}$ & $\begin{array}{l}15.5 \\
\pm 2.78 \\
(8-21)\end{array}$ & \\
\hline pre Hct & $\begin{array}{l}36.4 \\
\pm 2.17 \\
(32-42)\end{array}$ & $\begin{array}{l}38.5 \\
\pm 3.78 \\
(31-47)\end{array}$ & $\begin{array}{l}40.2 \\
\pm 2.31 \\
(34-45)\end{array}$ & $\begin{array}{l}37.1 \\
\pm 1.64 \\
(32-41)\end{array}$ & $\begin{array}{l}38.0 \\
\pm 3.66 \\
(31-47)\end{array}$ & \\
\hline post Hct & $\begin{array}{l}37.1 \\
\pm 2.34 \\
(32-43)\end{array}$ & $\begin{array}{l}40.7 \\
\pm 2.13 \\
(36-46)\end{array}$ & $\begin{array}{l}40.3 \\
\pm 2.49 \\
(37-46)\end{array}$ & $\begin{array}{l}37.0 \\
\pm 2.05 \\
(31-41)\end{array}$ & $\begin{array}{l}38.0 \\
\pm 3.11 \\
(31-46)\end{array}$ & \\
\hline $\begin{array}{l}\text { pre rel } \\
\text { ferritin }\end{array}$ & $\begin{array}{l}76.2 \text { a } \\
\pm 50 \\
(12-356)\end{array}$ & $\begin{array}{l}127.9 \\
\pm 138 \\
(13-540)\end{array}$ & $\begin{array}{l}208.5 \mathrm{~b} \\
\pm 236 \\
(22-795)\end{array}$ & $\begin{array}{l}84.3 \\
\pm 153 \\
(5-945)\end{array}$ & $\begin{array}{l}84 \\
(8-792)\end{array}$ & \\
\hline $\begin{array}{l}\text { post rel } \\
\text { ferritin }\end{array}$ & $\begin{array}{l}85.6 \\
\pm 49 \\
(20-289)\end{array}$ & $\begin{array}{l}113.7 \\
\pm 59 \\
(14-358)\end{array}$ & $\begin{array}{l}84.3 \\
\pm 81 \\
(5-945)\end{array}$ & $\begin{array}{l}124.2 \\
\pm 98 \\
(8-468)\end{array}$ & $\begin{array}{l}64 \\
(5-945)\end{array}$ & \\
\hline $\begin{array}{l}\text { pre vit } A \\
\text { \&RDA }\end{array}$ & $\begin{array}{l}219 \\
\pm 230 \\
(30-999)\end{array}$ & $\begin{array}{l}289 \\
\pm 215 \\
(23-648)\end{array}$ & $\begin{array}{l}201 \\
\pm 167 \\
(37-587)\end{array}$ & $\begin{array}{l}218 \\
\pm 241 \\
(23-942)\end{array}$ & $\begin{array}{l}218 \\
(23-999)\end{array}$ & ch-185 \\
\hline $\begin{array}{l}\text { post vit } A \\
\text { or RDA }\end{array}$ & $\begin{array}{l}260 \mathrm{~b} \\
\pm 256 \\
(21-997)\end{array}$ & $\begin{array}{l}257 \mathrm{~b} \\
\pm 193 \\
(8-616)\end{array}$ & $\begin{array}{l}145 \text { a } \\
\pm 144 \\
(26-687)\end{array}$ & $\begin{array}{l}200 \mathrm{~b} \\
\pm 151 \\
(23-942)\end{array}$ & $\begin{array}{l}220 \\
(8-997)\end{array}$ & $w-124$ \\
\hline $\begin{array}{l}\text { pre vit } \mathrm{C} \\
\text { orDA }\end{array}$ & $\begin{array}{l}160 \\
\pm 129 \\
(20-587)\end{array}$ & $\begin{array}{l}204 \\
\pm 146 \\
(7-496)\end{array}$ & $\begin{array}{l}153 \\
\pm 188 \\
(10-683)\end{array}$ & $\begin{array}{l}129 \\
\pm 86 \\
(9-280)\end{array}$ & $\begin{array}{l}154 \\
(7-683)\end{array}$ & ch-221 \\
\hline $\begin{array}{l}\text { post vit } C \\
\text { or RDA }\end{array}$ & $\begin{array}{l}200 \\
\pm 148 \\
(36-601)\end{array}$ & $\begin{array}{l}238 \\
\pm 125 \\
(58-674)\end{array}$ & $\begin{array}{l}155 \\
\pm 115 \\
(10-727)\end{array}$ & $\begin{array}{l}187 \\
\pm 142 \\
(40-618)\end{array}$ & $\begin{array}{l}200 \\
(10-727)\end{array}$ & $w-132$ \\
\hline $\begin{array}{l}\text { pre calc } \\
\text { of RAA }\end{array}$ & $\begin{array}{l}102 \\
\pm 44 \\
(24-218)\end{array}$ & $\begin{array}{l}102 \\
\pm 60 \\
(27-276)\end{array}$ & $\begin{array}{l}112 \\
\pm 51 \\
(17-247)\end{array}$ & $\begin{array}{l}105 \\
\pm 51 \\
(37-231)\end{array}$ & $\begin{array}{l}105 \\
(17-276)\end{array}$ & ch-109 \\
\hline
\end{tabular}


Table 15 continued

\begin{tabular}{|c|c|c|c|c|c|c|}
\hline Variable & WIC & EFNEP $W$ & C-C EFNEP & TOTA & CSFII & \\
\hline $\begin{array}{l}\text { post calc } \\
\text { orDA }\end{array}$ & $\begin{array}{l}124 \\
\pm 45 \\
(39-271)\end{array}$ & $\begin{array}{l}139 \\
\pm 104 \\
(23-459)\end{array}$ & $\begin{array}{l}101 \\
\pm 47 \\
(28-183)\end{array}$ & $\begin{array}{l}109 \\
\pm 60 \\
(30-256)\end{array}$ & $\begin{array}{l}118 \\
(23-459)\end{array}$ & $w-79$ \\
\hline $\begin{array}{l}\text { pre iron } \\
\text { orDA }\end{array}$ & $\begin{aligned} & 80 \\
& \pm 44 \\
&(22-217)\end{aligned}$ & $\begin{aligned} & 62 \\
& \pm 27 \\
&(16-107)\end{aligned}$ & $\begin{aligned} & 59 \\
& \pm 16 \\
&(31-105)\end{aligned}$ & $\begin{array}{l}62 \\
\pm 17 \\
(19-98)\end{array}$ & $\begin{array}{l}65 \\
(16-217)\end{array}$ & $c h-80$ \\
\hline $\begin{array}{l}\text { post iron } \\
\text { orDA }\end{array}$ & $\begin{array}{l}124 \text { a } \\
\pm 158 \\
(30-806)\end{array}$ & $\begin{array}{l}78 \mathrm{~b} \\
\pm 34 \\
(40-195)\end{array}$ & $\begin{array}{l}59 \mathrm{~b} \\
\pm 21 \\
(10-98)\end{array}$ & $\begin{array}{l}80 \mathrm{~b} \\
\pm 25 \\
(38-131)\end{array}$ & $\begin{array}{l}86 \\
(10-806)\end{array}$ & $w-78$ \\
\hline $\begin{array}{l}\text { pre prot } \\
\text { orDA }\end{array}$ & $\begin{array}{l}268 \\
\pm 116 \\
(41-554)\end{array}$ & $\begin{array}{l}123 \\
\pm 39 \\
(33-231)\end{array}$ & $\begin{array}{l}140 \\
\pm 73 \\
(42-401)\end{array}$ & $\begin{array}{l}272 \\
\pm 109 \\
(81-512)\end{array}$ & $\begin{array}{l}209 \\
(33-554)\end{array}$ & $\mathrm{ch}-240$ \\
\hline $\begin{array}{l}\text { post prot } \\
\text { orda }\end{array}$ & $\begin{array}{l}348 \\
\pm 115 \\
(61-713)\end{array}$ & $\begin{array}{l}151 \\
\pm 45 \\
(60-260)\end{array}$ & $\begin{array}{l}115 \\
\pm 34 \\
(44-174)\end{array}$ & $\begin{array}{l}296 \\
\pm 12 \\
(148-590)\end{array}$ & $\begin{array}{l}245 \\
(44-713)\end{array}$ & $w-139$ \\
\hline
\end{tabular}

Note: Numbers in parentheses ( ) are ranges. Numbers followed by an "a" differ significantly from those followed by a "b" for that variable. CSFII = Continuing Survey of Food Intake for Individuals - 1985, , Hct = hematocrit, vit $\mathrm{A}=$ vitamin $\mathrm{A}$, vit $\mathrm{C}=$ vitamin $\mathrm{C}$, calc $=$ calcium, prot $=$ protein, nutr $=$ nutrition, know = knowledge, $\mathbf{s c}=$ score, rel ferritin = relative ferritin, \&RDA = percent dietary intake of the recommended dietary allowance, $\mathrm{ch}=$ child value of CSFII, $w=$ woman value of CSFII.

$44 \%$ of the participants were consuming less vitamin $A, 23 \%$ with less vitamin C, $40 \%$ with less calcium, $44 \%$ with less iron, and $32 \%$ with less protein than the RDA. In this study, $24 \%$ of the WIC participants consumed less than $100 \%$ of the RDA for vitamin A at postprogram evaluation, $36 \%$ with less vitamin C, $24 \%$ with less calcium, $64 \%$ with less iron, and $2 \%$ with less protein than the RDA. These figures cause reason for concern, yet improvement from preprogram values are encouraging (Tables 10-15). 
Mean Values and the Frequencies of Hematocrit and Relative Ferritin

The mean value and the frequency were calculated for both hematocrit and relative ferritin levels. They are summarized in Tables 16 and 17 . The frequencies and means were separated by program for both preprogram values and postprogram values. Two WIC children (5\%) were below the $34 \%$ cut-off level for low hematocrit at their preprogram evaluation. One WIC child (2\%) was below the $34 \%$ cut-off value at the postprogram evaluation. Eight EFNEP women (31\%) were below the $37 \%$ cut-off value for hematocrit for women at the preprogram evaluation, and one (4\%) was below the $37 \%$ value at the postprogram evaluation. Six EFNEPcontrol women (26\%) had low hematocrit levels at preprogram evaluation, and eight ( $34 \%$ ) had low hematocrit levels at postprogram evaluation. Relative ferritin values of less than $20 \mu \mathrm{g} / 1$, representing low iron stores, were found in three (9\%) WIC children preprogram and in one $(3 \%)$ of the participants postprogram. Two (8\%) of the EFNEP women participants preprogram and one $(4 \%)$ of the participants postprogram had relative ferritin values of $<20 \mu \mathrm{g} / \mathrm{l}$. None of the WIC-control children preprogram and three (15\%) of the participants postprogram had relative ferritin values of $<20 \mu \mathrm{g} / 1$. Three (18\%) EFNEP-control women participants preprogram and four (21\%) participants postprogram had relative ferritin levels $<20 \mu \mathrm{g} / \mathrm{l}$. 
Table 16. Hematocrit values of study subjects, tallied by program.

\begin{tabular}{|c|c|c|c|c|c|c|c|c|c|c|}
\hline \multirow[t]{2}{*}{$H=t$} & \multicolumn{2}{|c|}{ WIC } & \multicolumn{2}{|c|}{ EFNEP } & \multicolumn{2}{|c|}{$W I C-C$} & \multicolumn{2}{|c|}{ EFNEP-C } & \multicolumn{2}{|c|}{ COMPOSITE } \\
\hline & pre & post & pre & post & pre & post & pre & post & pre & Dos: \\
\hline 31 & $\cdot$ & $\cdot$ & $1(4)$ & - & - & - & - & $1(4)$ & $1(1)$ & $1(:)$ \\
\hline 32 & $2(5)$ & $1(2)$ & $\cdot$ & - & - & - & $1(4)$ & - & $\Xi(3)$ & $1(1)$ \\
\hline 33 & & - & & $\cdot$ & - & - & $1(4)$ & & $1(1)$ & - \\
\hline 34 & $5(12)$ & $4(9)$ & $1(4)$ & - & $1(4)$ & - & - & $3(; 3)$ & $7(6)$ & $T(6)$ \\
\hline 35 & $7(17)$ & $6(14)$ & $4(15)$ & - & - & - & $2(9)$ & $3(13)$ & $13(11)$ & $9(8)$ \\
\hline 35 & $4(9)$ & $8(19)$ & $2(8)$ & $1(4)$ & - & - & $2(9)$ & $1(4)$ & $8(7)$ & $10(9)$ \\
\hline 37 & $9(21)$ & $6(14)$ & $2(8)$ & - & - & $2(9)$ & $7(30)$ & $2(9)$ & $18(16)$ & $10(9)$ \\
\hline 38 & $10(24)$ & $8(19)$ & $2(8)$ & $3(11)$ & $2(9)$ & $3(; 3)$ & $4(17)$ & $6(26)$ & $18(16)$ & $20(18)$ \\
\hline 39 & $1(2)$ & $2(5)$ & $4(15)$ & $3(11)$ & $5(22)$ & $5(22)$ & $4(17)$ & $4(17)$ & $14(12)$ & $14(12)$ \\
\hline 40 & $3(7)$ & $3(7)$ & $3(11)$ & $5(19)$ & $5(22 !$ & E(25) & $1(4)$ & $2(9)$ & $12(10)$ & $i 6 i:-1$ \\
\hline $4+$ & & $1(2)$ & $1(4)$ & $4(15)$ & $2(9)$ & $1(4)$ & $1(4)$ & $1(4)$ & $4(4)$ & $i(\hat{6})$ \\
\hline 42 & $1(2)$ & $2(5)$ & $1(4)$ & $6(23)$ & $4(17)$ & $2(9)$ & $\cdot$ & $\cdot$ & $5(5)$ & $10(9)$ \\
\hline 43 & - & $1(2)$ & $4(15)$ & $1(4)$ & $2(9)$ & $3(13)$ & $\cdot$ & - & $5(5)$ & $2(2)$ \\
\hline 41 & & - & - & $2(8)$ & $1(4)$ & . & - & - & $1(1)$ & $5(4)$ \\
\hline 45 & $\cdot$ & - & - & & $1(4)$ & - & - & $\cdot$ & $1(1)$ & $\cdot$ \\
\hline 6 & & $\cdot$ & - & $1(4)$ & - & $1(4)$ & - & - & $\cdot$ & $2 ! 2 !$ \\
\hline 7 & $\cdot$ & - & $1(4)$ & - & - & . & . & $\cdot$ & $1(1)$ & - \\
\hline $\begin{array}{l}\text { nean } \\
\text { id dev. } \\
\text { angye }\end{array}$ & $\begin{array}{l}36.4 \\
2.17 \\
32.42 \\
42\end{array}$ & $\begin{array}{l}37.1 \\
2.34 \\
32-43 \\
42\end{array}$ & $\begin{array}{l}38.5 a^{*} \\
3.78 \\
31-47 \\
26\end{array}$ & $\begin{array}{l}40.7 b^{\circ} \\
2.13 \\
36 \cdot 46 \\
26\end{array}$ & $\begin{array}{l}40.2 \\
2.31 \\
34-45 \\
23\end{array}$ & $\begin{array}{l}40.3 \\
2.49 \\
37.46 \\
23\end{array}$ & $\begin{array}{l}37.1 \\
1.64 \\
32.41 \\
23\end{array}$ & $\begin{array}{l}37.0 \\
2.05 \\
31.41 \\
23\end{array}$ & $\begin{array}{l}38.0 \\
3.66 \\
31.47 \\
114\end{array}$ & $\begin{array}{l}38.0 \\
3.11 \\
31.45 \\
1: 4\end{array}$ \\
\hline
\end{tabular}

Note: Numbers in parentheses () are percentages

The number followed by an "a" differs significantly from the number followed by a "b."

*significant at $\mathrm{p}=.001$ level

sta rev = standard deviatinn 
Table 17. Relative ferritin values of study subjects, tallied by program.

\begin{tabular}{|c|c|c|c|c|c|c|c|c|c|c|}
\hline \multirow{2}{*}{$\begin{array}{l}\text { Relative } \\
\text { Ferritin ug/l }\end{array}$} & \multicolumn{2}{|c|}{$W: C$} & \multicolumn{2}{|c|}{ EFNEP } & \multicolumn{2}{|c|}{ WIC-C } & \multicolumn{2}{|c|}{ EFNEP.C } & \multicolumn{2}{|c|}{ CSMFOSTE } \\
\hline & pre & post & pre & post & pre & post & pre & post & pre & Dost \\
\hline$<20$ & $3(9)$ & $1(3)$ & $2(8)$ & $1(4)$ & - & $3(15)$ & $3(; 8)$ & $4(2 i)$ & $8 i 9$ & $\$(10)$ \\
\hline $21 \cdot 50$ & $8(25)$ & $8(27)$ & $1(4)$ & $4(i 7)$ & $4(\vdots \equiv)$ & $7(3 E)$ & $3(; 8)$ & $4(21)$ & 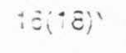 & $2 \xi i z \xi ;$ \\
\hline $51 \cdot 100$ & $9(29)$ & $1 E(E 0)$ & $11(\stackrel{-6)}{)}$ & $\subseteq(38)$ & 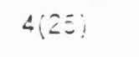 & $3(i \vdots)$ & $5(2 \leqq)$ & $5(25)$ & $2 S(32)$ & $\hat{s}\langle\hat{u})$ \\
\hline $101-150$ & $7(22)$ & $3(10)$ & $4(17)$ & $2(8)$ & $2(: 3)$ & $3(15)$ & $1(5)$ & $z(i 1)$ & $14(10)$ & $10(: 0)$ \\
\hline $151 \cdot 200$ & $3(\S)$ & $1(3)$ & $3(13)$ & $3(13)$ & $\cdot$ & - & $2(12)$ & $1(5)$ & $\delta(\Xi)$ & $5 i 5 ;$ \\
\hline $201-250$ & $\cdot$ & $1(3)$ & $1(4)$ & $3(13)$ & $1<5$ & $3(15)$ & $\cdot$ & $2(i i)$ & $3(3)$ & $\$: 0$ \\
\hline $251 \cdot 300$ & $\cdot$ & $1(3)$ & - & $1(4)$ & $1(\hat{z})$ & - & $1(5)$ & - & $1(1)$ & $2 \vdots 2 \vdots$ \\
\hline $301-350$ & $1(3)$ & $\cdot$ & - & $\cdot$ & $1 i \xi$ & - & : & $1(\equiv)$ & $2: 2)$ & $1(1)$ \\
\hline$>35.1$ & $1(3)$ & - & $2(8)$ & $1(-1)$ & $3: \vdots$ & $1(5)$ & $2\{; 2\}$ & $\cdot$ & $8(\Xi)$ & $2 ! 2 !$ \\
\hline $\begin{array}{l}\text { mean } \\
\text { sid } d \in v .\end{array}$ & $\begin{array}{l}76.2 \mathrm{a} \\
50\end{array}$ & $\begin{array}{l}85.4 \\
49\end{array}$ & $\begin{array}{l}127.9 \\
138\end{array}$ & $\begin{array}{l}113.7 \\
59\end{array}$ & $2 C \equiv . \bar{a} a^{\prime}$ & $8 \div .30^{\circ}$ & 124.2 & $10<.3$ & $8 \div 0$ & $0 \div 2$ \\
\hline sid deV. & so & $4 \cong$ & $13 \varepsilon$ & 59 & $3 \vdots$ & 81 & 154 & 98 & 125 & 117 \\
\hline range & $12 \cdot 353$ & $20 \cdot 2 \Xi \Xi$ & $13-520$ & $14-258$ & $22-722$ & $5-94 \vdots$ & 8.263 & $1 i-308$ & $8 \cdot 7 \leqq 2$ & $5-3 ム ミ$ \\
\hline 7 & 32 & 30 & 24 & 24 & $1 \vdots$ & 20 & 17 & 19 & 89 & 93 \\
\hline
\end{tabular}

Note: Numbers in parentheses () are percentages.

The number followed by an "a" differs significantly from the number followed by a "b."

*significant at $\mathrm{p}=.023$ level.

std dev = standard deviation

Yip et al. (1987b) reported a declining prevalence of anemia in childhood, which the data of this study reinforced. Although this may appear encouraging, the point discussed by stockmar (1987) was that only $25-30 \%$ of low income individuals take advantage of the WIC program; thus, the real prevalence of anemia is unknown and should be considered seriously. The possibility that those with greatest concern for the health of their children 
participate in WIC would indicate that the incidence of anemia in childhood is higher than the centers for Disease Control (CDC) suggest. Most anemia statistics gathered by the CDC on children are collected from the WIC program.

The percentage of women with hematocrits less than $37 \%$, the CDC cut-off value for anemia, was high (31\% for EFNEP women and $26 \%$ for EFNEP-control women at preprogram evaluation). The mean hematocrit levels for EFNEP participants increased by the end of the study, yet it fell slightly for the EFNEP-control women. This was in agreement with Kris-Etherton (1986) and Tilgner and Schiller (1990) who reported a high incidence of anemia in healthy athletic and nonathletic women. It is thought that the high incidence of low hematocrit levels is due to a decreased dietary iron intake, which may be compounded by the desire for thinness, or to a higher rate of hemolysis and gastrointestinal loss due to strenuous exercise.

\section{Correlation Analysis}

Correlations were calculated among the postprogram nutrition knowledge scores, dietary iron intake, and hematocrit levels to determine any causal relation in knowledge score to behavior and to health (Table 18). The only correlation above 0.23 was that of the postprogram dietary iron intake with postprogram hematocrit level in the EFNEP-control participants of 0.507 . 
Table 18. Correlations of nutrition knowledge scores, iron intake, and hematocrit, reported by program.

\begin{tabular}{|c|c|c|}
\hline Program & Variables & $p$ \\
\hline WIC & $\begin{array}{l}\text { 2nd knowledge score \& 2nd iron intake } \\
\text { 2nd knowledge score \& 2nd hematocrit } \\
\text { 2nd iron intake \& 2nd hematocrit }\end{array}$ & $\begin{array}{l}-0.189 \\
+0.087 \\
-0.151\end{array}$ \\
\hline EFNEP & $\begin{array}{l}\text { 2nd knowledge score \& 2nd iron intake } \\
\text { 2nd knowledge score \& 2nd hematocrit } \\
\text { 2nd iron intake \& 2nd hematocrit }\end{array}$ & $\begin{array}{l}+0.248 \\
+0.158 \\
-0.138\end{array}$ \\
\hline WIC Control & $\begin{array}{l}\text { 2nd knowledge score \& 2nd iron intake } \\
\text { 2nd knowledge score \& 2nd hematocrit } \\
\text { 2nd iron intake \& 2nd hematocrit }\end{array}$ & $\begin{array}{l}+0.129 \\
-0.226 \\
+0.073\end{array}$ \\
\hline EFNEP Control & $\begin{array}{l}\text { 2nd knowledge score \& 2nd iron intake } \\
\text { 2nd knowledge score \& 2nd hematocrit } \\
\text { 2nd iron intake \& 2nd hematocrit }\end{array}$ & $\begin{array}{l}+0.018 \\
-0.171 \\
+0.507\end{array}$ \\
\hline
\end{tabular}

* Significant at $p=0.05$ level. No other correlations
were significant.

Pearson correlations were calculated between several dependent and independent variables. Those close to or greater than 0.2 are recorded in Table 19. Correlations of "income" with "dietary iron intake," "income" with "dietary vitamin C intake," and "years of education" with "nutrition knowledge scores" appear repeatedly with different programs. This finding was not surprising, as high iron foods and high vitamin $\mathrm{C}$ foods are generally more expensive to purchase. Those with the highest level of education would be expected to score high on a test since they are experienced test takers.

Iron intake does not correlate to hematocrit level in a straight line relationship because iron absorption 
Table 19. Correlations of independent variables.

\begin{tabular}{llc}
\hline Program & Variables & p \\
\hline WIC & $\begin{array}{l}\text { income \& 2nd iron intake } \\
\text { income \& 1st vitamin C intake }\end{array}$ & $+0.7155^{*}$ \\
& family size \& 1st vitamin C intake & $+0.4655 *$ \\
& family size \& 2nd knowledge score & $+0.3575 *$ \\
& individual income \& 2nd iron intake & $+0.3499^{*}$ \\
& individual income \& 1st vit. C intake & $+0.7390 *$ \\
& years education \& 2nd knowledge score & $+0.5006 * *$ \\
EFNEP & family size and 2nd knowledge score & $+0.4442 *$ \\
& years ed. \& 2nd relative ferritin & $+0.4379 *$ \\
WIC Control & years education \& 1st relative ferritin & $+0.5367 *$ \\
EFNEP Control & income \& 1st vitamin C intake & $+0.5107 *$ \\
& individual income \& 1st vit C intake & $-0.6091 * *$
\end{tabular}

Pearson correlations were used.

* Significant at $p=0.05$ level

** Significant at $\mathrm{p}=0.01$ level

decreases as iron stores increase (Green et al., 1968).

The cut-off value for a low hematocrit as outlined by CDC is less than or equal to 37 for adults and 34 for children. Correlations between iron intake and hematocrit level were conducted for only those participants with a hematocrit of 37 or less (there were too few with less than a 34 hematocrit for children), and they are reported in Table 20. Only preprogram hematocrit levels and dietary iron intake showed a significant correlation in the WIC group. Preprogram hematocrit and protein intake were significant in the WIC and EFNEP-control groups. The same correlations were conducted for participants not taking vitamin or mineral supplements, and results are reported in Table 21 . Again, the WIC program had a significant correlation between preprogram hematocrit level and dietary iron 
intake. The WIC and EFNEP control groups had significant preprogram hematocrit and dietary protein intake.

Table 20. Correlations for study participants with a hematocrit of 37 or less.

\begin{tabular}{|c|c|c|c|c|}
\hline Program & $\mathrm{N}$ & Variables & $\mathrm{R}^{2}$ & $p$ \\
\hline WIC & 27 & $\begin{array}{l}\text { pre Hct \& pre protein } \\
\text { pre Hct \& pre iron }\end{array}$ & $\begin{array}{l}0.376 \\
0.314\end{array}$ & $\begin{array}{l}0.027 * \\
0.050 *\end{array}$ \\
\hline EFNEP-C & 9 & $\begin{array}{l}\text { pre Hct \& pre protein } \\
\text { pre Hct \& pre iron }\end{array}$ & $\begin{array}{l}0.719 \\
0.749\end{array}$ & $\begin{array}{l}0.014 * \\
0.010 * *\end{array}$ \\
\hline Composite & 46 & $\begin{array}{l}\text { pre iron \& pre vitamin C } \\
\text { pre vitamin A \& pre vitamin C }\end{array}$ & $\begin{array}{l}0.329 \\
0.261\end{array}$ & $\begin{array}{l}0.013 * \\
0.040 *\end{array}$ \\
\hline
\end{tabular}

Note: protein, iron, vitamin A \& vitamin C are dietary intakes of these nutrients, Hct $=$ hematocrit, pre $=$ preprogram, $*=$ significant at $\mathrm{p}=0.05, \star \star=$ significant at $\mathrm{p}=0.01$, EFNEP-C = EFNEP-control group.

Table 21. Correlations for study participants not taking vitamin supplements and with a hematocrit of 37 or less.

\begin{tabular}{lllll}
\hline Program & N & Variables & $\mathrm{R}^{2}$ & $\mathrm{P}$ \\
\hline WIC & 21 & $\begin{array}{l}\text { pre Hct \& pre protein } \\
\text { pre Hct \& pre iron } \\
\text { post iron \& post protein } \\
\text { post vit A \& post vit C }\end{array}$ & 0.540 & $0.006^{*}$ \\
& & 0.396 & $0.044^{*}$ \\
EFNEP-C & 7 & pre Hct \& pre protein & 0.505 & $0.012^{*}$
\end{tabular}

Note: $\operatorname{vit} \mathrm{A}=$ vitamin $\mathrm{A}$, vit $\mathrm{C}=$ vitamin $\mathrm{C}$. Protein, iron, $\mathrm{vit} \mathrm{A}$, vit $C$ are dietary intakes of these nutrients. Hct = hematocrit, pre $=$ preprogram, post $=$ postprogram, $*=$ significant at $\mathrm{p}=$ $0.05, \star \star=$ significant at $\mathrm{p}=0.01$, EFNEP-C = EFNEP-Control group. 
Grouped T-Tests for Hematocrit, Nutrition Knowledge Scores and Five Nutrients when separated by the Discrete Variables of "Taking Nutrition Classes" and "Participating in Food Programs"

Grouped t-tests were calculated to determine if taking nutrition classes in high school or college, or if participation in other supplemental food programs had an effect on hematocrit level, relative ferritin level, nutrition knowledge score, or dietary intake of various nutrients. Table 22 lists the variables that show a significant difference between those who had participated in nutrition classes or in food programs and those who had not participated. Hematocrit, nutrition knowledge scores, vitamin A intake, and relative ferritin values were the variables that showed a significant difference between those that did and those that did not participate in nutrition classes or food programs. The results indicate that nutrition classes in college do have a positive effect on iron status and nutrition knowledge. Participating in federal food programs was associated with lower mean nutrition knowledge scores and lower relative ferritin levels. Participation in high school nutrition classes was associated with lower hematocrit levels and lower vitamin A intakes. This negative finding is a concern, and the different results between high school and college nutrition classes could be attributed to the level of difficulty 
between the two curricula. Based on these data findings, participation in nutrition classes in college or high school or even earlier should be encouraged.

\section{Regression Analysis}

Regression analyses were conducted to determine effective predictor variables for the dependent variables of hematocrit, relative ferritin levels, nutrition knowledge scores, and several nutrient components. Table 23 lists the significant predictor variables, as separated by program. Income level and participation in nutrition classes in high school or college were the best predictors for dietary intake of several nutrients, while years of education, participation in nutrition classes in college, and preprogram nutrition knowledge score were the best predictors for the nutrition knowledge score. The best predictor for the postprogram hematocrit level was preprogram hematocrit level (except for the WIC participants, for whom the best predictor was participation in nutrition classes in high school). Table 24 is part of Table 23 reformatted to emphasize the effect income and nutrition classes in high school or college had on nutrient intake and nutrition knowledge scores. These data would suggest improved dietary intake and improved health are associated with participating in nutrition classes in college and high school. 
Table 22. Grouped t-tests for hematocrit levels, nutrition knowledge scores and several nutrients when separated by the discrete variables "taking nutrition classes in high school," "taking nutrition classes in college," and "participating in other food programs."

\begin{tabular}{|c|c|c|c|c|c|c|}
\hline $\begin{array}{l}\text { Discr } \\
\text { Varia }\end{array}$ & $\begin{array}{l}\text { cete } \\
\text { able }\end{array}$ & Program & $\begin{array}{l}\text { Dependent } \\
\text { Variable }\end{array}$ & Mean & T-value & $\mathrm{p}$ \\
\hline $\begin{array}{l}\text { Nutr. } \\
\text { No } \\
\text { Yes }\end{array}$ & $\begin{array}{l}\text { H.S. } \\
(\mathrm{n}=31) \\
(\mathrm{n}=11)\end{array}$ & WIC & $\begin{array}{l}\text { pre Hct } \\
\text { pre Hct }\end{array}$ & $\begin{array}{l}36.98 \\
34.98\end{array}$ & 3.35 & 0.0003 \\
\hline $\begin{array}{c}\text { Nutr. } \\
\text { No } \\
\text { Yes }\end{array}$ & $\begin{array}{l}\text { H.S. } \\
\quad(n=21) \\
(n=5)\end{array}$ & EFNEP & $\begin{array}{l}\text { post Vit } A \\
\text { post vit } A\end{array}$ & $\begin{array}{rl}324 \% & R D A \\
91 \% & R D A\end{array}$ & 4.6 & 0.000 \\
\hline $\begin{array}{l}\text { Nutr. } \\
\quad \text { No } \\
\text { Yes }\end{array}$ & $\begin{array}{c}\text { College } \\
(n=37) \\
(n=5)\end{array}$ & WIC & $\begin{array}{l}\text { pre Hct } \\
\text { pre Hct }\end{array}$ & $\begin{array}{l}36.18 \\
38.68\end{array}$ & -2.39 & 0.064 \\
\hline $\begin{array}{l}\text { Nutr. } \\
\text { No } \\
\text { Yes }\end{array}$ & $\begin{array}{l}\text { College } \\
(\mathrm{n}=12) \\
(\mathrm{n}=11)\end{array}$ & WIC-C & $\begin{array}{l}\text { pre know score } \\
\text { pre know score }\end{array}$ & $\begin{array}{l}15.83 \\
17.55\end{array}$ & -2.23 & 0.041 \\
\hline $\begin{array}{l}\text { Nutr. } \\
\text { No } \\
\text { Yes }\end{array}$ & $\begin{array}{l}\text { College } \\
(\mathrm{n}=12) \\
(\mathrm{n}=11)\end{array}$ & EFNEP-C & $\begin{array}{l}\text { pre know score } \\
\text { pre know score }\end{array}$ & $\begin{array}{l}15.83 \\
17.55\end{array}$ & 2.23 & 0.041 \\
\hline $\begin{array}{l}\text { Food } \\
\text { No } \\
\text { Yes }\end{array}$ & $\begin{array}{l}\text { Program } \\
\qquad \begin{array}{l}(n=35) \\
(n=7) \mathrm{F}\end{array}\end{array}$ & WIC & $\begin{array}{l}\text { pre know score } \\
\text { pre know score }\end{array}$ & $\begin{array}{l}14.90 \\
10.75\end{array}$ & 3.2 & 0.021 \\
\hline $\begin{array}{l}\text { Food } \\
\text { No } \\
\text { Yes }\end{array}$ & $\begin{array}{l}\text { Program } \\
\qquad \begin{array}{c}n=35) \\
(n=7)\end{array}\end{array}$ & WIC & $\begin{array}{l}\text { post know score } \\
\text { post know score }\end{array}$ & $\begin{array}{l}15.49 \\
12.57\end{array}$ & 3.48 & 0.004 \\
\hline $\begin{array}{l}\text { Food } \\
\text { No } \\
\text { Yes }\end{array}$ & $\begin{array}{l}\text { Program } \\
\quad(n=22) \\
(n=4)\end{array}$ & EFNEP & $\begin{array}{l}\text { post rel fer } \\
\text { post rel fer }\end{array}$ & $\begin{array}{r}123 \mathrm{ug} / \mathrm{l} \\
67 \mathrm{ug} / \mathrm{l}\end{array}$ & 2.63 & 0.015 \\
\hline ote: & $\begin{array}{l}\text { nutr. H. } \\
\text { nutritio } \\
\text { food pro } \\
\text { relative } \\
\text { EFNEP-C }\end{array}$ & in colle & $\begin{array}{l}\text { on classes in } \\
\text { food program } \\
\text { score = total } \\
\text { lct = hematocrit }\end{array}$ & $\begin{array}{l}\text { gh schoo } \\
\text { partici } \\
\text { owledge } \\
\text { WIC-C = }\end{array}$ & $\begin{array}{l}\text { l, nutr. } \\
\text { pating i } \\
\text { score, r } \\
\text { WIC con }\end{array}$ & $\begin{array}{l}\text { college= } \\
\text { federal } \\
\text { l fer = } \\
\text { rol, }\end{array}$ \\
\hline
\end{tabular}


Table 23. Regression analysis calculations showing significance.

\begin{tabular}{|c|c|c|c|c|}
\hline Program & Dep Variable I & Ind Variable & $\mathrm{R}^{2}$ & $\mathrm{p}$ \\
\hline WIC & post know sc & $\begin{array}{l}\text { pre know sc } \\
\text { +pre Hct }\end{array}$ & $\begin{array}{l}0.67 \\
0.76\end{array}$ & $\begin{array}{l}0.0000 \\
0.0000\end{array}$ \\
\hline WIC & post rel fer. & $\begin{array}{l}\text { family size } \\
\text { +nutr H.S. }\end{array}$ & $\begin{array}{l}0.45 \\
0.65\end{array}$ & $\begin{array}{l}0.0120 \\
0.0052\end{array}$ \\
\hline WIC & post iron & ind income & 0.55 & 0.0000 \\
\hline WIC & post vit C & family size & 0.13 & 0.0201 \\
\hline WIC & pre vit C & ind income & 0.25 & 0.0000 \\
\hline WIC & pre prot & $\begin{array}{l}\text { nutr H.S. } \\
\text { +food prog } \\
\text { +vit supp }\end{array}$ & $\begin{array}{l}0.24 \\
0.43 \\
0.54\end{array}$ & $\begin{array}{l}0.0154 \\
0.0029 \\
0.0011\end{array}$ \\
\hline WIC & pre iron & family size & 0.22 & 0.0193 \\
\hline WIC & pre vit $A$ & years ed & 0.19 & 0.0342 \\
\hline WIC & pre Hct & $\begin{array}{l}\text { nutr H.S. } \\
\text { +nutr coll }\end{array}$ & $\begin{array}{l}0.43 \\
0.57\end{array}$ & $\begin{array}{l}0.0005 \\
0.0002\end{array}$ \\
\hline EFNEP & post know sc & pre know sc & 0.27 & 0.0068 \\
\hline EFNEP & post vit $C$ & ind income & 0.21 & 0.0196 \\
\hline EFNEP & post vit $A$ & $\begin{array}{l}\text { nutr H.S. } \\
\text { +nutr coll }\end{array}$ & $\begin{array}{l}0.21 \\
0.37\end{array}$ & $\begin{array}{l}0.0171 \\
0.0048\end{array}$ \\
\hline EFNEP & post calc & pre calc & 0.31 & 0.0031 \\
\hline EFNEP & post HCt & pre Hct & 0.33 & 0.0020 \\
\hline EFNEP & post rel fer & post know sc & 0.27 & 0.0108 \\
\hline EFNEP & pre prot & vit supp & 0.15 & 0.0448 \\
\hline EFNEP & pre know sc & years ed & 0.20 & 0.0230 \\
\hline WIC-C & post know sc & pre know sc & 0.35 & 0.0029 \\
\hline WIC-C & post prot & nutr H.S. & 0.24 & 0.0170 \\
\hline WIC-C & post calc & $\begin{array}{l}\text { nutr H.S. } \\
\text { +pre calc }\end{array}$ & $\begin{array}{l}0.31 \\
0.55\end{array}$ & $\begin{array}{l}0.0059 \\
0.0004\end{array}$ \\
\hline WIC-C & post Hct & pre Hct & 0.37 & 0.0019 \\
\hline WIC-C & post rel fer & nutr H.S. & 0.37 & 0.0044 \\
\hline WIC-C & pre vit $A$ & $\begin{array}{l}\text { nutr coll } \\
+ \text { vit supp }\end{array}$ & $\begin{array}{l}0.21 \\
0.38\end{array}$ & $\begin{array}{l}0.0281 \\
0.0089\end{array}$ \\
\hline
\end{tabular}


Table 23 continued

\begin{tabular}{|c|c|c|c|c|}
\hline Program & Dep Variable & Ind Variable & $\mathrm{R}^{2}$ & $\mathrm{p}$ \\
\hline WIC-C & pre know sc & nutr coll & 0.197 & 0.0337 \\
\hline WIC-C & pre rel fer & years ed & 0.29 & 0.0321 \\
\hline EFNEP-C & post know sc & pre know sc & 0.35 & 0.0029 \\
\hline EFNEP-C & post prot & $\begin{array}{l}\text { nutr H.S. } \\
\text { +pre prot }\end{array}$ & $\begin{array}{l}0.63 \\
0.72\end{array}$ & $\begin{array}{l}0.0000 \\
0.0000\end{array}$ \\
\hline EFNEP-C & post iron & nutr H.S. & 0.23 & 0.0233 \\
\hline EFNEP-C & post calc & nutr H.S. & 0.77 & 0.0000 \\
\hline EFNEP-C & post Hct & $\begin{array}{l}\text { vit supp } \\
\text { +pre Hct }\end{array}$ & $\begin{array}{l}0.25 \\
0.51\end{array}$ & $\begin{array}{l}0.0179 \\
0.0012\end{array}$ \\
\hline EFNEP-C & pre vit C & ind income & 0.37 & 0.0020 \\
\hline EFNEP-C & pre know sc & nutr coll & 0.21 & 0.0303 \\
\hline COMPOSITE & post prot & EFNEP part & 0.11 & 0.0003 \\
\hline COMPOSITE & post iron & ind income & 0.48 & 0.0000 \\
\hline COMPOSITE & post know sc & $\begin{array}{l}\text { year ed } \\
\text { + nutr coll } \\
\text { +family size }\end{array}$ & $\begin{array}{l}0.15 \\
0.20 \\
0.23\end{array}$ & $\begin{array}{l}0.0000 \\
0.0000 \\
0.0000\end{array}$ \\
\hline COMPOSITE & post Hct & $\begin{array}{l}\text { EFNEP part } \\
\text { +nutr coll }\end{array}$ & $\begin{array}{l}0.19 \\
0.28\end{array}$ & $\begin{array}{l}0.0000 \\
0.0000\end{array}$ \\
\hline COMPOSITE & pre prot & EFNEP part & 0.13 & 0.0001 \\
\hline COMPOSITE & pre know sc & $\begin{array}{l}\text { nutr coll } \\
\text { +years ed }\end{array}$ & $\begin{array}{l}0.17 \\
0.23\end{array}$ & $\begin{array}{l}0.0000 \\
0.0000\end{array}$ \\
\hline \multicolumn{5}{|c|}{$\begin{array}{l}\text { Note: } \\
\text { intake, calc = calcium intake, vit A = vitamin A intake, } \\
\text { vit C = vitamin C intake, iron = iron intake, rel fer = } \\
\text { relative ferritin, Hct = hematocrit, vit supp = vitamin } \\
\text { supplementation, ind income = individual income, years } \\
\text { ed = years of education, nutr H.S. = nutrition classes in } \\
\text { high school, nutr coll = nutrition classes in college, } \\
\text { food prog = food program participation. }\end{array}$} \\
\hline
\end{tabular}


Table 24. Regression analysis outlined with income level and nutrition classes as predictor variables.

\begin{tabular}{|c|c|c|c|c|}
\hline $\begin{array}{l}\text { Predictor } \\
\text { Variable }\end{array}$ & Program & Dep Variable & $\mathrm{R}^{2}$ & $\mathrm{p}$ \\
\hline \multirow{2}{*}{$\begin{array}{l}\text { Individual } \\
\text { Income } \\
\text { " }\end{array}$} & WIC & post iron & 0.55 & 0.0000 \\
\hline & WIC & pre vit C & 0.25 & 0.0000 \\
\hline$"$ & EFNEP & post vit C & 0.21 & 0.0196 \\
\hline$"$ & EFNEP-C & pre vit C & 0.37 & 0.0020 \\
\hline$"$ & Composite & post iron & 0.48 & 0.0000 \\
\hline \multirow{2}{*}{$\begin{array}{l}\text { Nutrition } \\
\text { High School }\end{array}$} & WIC & pre prot & 0.24 & 0.0154 \\
\hline & WIC & pre Hct & 0.43 & 0.0005 \\
\hline$"$ & EFNEP & pre vit $A$ & 0.21 & 0.0171 \\
\hline$"$ & WIC-C & post prot & 0.24 & 0.0170 \\
\hline$"$ & WIC-C & post calc & 0.31 & 0.0054 \\
\hline$"$ & WIC-C & post Rel Fer & 0.37 & 0.0044 \\
\hline$"$ & EFNEP-C & post prot & 0.63 & 0.0000 \\
\hline$"$ & EFNEP-C & post iron & 0.23 & 0.0233 \\
\hline " & EFNEP-C & post calc & 0.77 & 0.0000 \\
\hline \multirow{2}{*}{$\begin{array}{l}\text { Nutrition } \\
\text { College } \\
\text { " }\end{array}$} & WIC-C & pre vit $A$ & 0.21 & 0.0281 \\
\hline & WIC-C & pre know sc & 0.197 & 0.0337 \\
\hline$"$ & EFNEP-C & pre know sc & 0.21 & 0.0303 \\
\hline$"$ & Composite & pre know sc & 0.17 & 0.0000 \\
\hline $\begin{array}{l}\text { vit } \\
\text { know }\end{array}$ & $\begin{array}{l}-\mathrm{C}=\text { EFNEP } \\
\mathrm{calc}=\mathrm{C} \\
=\mathrm{vitamin}\end{array}$ & $\begin{array}{l}\text { ntrol group, } \\
\text { ium intake, } \\
\text { intake, vit } \\
\text { n knowledge }\end{array}$ & $\begin{array}{l}\text { C }=h \\
=\text { pro } \\
\text { itami } \\
\text {. }\end{array}$ & $\begin{array}{l}\text { ontrol } \\
\text { intake, } \\
\text { intake, }\end{array}$ \\
\hline
\end{tabular}


Since the relationship between iron intake and hematocrit level is not a straight line relationship as discussed previously (Green et al., 1968), study participants with a hematocrit of 37 or less were selected for a regression analysis. With hematocrit level as the dependent variable the only significant predictor variables were dietary iron intake in the EFNEP-control group $\left(R^{2}=\right.$ 0.561 ) and dietary protein intake for the entire study group $\left(R^{2}=0.1387\right.$ and $\left.p=0.0276\right)$. 
CHAPTER V

CONCLUSIONS AND RECOMMENDATIONS

Nutrition Knowledge

Nutrition knowledge test scores for the Women, Infants, and Children Supplemental Food Program (WIC) participants increased significantly from preprogram to postprogram (14.2 \pm 3.27 to $15.5 \pm 2.89)$ when analyzed by paired t-tests. The Expanded Food and Nutrition Education Program (EFNEP) participants also showed a significant improvement in nutrition knowledge test score from preprogram to postprogram $(14.2 \pm 3.77$ to $15.6 \pm 2.79)$ when analyzed by paired t-tests. The control participants did not have an increase in nutrition knowledge score in paired t-test analysis; yet, their preprogram scores were significantly higher than the WIC and EFNEP preprogram scores, a probable result of their higher level of formal education. This was recognized as a limitation of the study and an analysis of covariance with level of formal education and knowledge test scores as covariables revealed there was no difference among the WIC, EFNEP, and control participants for preprogram knowledge scores.

The results of this study can be interpreted favorably for both the WIC and EFNEP programs. The participants in this study were less isolated, more sophisticated, better educated, more discriminating, and more self-motivated than 
earlier EFNEP participants, but they were similar to the EFNEP participants reported by Chipman and Kendall (1989). They would be expected to score higher on a posttest evaluation. This did not occur in this study's control participants (those not receiving nutrition education). The nutrition education programs for both the EFNEP and WIC participants were effective in increasing the participants' knowledge about practical nutrient information that is essential to optimal health.

\section{Hematocrit Levels}

The hematocrit levels for the EFNEP participants showed a significant increase from preprogram (38.5 \pm 3.78 ) to postprogram $(40.7 \pm 2.13)$ when analyzed by paired $t-$ tests. The mean preprogram value of $38.5 \pm 3.78$ was above the cut-off value for low hematocrit (termed "low normal"), and an increase within an already normal range is impressive. An analysis of variance was conducted on the difference scores of hematocrit level from preprogram to postprogram. There was a significant difference in hematocrit level for EFNEP participants from the WIC and control participants $(F=0.0018)$.

The change in hematocrit values for WIC participants was not significant (mean of $36.4 \pm 2.17$ at preprogram to $37.1 \pm 2.34$ at postprogram) when analyzed by paired $t-$ tests. The hematocrit values for the control groups 
remained unchanged.

Participation in the EFNEP program appeared to improve iron status by increasing mean hematocrit levels from a "low normal" level to a "normal" level. These findings should be considered when allocating money for nutrition education programs. The EFNEP program (the program with more emphasis on nutrition education accompanied by handson training) appears to be superior in increasing iron status over the WIC program (the program with emphasis on nutrition education and food supplements). The difficult task of defining motivation for program participation needs to be considered and studied. WIC participants often, on informal questioning, reported the food supplements as the incentive to participate in the program. The EFNEP participants, however, stated an interest in selfimprovement and better health. Enrollment of participants in both programs simultaneously could prove synergistic in improving nutrition knowledge levels and iron status in program participants.

\section{Dietary Nutrients}

The mean intake of vitamin $A$, vitamin $C$, calcium, and protein were above the RDA at preprogram evaluation and postprogram evaluation (Table 8); yet, the percentage of individual participants who consumed less than $67 \%$ of the RDA (Table 14) was high, similar to the Continuing Survey 
of Food Intake by Individuals 1985 study data (16\% for vitamin A, 33\% for vitamin C, 25\% for calcium, and $5 \%$ for protein at preprogram evaluation; $12 \%$ for vitamin A, $15 \%$ for vitamin C, $19 \%$ for calcium, and $4 \%$ for protein at postprogram evaluation). The mean value of all nutrients reported in Table 8 may represent a false "high" since a few individuals consumed as high as $999 \%$ of the RDA.

Iron intake was a concern when examining mean values of dietary iron for each program (58 - 74\% of the RDA), as shown in Table 8 , or when observing that $62 \%$ of the participants consumed less than $67 \%$ of the RDA (Table 14). There was a significant increase in dietary protein in the WIC program, for calcium and protein in the EFNEP program, and for iron in the EFNEP-control group between preprogram and postprogram evaluation when analyzed by paired t-tests. The proportion of WIC and EFNEP participants that consumed less than $67 \%$ of the RDA of a nutrient (any of the five) decreased from preprogram evaluation to postprogram evaluation. It was impressive that those at highest risk for nutrient deficiencies improved their dietary intake after participation in these programs. Control participants at highest risk for nutrient deficiencies $(<67 \% \mathrm{RDA})$ did not show the same trends for dietary improvement. 
Effect of Nutrition Education Sessions in High School or College and Income Level on Dietary Intake and Nutrition Knowledge Scores

Grouped t-tests were conducted between study participants who took nutrition classes in high school and those who did not, between study participants who took nutrition classes in college and those who did not, and between study participants who enrolled in other food programs (e.g., food stamps) and those who did not. The results reported in Table 22 indicate participating in nutrition education in college had a positive effect on iron status and nutrition knowledge scores. Participating in nutrition classes in high school and in other food programs had a negative effect on hematocrit, nutrition knowledge scores, and vitamin A intake. The differences between the nutrition curriculum in college and high school could account for the frequency of exposure and detail of information. The Utah state Board of Education does not have a nutrition curriculum for secondary schools. In contrast, the nutrition courses taught in Utah at the college level are curriculum outlined in detail for 10-15 weeks. These data show that more emphasis on nutrition curriculum in high school or earlier could provide important benefits. 
Limitations

1) The control group in this study had a higher education level, which may have altered nutrition knowledge test scores. Yet, when using years of formal education as a covariate with nutrition knowledge test scores, there was no significant difference among the groups.

2) Dietary intake values were calculated on a 24-hour dietary recall, checked against a food frequency. This limits the validity of individual analysis, but is accepted for groups of people.

3) The income level of this study population was higher than income level of WIC and EFNEP participants reported in previous studies.

Recommendations

1) This study should be conducted on a larger sample size (having the clinics' personnel collect the data to help decrease the problems of the high dropout rates).

2) The study should be conducted with accurate ferritin values (obtain permission from local clinics for a larger blood sample).

3) The data of this study could be expanded by including information on the amount of iron enhancers and iron inhibitors in the diets.

4) This study should be conducted on high school students versus college students who have standardized 
nutrition curricula.

5) This study should be conducted when different methods of education are used (monitor the class topics, method of instruction, and follow-up procedures). 


\section{REFERENCES}

Bezwoda WR, Bothwell TH, Charlton RW, Torrance JD, MacPhail AP, Derman DP, Mayet F. The relative dietary importance of haem and non-haem iron. SA Med. J. 1983; $64: 552-56$.

Blot IE, Papiernik E, Kaltwasser J, Werner E, Tchernia G. Influence of routine administration of folic acid and iron during pregnancy. Gyn \& Obstet Invest. 1981; 12(6):294304 .

Bull BS, Rittenbach JD. A proposed reference haematocrit derived from multiple MCHC determinations via hemoglobin measurements. Clin Lab Haemat. 1990; 12(1):43-53.

Cangelosi JS. Designing Tests for Evaluating Student Achievement. New York, NY: Longman; 1989; 23-37.

Cangelosi JS. Measurement and Evaluation: An Inductive Approach for Teachers. Dubryne, IA: W.C. Brown Pub.; 1982 .

Carmines EG, Zeller RA. Reliability and Validity Assessment. 9th Ed. Beverly Hills, CA:: Sage Pub.; 1987.

Carriaga MT, Skikne BS, Finley B, Cutler B, Cook JD. Serum transferrin receptor for the detection of iron deficiency in pregnancy. Am J Clin Nutr. 1991; 54:107781 .

Centers for Disease Control. Criteria for anemia in children and childbearing-aged women. MMWR 38:401-404, 1989.

Chipman J, Kendall PA. 20 years of EFNEP: changes and challenges. J Nutr Ed. 1989; 21(6):276-279.

Cohon M, Zimmet P. Self-monitoring of blood glucose levels in non-insulin dependent diabetes mellitus. Med J Australia. 1983; 2:377-381.

Computrition Nutrition Software Library. Computrition Inc. 1989. 21049 Devonshire St., Suite 201, Chatsworth, CA 91311.

DelTredici AM, Joy AB, Omelich CL, Laughlin SG. Evaluation study of the California Expanded Food and Nutrition Education Program: 24 hour food recall data. J Am Diet Assoc. 1988; 88(2):185-19). 
Diagnostic Products Corporation. Double Antibody Ferritin Instruction Booklet. October 23, 1986. 5700 West 96 th Street, Los Angeles, CA 90045.

Dienard AS, Swartz S, Yip R. Developmental changes in serum ferritin and erythrocyte protoporphyrin in normal (nonanemic) children. Am J Clin Nutr. 1983; 38:71-76.

Farley MA, Smith PD, Mahoney AW, West DW, Post JR. Adult dietary characteristics affecting iron intake: a comparison based on iron density. J Am Diet Assoc. 1987; $87(2): 184-189$.

Filer LJ. Dietary Iron: Birth to Two Years. New York, NY: Raven Press; 1989; 6-8.

Finch $\mathrm{CA}$, Cook JA. Iron deficiency. Am J Clin Nutr. $1984 ; 39: 471-477$.

Galler JR. Examining the long-term consequences of under nutrition. Pediat Basics. 1987; 47:1-3.

Garn SM, Ridella SA, Petzold AS, Falkner F. Maternal hematological levels and pregnancy outcome. Seminars in Perinatol. 1981; 5:155-162.

Gillooley M, Bothwell TH, Torrance JD, MacPhail AP, Derman DP, Bezwoda WR, Mills W, Charlton RW. The effects of organic acids, phytates and polyphenols on the absorption of iron from vegetables. $\mathrm{Br} J$ Nutr. 1983; 49:331-341.

Glanz K. Nutrition education for risk factor reduction and patient education: a review. Preventive Medicine. $1985 ; 14721-752$.

Green R, Charlton RW, Seftel H, Bothwell TH, Mayet F, Adams EB, Finch CA, Layrisse M. Body iron excretion in man: a collaborative study. Am J Med. 1968; 45:336-353.

Hallberg L, Hogdahl AM, Nilsson L, Rybo R. Menstrual blood loss - a population study. Variations in different ages and attempts to define normality. Acta obstet Gynecol. 1966; 45:320-351.

Hallberg L, Rossander-Hulten L. Iron requirements in menstruating women. Am J Clin Nutr. 1991; 54:1047-58.

Harper AE. Transitions in health status: implication for dietary recommendations. Am J Clin Nutr. 1987; 45:10941107 . 
Johnson DW, Johnson RT. The process of nutrition education: a model of effectiveness. J Nutr Ed. 1985; 17 (supp) : s1-s44.

Kennedy ET, Gershoff S. Effect of WIC supplemental feeding on hemoglobin and hematocrit of prenatal patients. $\mathrm{J}$ Am Diet Assoc. 1982; 80:227-30.

Kris-Etherton PM. Nutrition and the exercising female. Nutrition Today. 1986; 6-16.

Lubin AF, Bonner JL, Shrock RO. Effect of maternal iron status on the subsequent development of iron deficiency in the infant. J Pediat. 1980; 96(6):1114-1115.

Macfarlane BJ, Bezwoda WR, Bothwell TH, Baynes RD, Bothwell JE, MacPhail AP, Lamparelli RD, Mayet F. Inhibitory effect of nuts on iron absorption. Am J Clin Nutr. $1988 ; 47: 270-4$.

Meyers LD, Habicht JP, Johnson CL, Brownie C. Prevalence of anemia and iron deficiency anemia in black and white women in the United states estimated by two methods. Am J Public Health. 1983; 73:1042-1049.

Miller V, Swancy S, Dienard A. Impact of the WIC program on the iron status of infants. Pediat. 1985; 75(1):100105 .

Milman N, Kirchhoff M. Iron stores in 1359, 30 to 60 year old Danish women: evaluation by serum ferritin and hemoglobin. Ann Hematol. 1992; 64(1):22-7.

National Research Council, Food and Nutrition Board, Commission on Life Sciences. Recommended Dietary Allowances. loth Ed. Washington, DC: National Academy Press; 1989 .

Pollitt E, Soemantri AG, Yunis F, Scrimshaw NS. Cognitive effects of iron deficiency anemia. Lancet. 1985; 1:158.

Randall MJ, Brink MS, Joy AB. EFNEP: changes and challenges. J Nutr Ed. 1989; 21(6):276-279.

Robinson C, Lawler MR. Normal and Therapeutic Nutrition. 16th Ed. New York, NY: MacMillan Publishing Co.; 1982 ; 502-509.

Rush D, Leighton J, Sloan NL, Alvir JM, Garbowski GC. Review of past studies of WIC. Am J Clin Nutr. 1988a; $48: 394-411$. 
Rush D, Alvir JM, Kennedy DA, Johnson SS, Horvitz DG. Historical study of pregnancy outcomes. Am J Clin Nutr. $1988 \mathrm{~b} ; 48: 412-428$.

Rush D, Horvitz DG, Seaver WB, Leighton J, Sloan NL, Johnson SS, Kulka RA, Devore JW, Holt M, Lynch JT, Virag TG, Woodside MB, Shanklin DS. Study methodology and sample characteristics in the longitudinal study of pregnant women, the study of children, and food expenditures study. Am J Clin Nutr. 1988C; 48:429-538.

Rush D, Sloan NL, Leighton J, Alvir JM, Horvitz DG, Seaver WB, Garbowski GL, Johnson SS, Kulka RA, Holt M, Devore JW, Lynch JT, Woodside MB, Shanklin DS. Longitudinal study of pregnant women. Am J Clin Nutr. $1988 d ; 48: 439-483$.

Rush D, Leighton J, Sloan NL, Alvir JM, Horvitz DG, Seaver WB, Garbowski GC, Johnson SS, Kulka RA, Devore JW, Holt M, Lynch JT, Vivag TG, Woodside MB, Shanklin DS. study of infants and children. Am J Clin Nutr. 1988e; $48: 484-511$.

Rush D, Kurzon MR, Seaver WB, Shanklin DS. Study of food expenditures. Am J Clin Nutr. 1988f; 48:512-519.

Singh A, Deuster PA, Day BA, Moser-Veillon PB. Dietary intakes and biochemical markers of selected minerals: comparison of highly trained runners and untrained women. J Am Coll Nutr. 1989; 9(1):65-75.

Smith AL, Branch G, Henry SE, Magpuri PR. Effectiveness of a nutrition program for mothers and their anemic children under 5 years of age. J Am Diet Assoc. 1986; 86 (8) : 1039-1042.

Soemantri AG, Pollitt E, Kim I. Iron deficiency anemia and educational achievement. Am J Clin Nutr. 1985; $42: 1221-1228$.

Stockman JA. Iron deficiency anemia: have we come far enough? JAMA. 1987; 258(12):1645-47.

Stockbauer JW. Evaluation of the Missouri WIC program: prenatal component. J Am Diet Assoc. 1986; 86:61-67.

Stockbauer JW. WIC prenatal participation and its relation to pregnancy outcomes in Missouri: a second look. AJPH. 1987; 77(7):813-818. 
Tilgner SA, Schiller MR. Dietary intakes of female college athletes: the need for nutrition education. Diet Assoc. 1990; 90(12):967-69.

Torisky DM, Hertzler AA, Johnson JM, Keller JF, Hodges PAM, Mifflin BS. Virginia EFNEP homemaker's dietary improvement and relation to selected family factors. J Nutr Ed. 1989; 26(6):249-258.

Torisky DM, Hertzler A, Mifflin B. Evaluation of the extent and retention of dietary improvement and relation family factors. Virginia Cooperative Extension Service. 1987.

Trevisan M, Cooper R, Stamler R, Gosch F, Allen A, Liu K, Ostrow D, Stamler J. Dietary salt and blood pressure. Prev Med. 1983; 12:133-137.

Utah state Department of Health, Family Health Services, WIC Program. Biochemical Assessment-Module No. 4. 1991.

United States Code 1988; 7 U.S.C. 3175. Washington, DC.: United States Printing office; 1989.

United states Department of Agriculture, Human Nutrition Information Service, Nutrition Monitoring Division.

Nationwide Food Consumption Survey Continuing Survey of Food Intakes by Individuals. Low-Income Women 19-50 Years and Their Children 1-5, 1 Day. Hyattsville, MD: 1985.

U.S. Senate Select Committee on Nutrition and Human Needs. Dietary Goals for the United States. 2nd Ed. Washington, DC: U.S. Govt Printing office; 1977.

Weiler PG, Stalker HP, Jennings SW, Fister WT. Anemia as a criterion for evaluation of a special supplemental food program for women, infants and children. Pediat. 1979; $63(4): 584-590$.

Worthington-Roberts B. Nutritional support of successful reproduction: an update. J Nutr Ed. 1987; 19(1):1-10.

Whitney EN, Cataldo CB, Rolfes SR. Understanding Normal and Clinical Nutrition. 2nd Ed. New York, NY: West Publishing Company; 1987; 7-15.

Yip R, Walsh KM, Goldfarb MG, Binkin NJ. Declining prevalence of anemia in childhood in a middle-class setting: a pediatric success story? Pediat. 1987a; $80(3): 330-334$. 
Yip R, Binkin NJ, Fleshood L, Trowbridge FL. Declining prevalence of anemia among low-income children in the United States. JAMA. 1987b; 258(12):1619-23.

Zeman FJ. Clinical Nutrition and Dietetics. 2nd Ed. New York, NY: MacMillan Publishing; 1991. 
120

APPENDICES 
APPENDIX A: Study Participant Characteristics 
Table A.1. Age distribution for WIC and WIC control study participants.

\begin{tabular}{lcccccc}
\hline $\begin{array}{l}\text { Age in } \\
\text { years }\end{array}$ & \multicolumn{1}{c}{ pre } & post & pre & post & pre & post \\
\hline 1 & $8(19)$ & $3(7)$ & $3(13)$ & & $11(17)$ & $3(5)$ \\
2 & $11(26)$ & $12(29)$ & $6(26)$ & $7(30)$ & $17(26)$ & $19(29)$ \\
3 & $18(43)$ & $13(31)$ & $9(39)$ & $4(17)$ & $27(42)$ & $17(26)$ \\
4 & $5(12)$ & $13(31)$ & $5(22)$ & $7(30)$ & $10(15)$ & $20(31)$ \\
5 & - & $1(2)$ & - & $5(22)$ & - & $6(9)$ \\
mean & 2.47 & 2.93 & 2.70 & 3.43 & 2.55 & 3.11 \\
range & $1-4$ & $1-5$ & $1-4$ & $1-5$ & $1-4$ & $1-5$ \\
n & 42 & 42 & 23 & 23 & 65 & 65
\end{tabular}

Note: Numbers in parentheses ( ) are percentages. 
Table A.2. Study participants categorized by family size and tallied by program.

\begin{tabular}{|c|c|c|c|c|c|c|}
\hline Family & Size & WIC & EFNEP & WIC-C & EFNEP-C & COMPOSITE \\
\hline 2 & & 2 (5) & - & 1 (4) & 1 (4) & 4 (4) \\
\hline 3 & & $14(33)$ & $4(15)$ & $9(39)$ & 9 (39) & 36 (31) \\
\hline 4 & & $13(31)$ & $7 \quad(27)$ & $3(13)$ & 3 (13) & $26(23)$ \\
\hline 5 & & $10 \quad(24)$ & $6(23)$ & $10(44)$ & 10 (13) & 7 (6) \\
\hline 6 & & $3(7)$ & 4 (15) & - & - & 7 (6) \\
\hline 7 & & - & 4 (15) & - & - & 4 (4) \\
\hline 8 & & - & 1 (4) & - & - & 1 (1) \\
\hline mean & & $\begin{array}{l}3.95 b \text { b* } \\
\pm 1.03\end{array}$ & $\begin{array}{l}5.0 a^{\star} \\
\pm 1.44\end{array}$ & $\begin{array}{l}3.96 b \text { * } \\
\pm 1.02\end{array}$ & $\begin{array}{l}3.96 b * \\
\pm 1.02\end{array}$ & $\begin{array}{l}4.19 \\
\pm 1.20\end{array}$ \\
\hline range & & $2-6$ & $3-8$ & $2-5$ & $2-5$ & $2-8$ \\
\hline $\mathrm{n}$ & & 42 & 26 & 23 & 23 & 114 \\
\hline Note: & $\begin{array}{l}\text { Numbe } \\
\text { Numbe } \\
\text { those } \\
\text { * sig }\end{array}$ & $\begin{array}{l}\text { in paren } \\
\text { followed } \\
\text { llowed b } \\
\text { icant at }\end{array}$ & $\begin{array}{l}\text { eses ( ) } \\
y \text { an "a" } \\
\text { "b." } \\
\text { p. } 001\end{array}$ & $\begin{array}{l}\text { are percen } \\
\text { differ sig } \\
\text { evel }\end{array}$ & $\begin{array}{l}\text { ages. } \\
\text { ificantly }\end{array}$ & from \\
\hline
\end{tabular}


Table A.3. Study participants categorized by monthly income and tallied by program.

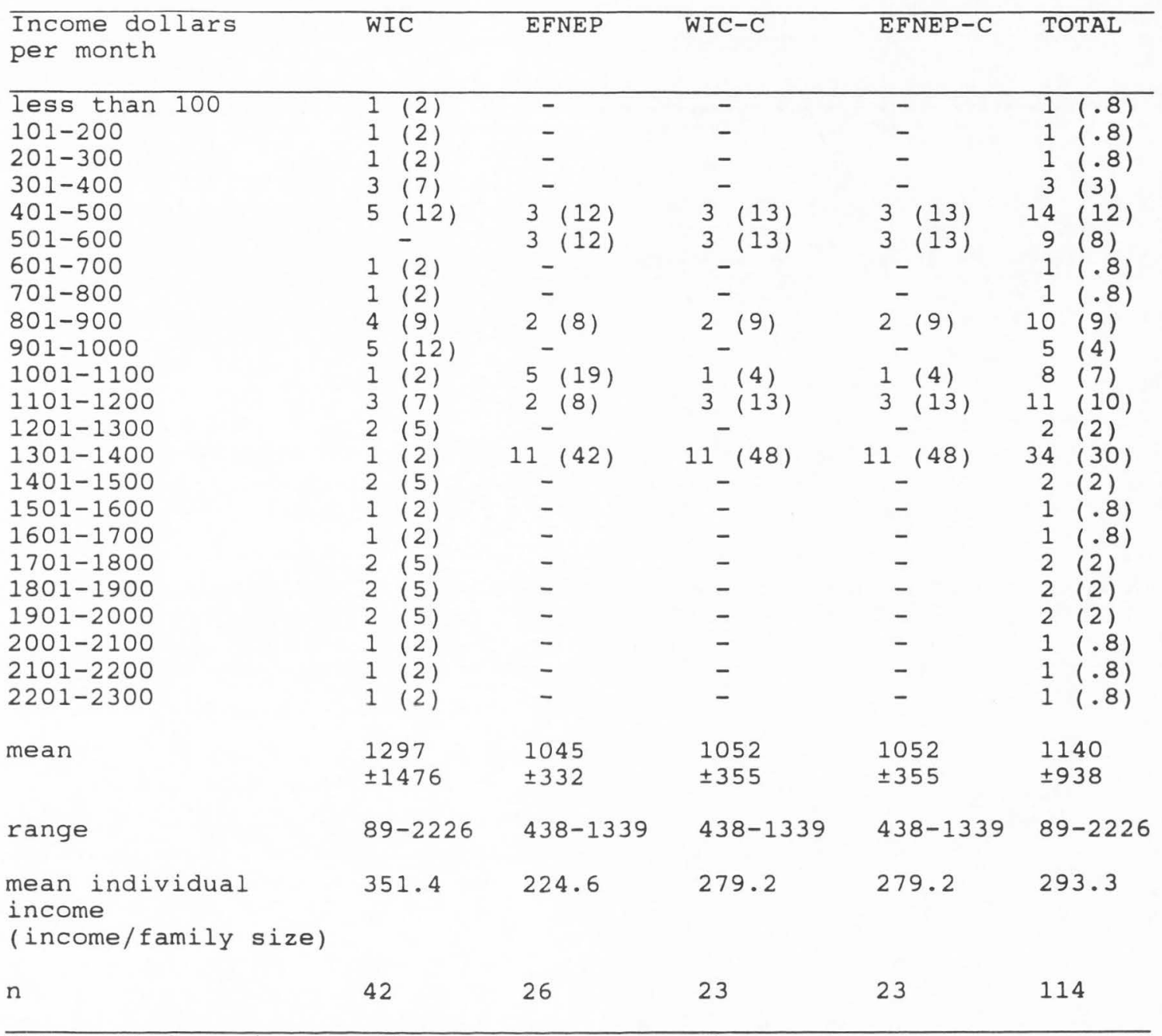

Note: Numbers in parentheses ( ) are percentages. 
Table A.4. Study participants categorized by years of formal education and tallied by program.

\begin{tabular}{|c|c|c|c|c|c|}
\hline $\begin{array}{l}\text { Years of } \\
\text { Education }\end{array}$ & WIC & EFNEP & WIC-C & EFNEP-C & COMPOSITE \\
\hline 6 & - & $1(4)$ & - & - & 1 (1) \\
\hline 7 & 1 (2) & - & - & - & 1 (1) \\
\hline 8 & 1 (2) & - & - & - & 1 (1) \\
\hline 9 & - & 1 (4) & - & - & 1 (1) \\
\hline 10 & $3(7)$ & 1 (4) & - & - & $4 \quad(4)$ \\
\hline 11 & $2(5)$ & 1 (4) & - & - & 3 (3) \\
\hline 12 & $26(62)$ & $10 \quad(38)$ & 1 (4) & 1 (4) & $38 \quad(33)$ \\
\hline 13 & $4(9)$ & $12(46)$ & $15(65)$ & $15 \quad(65)$ & $46(40)$ \\
\hline 14 & $3(7)$ & - & $2(9)$ & $2(9)$ & $7(6)$ \\
\hline 15 & - & - & - & - & - \\
\hline $16+$ & $2(5)$ & - & $5 \quad(22)$ & $5 \quad(22)$ & 12 (11) \\
\hline mean & $\begin{array}{l}12.02 a^{*} \\
\pm 1.58\end{array}$ & $\begin{array}{l}12.00 a^{*} \\
\pm 1.57\end{array}$ & $\begin{array}{l}13.80 b^{*} \\
\pm 1.51\end{array}$ & $\begin{array}{l}13.80 b * \\
\pm 1.51\end{array}$ & $\begin{array}{l}12.73 \\
\pm 1.76\end{array}$ \\
\hline range & $7-16$ & $6-13$ & $12-18$ & $12-18$ & $6-18$ \\
\hline $\mathrm{n}$ & 42 & 26 & 23 & 23 & 114 \\
\hline
\end{tabular}

Note: Numbers in parentheses ( ) are percentages.

Numbers followed by an "a" differ significantly from those followed by a "b."

* significant at $p=.0000$ level 
Table A.5. Percent of study participants who were taking vitamin supplements, participated in other federal food programs, or took a nutrition class in high school or college.

\begin{tabular}{|c|c|c|c|c|c|c|c|c|c|c|}
\hline \multirow[t]{2}{*}{ Category } & \multicolumn{2}{|l|}{ WIC } & \multicolumn{2}{|c|}{ EFNEP } & \multicolumn{2}{|c|}{ WIC.C } & \multicolumn{2}{|c|}{ EFNEP.C } & \multicolumn{2}{|c|}{ COMFOSITE } \\
\hline & pre & post & pre & post & pre & post & pre & post & pre & posi \\
\hline $\begin{array}{l}\text { Vitamin } \\
\text { Supplement }\end{array}$ & $8(19)$ & $11(26)$ & $6(23)$ & $5(19)$ & $3(13)$ & $4(17)$ & $4(17)$ & $4(17)$ & $2:(i 8)$ & $2:(2)$ \\
\hline $\begin{array}{l}\text { Food } \\
\text { Programs }\end{array}$ & $7(17)$ & $7(17)$ & $3(12)$ & $3(12)$ & $1(4)$ & $1(4)$ & $1(4)$ & $1(4)$ & $12(i 1)$ & $12(1:)$ \\
\hline $\begin{array}{l}\text { Nutrition } \\
\text { in High } \\
\text { School }\end{array}$ & $11(26)$ & $11(26)$ & $5(19)$ & $5(19)$ & $2(9)$ & $2(\theta)$ & $2(9)$ & $2(9)$ & $20(18)$ & $20(+8)$ \\
\hline $\begin{array}{l}\text { Nutrition } \\
\text { in college }\end{array}$ & $5(12)$ & $5(12)$ & $2(8)$ & $2(8)$ & $1:(48)$ & $11(48)$ & $11(48)$ & $11(48)$ & $29(25)$ & $29(25)$ \\
\hline$n$ & 42 & 42 & 26 & 25 & 23 & 23 & 23 & 23 & 114 & $1: 4$ \\
\hline
\end{tabular}

Note: Numbers in parentheses () are percentages. 
APPENDIX B: Data Collection Forms and Consent Form 


\section{NOTRITION KNOWLEDGE}

NAME:

Revised $10-30-90$

NUMBER :

DATE :

Select the correct answer to the following questions by marking a letter in the space provided.

1. What is the best buy for 10 -fat protein?

a. Boneless, skinless chicken breasts at $\$ 2.49$ a pound.

b. Chicken nuggets 6 for $\$ 1.75$.

c. Whole chicken at 49 cents a pound and skin it at home.

2. The best source of Iron is:
a. Old rusty nails
b. Yogurt
c. Broccoli
d. Eggs

3. A food which is a good source of Vitamin A is:
a. Pineapole
b. Broccoli
c. Whole Wheat Bread
d. Chicken lean

4. The following infornation is found on food labels. Which food has the most protein per calorie?
a. Split pea soup
b. Bacon
c. Oatmeal
d. Corn

\begin{tabular}{cc}
$\mathrm{cm}$ protein & calories \\
\hline 1 & 22 \\
1 & 82 \\
1 & 28 \\
1 & 30
\end{tabular}

5. Protein is important to the human body because:
a. It prevents heart attacks.
b. Builds and repairs cells.
c. Speeds up how fast you digest food.
d. Reduces blood clotting time. 
6. A good source of Vitamin C is:
a. Potato
b. Rice
c. Bread
d. Milk
e. Sunshine

7. From the list below the best source for calciun is:
a. Beans or Legumes
b. Tomatoes
c. Eggs
d. Rice

8. Which of the following lists contain the Basic 4 focd groups?
a. Nuts and seeds
Fruits and Vegetables
Meat, Poultry, Fish, Beans
b. Milk and Cheese
Breads and cereals
Milk and Cheese
Meat, poultry, Fish, Beans
Fruits and Vegetables
c. Milk and Cheese
Breads and Cereals
Fats and Sweets
Fruits and Vegetables
d. Fruits
Vegetables
Meat, Poultry, Fish, Beans Milk and Cheese.

9. A most Nutriticus food is one that:
a. Is low in nutrients and high in calories.
b. Has a lot of calories or energy.
c. Is high in nutrients and low in calories.

d. Contains a large amount of protein.

10. Which of the following foods would have the most calories?
a. Skim milk (1 cup)
arms carbohydrate
b. French Fries ( 15 pieces)
c. Hot Dog without a Bun (1)
d. Cantaloupe (2/3 melon)

12
15
1
30
arms orotein

$\begin{array}{cr}\text { otein } & \text { grms fat } \\ 8 & 0 \\ 6 & 15 \\ 0 & 10 \\ & 0\end{array}$

11. When adding fat or sugar to a food, the nutrient value per calorie is:
a. Increased.
b. Decreased.
c. Not changed. 
12. When purchasing a beverage, the most nutritious is:

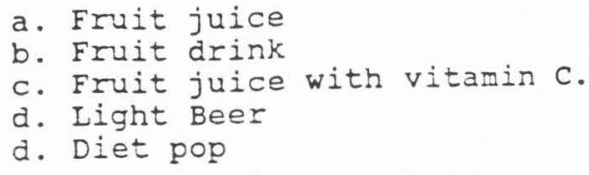

a. 16 oz bag dry pinto beans Price $\$ 1.29$ Servings per container 12 Serving size 1/2 C Nutrients per serving

14. Eating foods with complex carbohydrates and fiber has beneficial effects, these include:

a Helping prevent certain types of cancer (especially if high in vitamin $A$ and vitamin $C$ )

b. Helping control diabetes

c. Helping prevent colon problems

d. All of the above

15. Pinto Beans are high in iron. Which food should be included with the meal to increase the iron absorption?
a. Hammer and nails
b. Milk
c. Tomatoes
d. Carrots

16. Pinto beans are high in protein. Which food should be added to make a complete protein?
a. Orange juice
b. Corn tortilla
c. Brocoli 
17. Mrs. Jones is 7 months pregnant and has noticed she needs to take rapid breaths to get enough oxygen ( $a i r)$. If the baby is nct pushing on the lungs, this condition could possibly be helped if she ate more foods high in:
a. Vitamin $A$
b. Vitamin $C$
c. Iron
d. Calcium

18. Jane at age 22 wants to decrease her risk for osteoporosis, since her grandmother just had a broken hip. She has increased he: diet in:
a. Vitamin A
b. Calcium
c. Vitamin C
d. Iron

19. Jerry has noticed that his gums bleed when he brushes his teeth. His bruises and scratches also take a long time to heal. He should try increasing his diet in:
a. Vitamin $c$
b. Vitamin D
c. Fluoride
d. Calcium

20. Jessie has noticed she has trouble driving at nighttime becalise her eyes do not adjust to dark. The doctor diagnosed her condition as nightblindness and told her to increase her diet in:
a. Vitamin D
b. Vitamin $C$
c. Vitamin A
d. Niacin

21. Hot foods should be kept hot and cold foods should be kept cold to:
a. Preserve nutrients
b. Avoid food poisoning
c. To keep a person busy 
PARTICIPATION ANO CONSENT FORM Nutrition Education Proiect
Name

Socia' Securit

Birth Date

County Compltar =

"The Effect of Nutrition Knowledge on Hematocrit Values"

Informed consent to participate in a Utah State Lriversity Research frojeaz concucted by stazf from USU Extension and Hicher, infan, ch: icher. Supplementa? Food Program (W|C). project: underszand thaz as a farticifart in this

1) I wili provide a written diet history (tre w:C 24 hoir ciet reaall) on my child at the beginning of the research project and 6 montis later. (These are the usual time frames this is done for the EFNE? and W:C programs and will be fart of the Wic rezertilication procedure.)

2) I will provide a written medica: history on my crild at tre beginning of the research project. This is the standard H:O medica: history form.

3) I wi? al how a trained person to take a inger prick biocd a impie on my child at the start of the study and at a 6 month foliow-ui screer.ing (the usual scheduled certification acpointmenti. This is the nonmal procedure for WiC enroliment.

4) I wili arisiwer a questionnaire or nutrition at the beginning of the study and at a 6 month follow-up (certificaticr appointment)

5) : wi: attend the nutrition lessoris presented tirough E=NE? or wio while my child is particicazing in the study.

In return for my participation I uncerstand I will have acess zo a: my child's data including the dietary evaiuations and bloca chemiszry data

1 understard: or my child am free to withdraw our participation in this project at any time and the walk in no way jeopardizes my child's continued participation in the wiC or EFve? program.

I understand there are no expected risks to my child involved cue to our participation in this project.

Any questions relating to the procecures used in tis fis project wi:i be answered by Nedra Christensen (484-93-4) or Becky Low $(408-3: 8 i)$.

Guardiar Signature

Witness

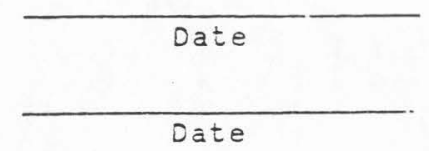

Date

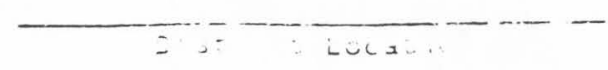

$C H I L D$ 
133

FIRST VISIT

Name

Address

Prone

Child's Name

Child's Age

Child's Ht

$$
W \pm
$$

HOt
RETURN VISIT

Ht \%: le

WE \% : ?

Hot

Family size

income level

Family size

Income/Mon

Previous Nutrition Classes

Last Level? cf Education Completed

Ethnic origin

Enrolled in EFNEF Y Y N

Encolled in other: Government food Programs 
Name

Address

Phone Number

Income Level (Please check one of the following)

Under $\$ 438$ per month
$\$ 439-588$ per month
$\$ 589-738$ per month
$\$ 739-888$ per month

- $\$ 889-1038$ per month
$\$ 1039-1183$ per month
$\$ 1189-1338$ per month
$\$ 1339$ and over per month

Total number on individuals living in household

Please circle the last grade of formal education completed

$\begin{array}{llllllllllllll}\text { None } & 1 & 2 & 3 & 4 & 5 & 6 & 7 & 8 & 9 & 10 & 11 & 12 & \text { soze college }\end{array}$ BS Degree Graduate Degree

List any type and number of nutrition classes recieved in the past. 
UTAH DEPARTMEVT OF HEALTH

FAMILY HE. AL TH SERVICES DIVISION

NLTRTION HISTORY - TEENS AND ADULTS BASIC FOUR

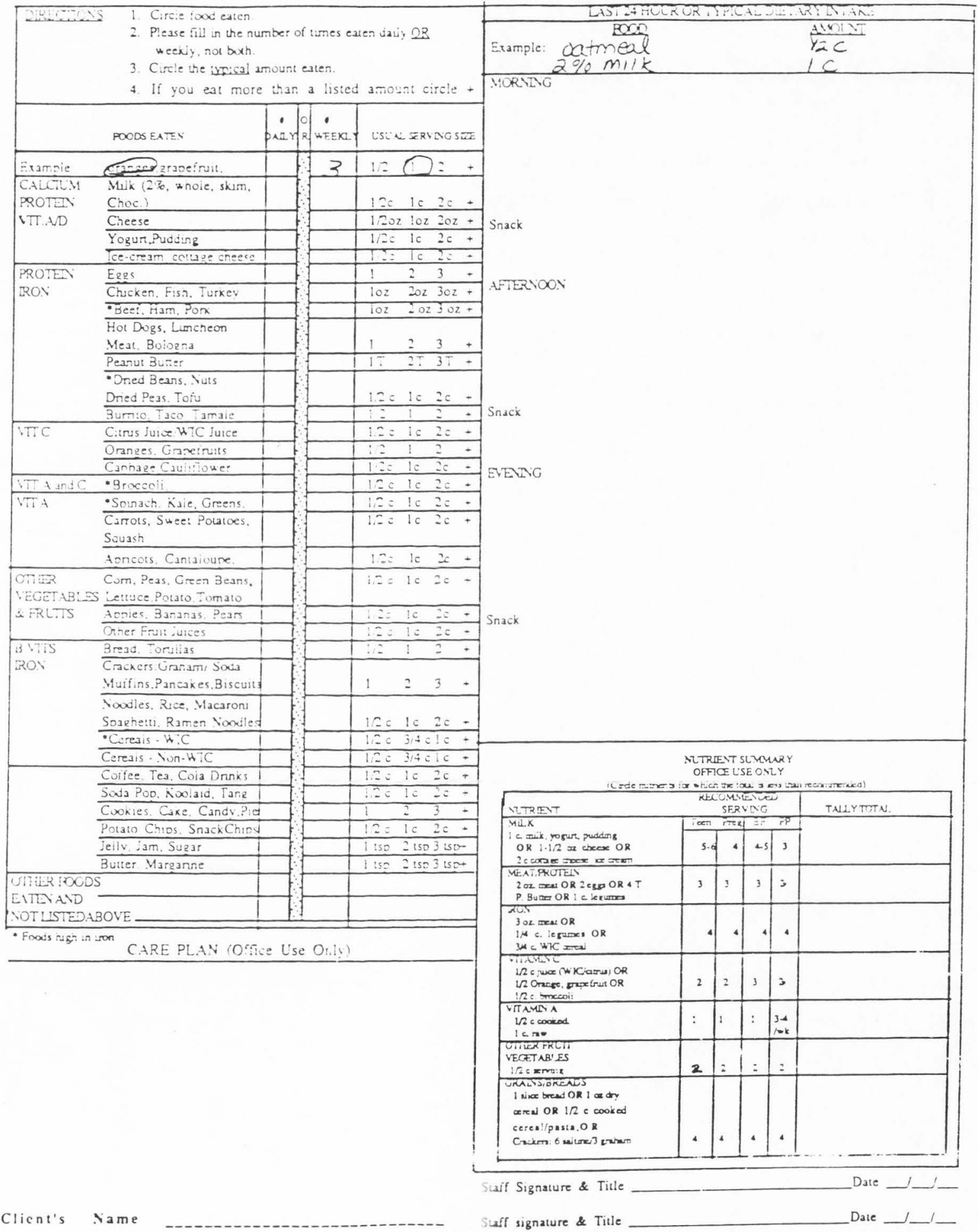


UTAH STATE WIC PROGRAM

Pregnancy \& Medical Interview

Date
Birthdate
Age at start of menstruation

\begin{tabular}{|c|c|c|c|}
\hline \multicolumn{4}{|c|}{ De you Have: (Please circle) } \\
\hline Headaches & $\begin{array}{l}\text { Persistent Nausea/ } \\
\text { Vomiting }\end{array}$ & Problems Seeing & Gestational Diabetes \\
\hline Dizziness & Swelling & $\begin{array}{l}\text { Toxemia or } \\
\text { Pre-eclampsia }\end{array}$ & $\begin{array}{l}\text { Spotting or } \\
\text { Hemorrhaging }\end{array}$ \\
\hline $\begin{array}{l}\text { Stomach or } \\
\text { Intestinal Problems }\end{array}$ & $\begin{array}{l}\text { Vitamin/Mineral } \\
\text { Deficiencies }\end{array}$ & Tuberculosis & Cancer \\
\hline Chronic Infections & Diabetes & Heart Disease & Kidney Disease \\
\hline Liver Disease & Lung Disease & Thyroid Disease & High Blood Pressure \\
\hline Food Allergies & Anemia & $\begin{array}{l}\text { Family History of } \\
\text { Genetic Disorders }\end{array}$ & Mental Retardation \\
\hline Venereal Disease & HIV Positive & & Hepatitis \\
\hline
\end{tabular}

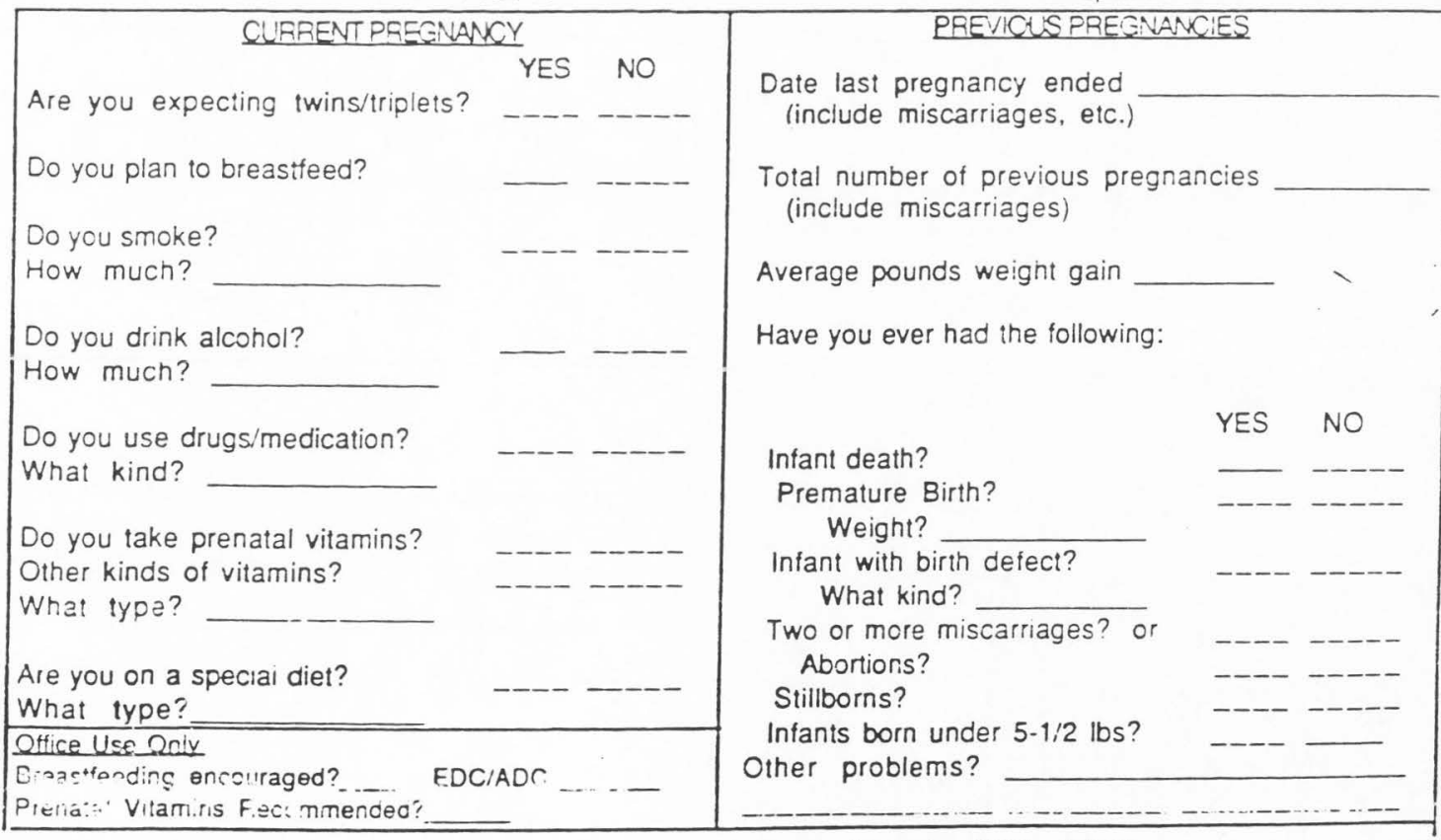

Your signature indicates consent for use of this information to determine WIC eligibility.

Client Signature

CPAvivutritionist/Title 
137

UTAH DEPARTMENT OF HEALTH

FAMILY HEALTH SERVICES DIVISION

NUTRITION HISTORY - TEENS AND ADULTS BASIC FOUR

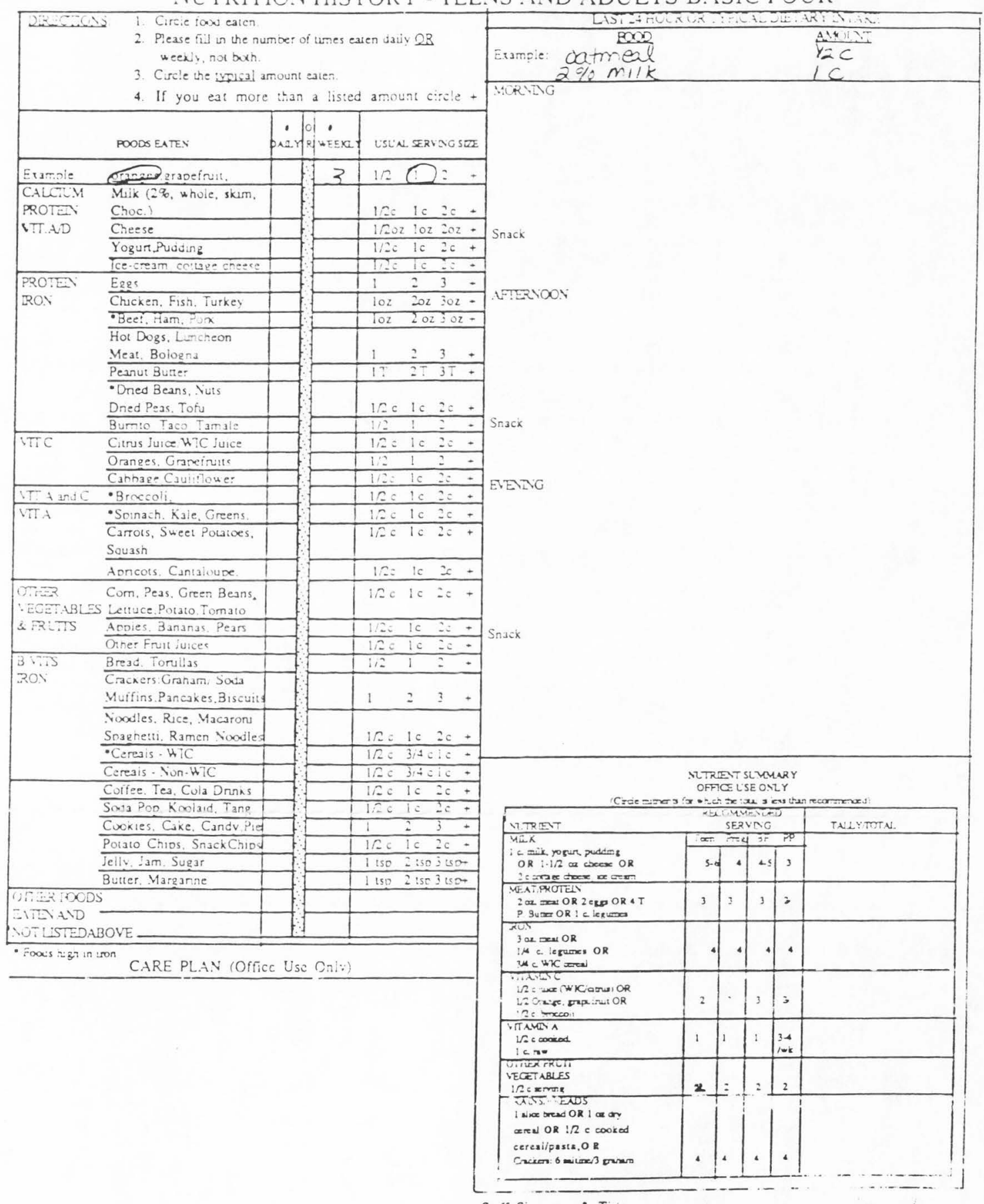

Staff Signature \& Title

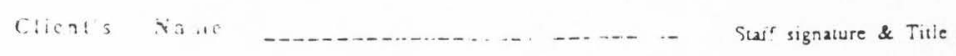
Date - $1-$

(PLEASE COMPLETe OTHER SIDE)

$5 / 89$ 
LTAH STATE WIC PROGRAM

\section{CHILD'S MEDICAL HISTORY}

TODAY'S DATE

PARENT/GUARDLAN

CHILD'S NAME

DOCTOR'S NAME

BIRTHDATE

MEDICAL HISTORY

DOES YOUR CHID HAVE: (Please Circle)

Frequent diarrhea

Food Allergies

Dental Cavities or

Problems

Down Syndrome

PKL

Hear Disease

Liver Disease

Maple Syrup Urine Disease

Cancer
Chronic

Constipation

Vomiting

Stomach or Intestinal

Problems

Cerebral Pals:

Diabetes

High Blood Pressure

Thytoid Problems

Cystic Fibrosis

Hepatis
Growth Problems

(Failure to Tnrive)

Swallowing Problems

Birth Defects

Mental Re:ardarion

Celiac Disease

Kidne: Disease

Wilson's Disease

Colic

$\mathrm{HIV}+$

HAVE ANY FAMILY MEMBERS HAD ANY OF THE ABOVE? YeS No

IF YES, PLEASE INDICATE WHICH:

ARE YOUR CHILD'S IMMUNIZATIONS CURRENT? YES NO

DOES YOUR CHILD GET FREQUENT INFECTIONS? (Ear, tonsillitis, sore throat, bronchitis, etc.) YES NO EXPLAIN

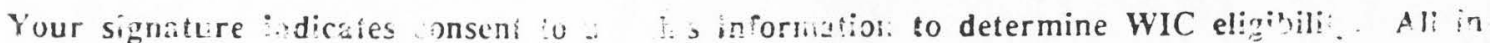
formation will be kept confidential.

Parent's Signature:

Nutrit. , ist/CPA. Signature 


\section{Statement of the PI to the IRB for Proposed}

Recearci Involving Human Subjec:s

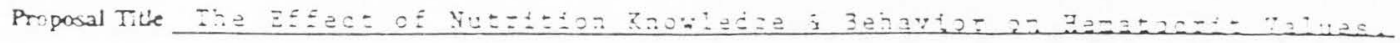

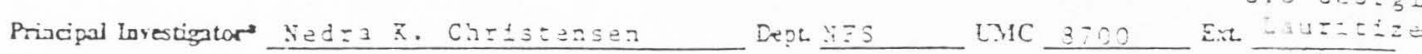

Student Researcier _ Lept. UMC Ext.

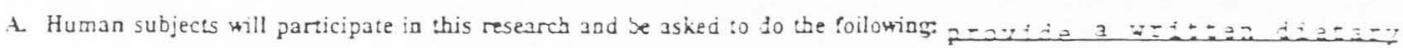

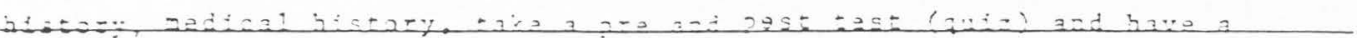

Eingez-orick heaatocite (Hc:) value.

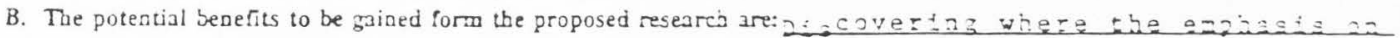

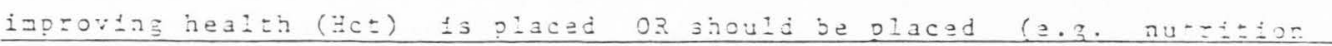

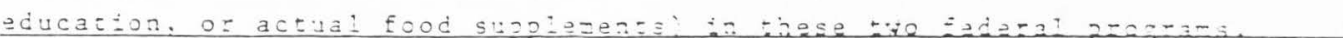

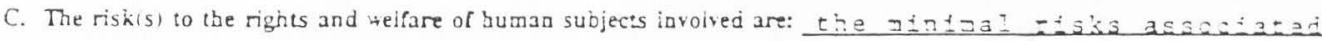
with a ziagez stick blood sa=pia.

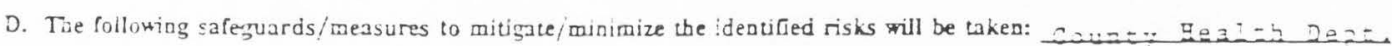
procedures will be utilized (e.j. cleas equipaent jetreen each sujiect, zes Iancets, gioved ezployees, aicohol swas, etc for eaci aew partictpant).

E. The informed consent procedures for subjects will be as follows: Eroiain procedures to be !ollowed and attach an example of the informed consent instrument) Each partictoant 0112 be told that particfoation fs voluntary and will follow the federal prograp protocols - see atcacied conse

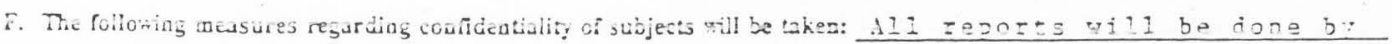
participant nujoer (sot name). Raw data will not be distrijuted.

G. Other: (If, in your opinion no, or minimal, risk to subjects exists, please explain in this section)

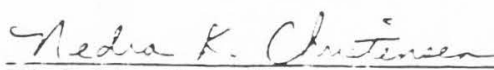

Principal Investigator Signature

Student Researcter Signature

- A student researcher should name his/her advisor or chairman as the principal investigator. Both are required to sign this form.

Retura to: Sidney Peterson, LMC 9600 
APPENDIX C: Standards for Anemia and Blood Collection (Permission to reprint granted orally by

Don Johnson, Utah Department of Health, WIC Director, March 16, 1993) 


\section{TAELE 1. AMEXIA STAHDAROS AOJUSTED FOR ALTITUDE}

1. The following chare should be used to determine nutritionai risk and wic eligiollity. Values iess than the cut-off are recutrad to designate nutritional risk.

2. Please nota the following:

* Hemoglobin and hematocrit leyels indicating risk adjust win altitude change. The altitude for your ciinic specified on the following page should be applied for all clients seen in the citan

\begin{tabular}{|c|c|c|c|c|c|c|}
\hline Age of Individuais & $0-2999$ & $3000-4999$ & $5000-5999$ & 7000 & or $n$ & $\pi=r 3$ \\
\hline Less than 6 months & \multicolumn{6}{|c|}{ No standards } \\
\hline $6-23$ months & $33:$ & \multirow{2}{*}{$\begin{array}{l}34 \% \\
35 \%\end{array}$} & \multirow{2}{*}{$35:$} & \multirow{2}{*}{\multicolumn{3}{|c|}{$\begin{array}{l}36 \% \\
37 \%\end{array}$}} \\
\hline $\begin{array}{l}2 \text { - } 4 \text { years } 11 \text { months } \\
\text { Breastfeedinc and Post }\end{array}$ & $34 \%$ & & & & & \\
\hline Partum women & $35:$ & \multirow[t]{2}{*}{$37 \%$} & \multirow[t]{2}{*}{$38 \%$} & \multirow{2}{*}{\multicolumn{3}{|c|}{$39 \%$}} \\
\hline Pregnant women & & & & & & \\
\hline Ist Trimester & $35:$ & \multirow{2}{*}{$\begin{array}{l}36 \% \\
33 \%\end{array}$} & $37 \%$ & \multicolumn{3}{|c|}{$3 \varepsilon \%$} \\
\hline 2nd Trimester & $32 \%$ & & $34 \%$ & & $35 \%$ & \\
\hline 3rd Trimester & Зこั & $34 \%$ & $35 \%$ & \multicolumn{3}{|c|}{$36 \%$} \\
\hline Hemoglobin, mg: & \multicolumn{6}{|c|}{ Altitude (Feet) } \\
\hline Age of Indivicuais & $0-2909$ & $3000-4999$ & $5000-5009$ & 7000 & or & nors \\
\hline Less than 6 montins & & Nic & Stancaras & & & \\
\hline $6-23$ months & $11.0 \mathrm{gms}$ & $11.3 \mathrm{gms}$ & $11.7 \mathrm{gms}$ & & 2.0 & çs \\
\hline $\begin{array}{l}2 \text { - } 4 \text { years } 11 \text { months } \\
8 \text { reastfeeding and post }\end{array}$ & $11.2 \mathrm{gms}$ & $11.5 \mathrm{gms}$ & $11.9 \mathrm{gms}$ & & 2.2 & gns \\
\hline $\begin{array}{l}\text { Partum women } \\
\text { Pregnant women }\end{array}$ & $12.0 \mathrm{gms}$ & $12.3 \mathrm{gms}$ & $12.7 \mathrm{gms}$ & & 3.0 & $\mathrm{chs}$ \\
\hline Ist Trimester & $11.5 \mathrm{gms}$ & $11.8 \mathrm{gms}$ & $12.2 \mathrm{gms}$ & & 2.5 & gms \\
\hline 2nd Trimester & $10.5 \mathrm{gms}$ & $10.8 \mathrm{gms}$ & $11.2 \mathrm{gms}$ & & .5 & sms \\
\hline 3rj Trimester & $11.0 \mathrm{gms}$ & $11.3 \mathrm{gms}$ & $17.7 \mathrm{gms}$ & & .0 & chs \\
\hline
\end{tabular}

Centers for Disease Control, Criteria for Anemia in Children and Childbearing-Aged Women. MMWR 38: 401 - 404, 1989

Nutrition During Pregnancy.Subcomittee on Dietary Intake and Nutilent Supplements During Pregnancy. Food and Nutrition Board. Nitional Academy of Sciences, washington D.C., 1990. 
TABLE 2.

DISTRICT, CLINIC AND ALTITUDE TABLE

clinic

8ear River Oistrict Health Department

21001

21002

Logan

Brigham City

21003

Tremonton

21004

Randolph

Altitude (Feet)

Central Utah District Health Department

\begin{tabular}{ll} 
Central Utah District Health Department \\
\hline 24001 & Nephi \\
24002 & Delta \\
24003 & Manti \\
24004 & Richfield \\
24005 & Junction \\
24006 & Loa \\
24007 & Fillmore \\
24013 & Mt. Pleasant
\end{tabular}

Davis County Health Department

22201

Farmington

5119

4650

5800

5303

6000

7020

5061

5700

Familv Health Services

All Clinics

Salt Lake City

$\frac{\text { Salt Lake City/County Health Department }}{\text { All Clinics }}$

4366

4366

$\frac{\text { Salt Lake Indian Health Care Center }}{31000}$ Salt Lake City

4366

Southeastern District Health Department

27000

27002

27003

27004

27014

Price

Castledale

Moab

Blanding

Monticello

Southiwest Utah Oistrict Health Department

25001

25007

25008

25011

25012

25002

25003

25004

25005

25006

25009

2510 ?
St. George

Hurricane

Hillidale

Enterpise

Nevada

Cedar City

Kanab

Pinguitch

Escalante

Tropic

Antimony

Beaver
5567

5660

4000

6000

7050

2880

3279

5200

6000

1600

5800

4925

6570

5258

6400

6300

5895 
DISTRICT, CLINIC AND ALTITUDE TABLE

Clinic

Sumit City-County Health Department

28001 Coalvilie

Kamas

Park City

Tooele County Health Department

22401 Tooele

22402 wendover

Uintah Basin District Health Department

26101

26102

26112

26109

Vernal

Roosevelt

Duchesne

Manila

$U$ of $U$ Teen Mom Child Clinic

22601 Salt Lake City

City-County Health Department of Utah County

29001

29002

Provo

Orem

Utah Rural Develooment Corporation

30002

Provo

Ft. Duchesne

$\frac{\text { Ute Indian Tribe }}{26001}$

Wasatch-City-County Health Department

23101 Heber City

Weber Morgan District Health Department

22101

22103

22102

Ogden

Spanish

Morgan
Altitude (Feet)

5300

6500

7000

4900

4240

5331

5280

5515

6295

4366

4553

4553

4553

5331

5593

4370

4370

5068 
The information in this activity is imporant regardless of whether or not it is your job responsibility to perform the hematocit lest. lnderstanding hematoctit procedures will he! you answer related clieat questions and help you follow-up results of the test more effectively.

\section{IEST PROCEDIRES}

In order to be useful as an indicator of nutritonai status, the hemarocrit test wust ve accu-a:ely performed, recorded and compared with approptiate standards.

\section{EOIIPMENT}

Locate the centrifuge in your clinic. Have a siat: member lift the cover and then the inside !id which seals in the hematocit tubes. Find the grooves for holding tubes and the scaie used :o read results. Inhead hematocrit readers are nos to be used. Hematocrit Reader cards are required. The centrifuge must be kept calibrated and in good wotking condition wo assure accurate results. Check with the nutritionist regarding its waintenarce schedule.

Locate other equipment listed in the Materials and Supplies list on Page 6.

\section{GIIDAVCE OY THE HAVDINC, DE BODY FIUIDS IY THE WIC PQOCRAM}

WIC programs should be following your agency's or health deparment's policy on the handling of body fluids.

The Utah State Department of Health's recommendation is to follow the Center for Disease Controi's (CDC's) "Universal Precautions" for the Prevention of Transmission of H.I.Y. Hezatis B Virus, and other Bloodtome Pathogens in Health Care Settings publisined in the Mortidiry and Moraiity Weekiy Reson, June 24,1988

A copy of this resor, which is availabie from the Utah Deparment of Fealth, Bureau of Epicemioiogy, is included as ar appendix to this module. If you have any questions you can cail or write. Their telephone number is 538-6191

\section{TECHNIOUE}

(i) Put on disposable gioves (recommended to protect against possible contact with AIDS or hepartis-infected blood), or wash hands in hot, soapy water (as per healti depa-ment policy).

(2) Prepare equipment ahead to sceed procecure: unwrap bandaid, lancet (or secure sterile blade to Autole:) and gauze pad, moisten cotton ball with alcohol, secure 2 hematoctit tubes.

(3) Explain to client and/or parent why you are doing the test and how it will be done. Example: The hematocrit test is done to measure the amount of red blood ceils, and thus, the amount of iron in your blood. Low levels of iron in the blood can affect the health of you and your child and way even affect growth. It is easy to measure and if low, easy to correct by adding more high iron foods to your diet. I will take a few drops of blood from your finger and fill two glass tubes. Then, Fll put the tubes in this machine, which spins very fast and separates the red blood cells from the liquid part of the blood. 
(4)

If a child, grasp the client's entire hand and select either the middle or fourth (ring) finger for drawing biood. See Figure 1. For infants, it may be easier to draw blood from the big toe or heel. Ses "Skin Puncture oi Infants" (p. 13.14) and helpful hinis foincreasing blood now (on p. 12) betore doing this procedure.

(5) Wipe clean the finger or toe with a coton ball we: with alcohol and dry thoroughly before you puncture it (you may use a sierile gauze pad for this). Blood will not weil up and forma trop at the puncture site of a moist finger.

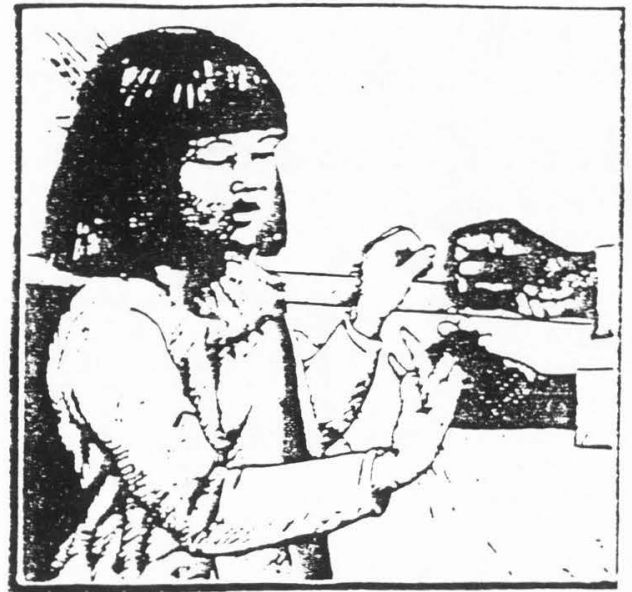

Figure 1. Position for Puncturing Finger to Draw Blocd

(6) Grasp the lancer between the thumb and foreñnger of your right hand. (If you are :et: handed the directions for which hand to use should be reversed.)

(7) Grasp the pacient's finger berween the fingers and the thumb of your left hand. You: fingers can be on top of the patient's finger with your thumb supporting his finger (fig. 2), or the thumb can be on top of the pacient's finger with your ingers supporting his finger (fig. 3).
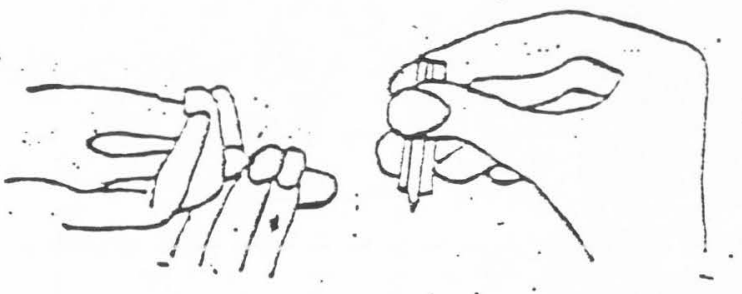

F:g. 2

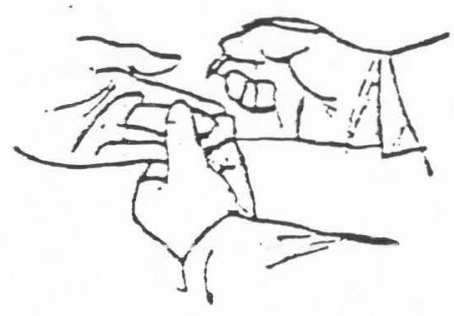

Fig. 3

(3) Hold the patient's finger firmiy with one hand and make a swift, deep puncture with the lance: halfway berween the center of the ball of the finger and its sice using a 10 to $20^{\circ}$ angle. It is not recommended to take blood from the fingertip. 
(9) The cut should be made across the fingerprints to produce a large round drop of bloct. (fig. 4)

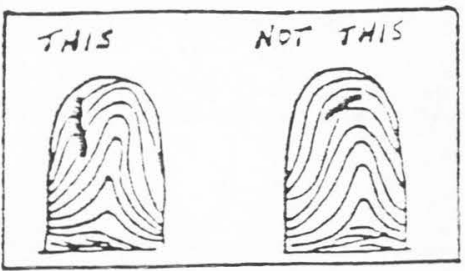

Throw away the blade cr lancet in a closed container with a ight fiting lid.

(10) Wipe away the first drop of biood with a clean gauze pad (it may be contaminated aith tissue fluids)

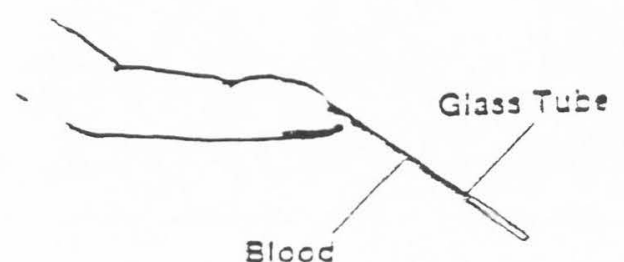

F:gure 5. Filling the Hemarccrit Tube With Blocd.
(11) A gentle squeeze and release action may be applied to obtain the blood. Avoid tightlv scueezing the client's finger since this may cause blood and tissue fluid to mix which wil affec: the accuracy of the test. If the blood does not flow freely, you 71 need to puncure the finget toe or hee! again.

(12) As soon as the second drop of biood apcears, piace the tube next to the b.00d and fill it uo to the biack line on the ate ( $2 / 3$ full). If using tubes withou: marked lines, fill rubes $2 / 3$ to $3 / 4$ full. It heips to hold tubes downward.

(13) Fill a second rube the same way. Do not change the volume of blood in the tube by using conon balls or kleenex to draw the blood out. This changes the fluid balance.

(14) Ast the clientparent to press the gauze pad a coron ball tightly on the finger, toe or heel to stop the blood flow. P!ace a bandaid around it.

(15) Stick one end of the tube in the clay and trist gently to seal. Greatly roll the hematocrit whe between your index and thumb several times in order to mix the blood and anticoagulant weil. Hematocit tubes break easily.

(16) Open the cover of the centrifuge and place the rubes in the numbered channels with the slay ends to the outside of the rack. The tubes shouid be placed onposite each other to balance the machine. If you only have one tube of blood, baiance it with a tube filled with water. As many as twenty tubes can be put in simultaneously. If you are including blood samoles from more than one client, be sure to write down each client's name and the number of the channels containing their blood.

(17) Lock the cover over the tutes and close the lid. The length of time to set the timer varies with different centrifuges depending on the rotations per minute (RPM's). Check with the 
nutritionist and your equipment guide concerning the clinic's equipment. Iceally, the centruge would be labelled with this information.

(13) When the centrifuge has comple:ely stopped spinning. remove the tubes. Red biood ceils should be "packed" at the bottom of the tube and clearly separate from the upoe- layer ct plasta.

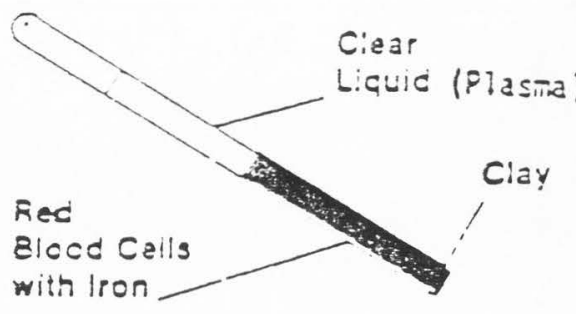

Figure 6. Blood Sample After Centrifuging
19) Read the leveis, as soon as possible. using a separate Hematocti Reacercarc. Place the tube vertically on the char with the bottom edge of the red blood ceils just touching the $C$ percent line. Slide the tube along the char until the top edge of the plasma intersects the 100 percent line. The height of the red ceil layer is then read as a percent of total blood volume.

TOTE: If you cannot read the tudes immedate!y, place them uprght (with red ceils on the borom) io delay mixing of packed red blood ce!ls with plasma. Tubes should be read within $5-10$ minutes.

(20) Record client name anc results on appropria:e sheets, inciuding the cer. form, de-pending on your agency's procedures. If results of the two tubes do not agree to within 2 percentage points, e.g.., $31 \% 34 \%$, repeat entire procedure. If they do agtee to within 2 percentage points, then average the values and record the value as a whole number or as a one half fraction e.z.. 31 and $33 \%$ average to $32 \%$ and $31 \%$, and $32 \%$ average to $31.5 \%$. Caution when using the reader card. read oniy fuil percentage points. DO NOT read half points. Haif points should only be derived from averaging of two rubes. You should never record hemato-crit values in, anything other than whole or half percentage

points.
Line uo ico of

clear licuid with

too line of ehar.

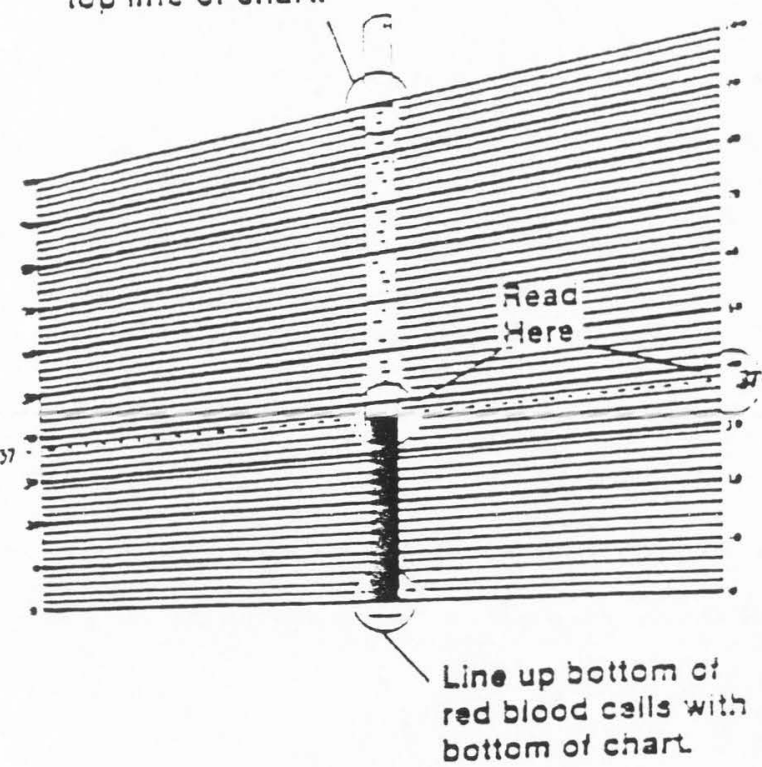

Figure 7. How to Read the Heratocrit 
(21) Also noe and record variaton in plasma color. milky white (indicates fat in piasmat) . ed (indicates hezolysis, or broken red blocd cells usually a techrique probiem); or yellow cange (indicans possibie hepates; clean the wox area and you hands weil) Reter abromaites to the nuteconis

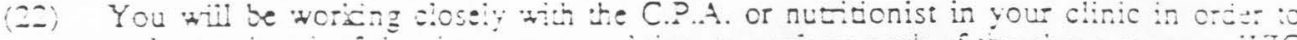
undersiand ach of the above siegs, and then to perion each of the above siegs on ti. citents.

\section{HELPEII HIXTS}

If the client has cold'pale hands, seems nerrous, or you did not get sufficien: blood the nirst time:

(1) Increase biood circulation to the hand by a) having the client open and close their hand th their arm dangling to the side: b) rubbing their hand between your two hands; or citaving the client hold their hand unce: warm watet for a few minutes.

(2) Frick the finger with their 3 mand hand hanging at their side.

(3) "Mils" the upper arm dowa to the hand. DO NOT SQLEEZE TFE FLIGER, as this with fore sssue fluid to come cut and dilute the sample.

(4) If $y$ ou can oriy cbtain one samole, fill the other tube with water, seal, and piace orocsite the sample in the centrifuge to balance the machine.

If Screening a Very Young Child:

(1) Ask the parent to hoid the child on their lap, holding the arms and/or knees firmy A scuiming child can be braced berween the parent's krees. If nesessary, the mother ian brace the child's shoulders zith one arm. ard use the other to oum the child's head toward her.

(2) Explain to the chiid that the sticx will be the only par that will hur Show the child the tuce ard touch the singer with the rute to show that it doesn't hur.

(3) Fave the sijid hold the barcaid and tell tim it will be his, when it's all over.

(4) Fricis yery quichy.

(5) Mixe sure to give the child positive comment

(6) You may choose :o draw a smiley face on the bandaid, make a rabbit with a long bandzid and cotion, cr :ill the chiid to "watch what happens to the magic striw."

1 Fat may be nomal in the plasma if the client has recently eaten (within 6 hours) a highfat meaj. Presence of fat in plaswa following a low-fat meal or on an empty stomaci ray be abromal, and the client fould be refered to hisher beaith car provicer. 


\section{GITDELIVES EOR HEEL STICKS IN WEAVT}

Figure 8. Potocer Positioning For Heei Sicks

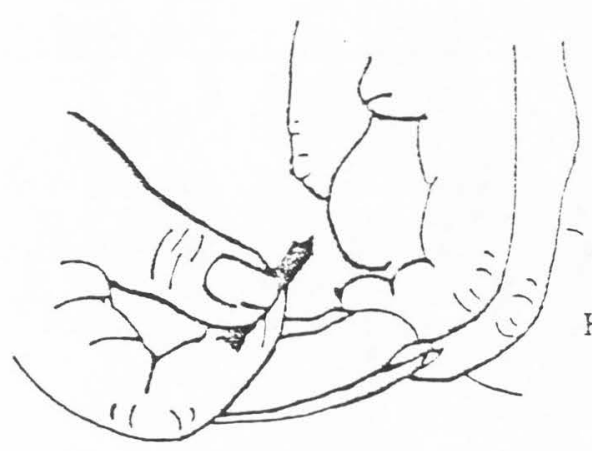

piacs the fore finger around the anic's and the thumb over the arch of the iol
HCLD TEE HEEI GE. I-Y BLT FRVILY

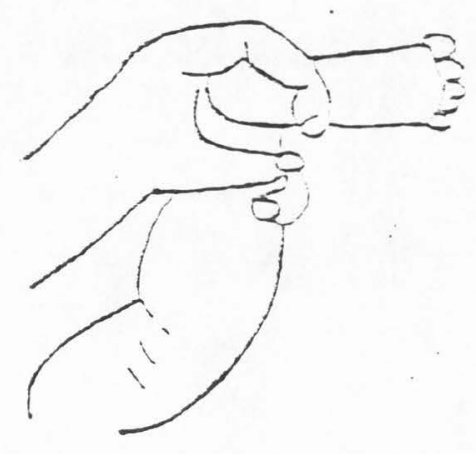

place the fcrefinger over the ath of the foot and the thumo below the punctire site at the anxie

\section{SKN PLXCTRE CF RFALTS}

1. Choose the site (foot that is not eiematous or swoilen).

2. Warm the area for 3 minutes (ircreased blocd tow to the area sevenioid).

3. Froperly cleanse the area (cne of the complications of an inproperiy cleansed area is infection)

4. Wipe ciry (the presence of aiconol will cuicicy hemolyze blood).

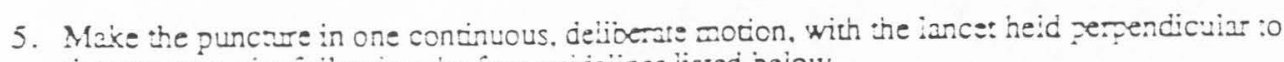
the puncure site following the four guicelines lister below.

6. Wipe ayay first drep (it may be contaminated with tissue fluics).

7. Ease, and reapply pressure of thumb or foreingers as drops of bicod form.

8. Fill two (2) cariliary wibes with blood and proced as with heratocrit instructions for chiicien and adults. 
FOUR GUIDELINES SHOULD BE FOLLOWED WHEN PERFORMING HEEL PUNCTLRES IN NFANTS TO AYOID PUNCTLRING THE HEEL BONE AND POSSIBLE RISK OF OSTEOCHONDRITIS AND SEPSIS

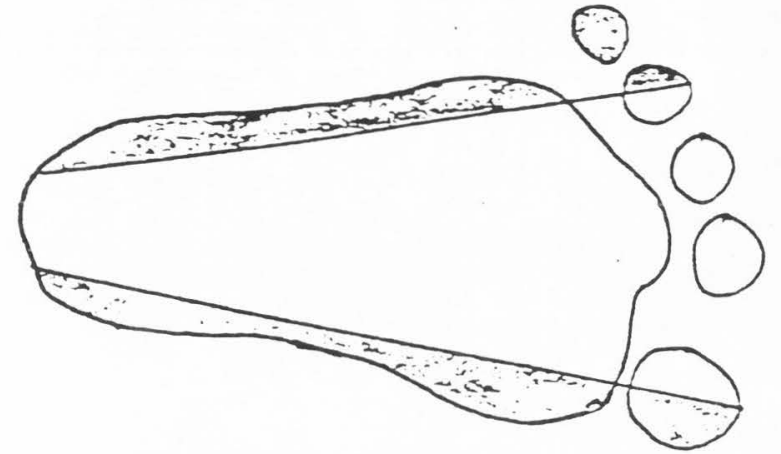

Figure 9. Location for Heel Puncture
1. Punctures should be made on the most medial or lateral portions of the plantar or flat surface of the heel.

2. Punctures should not be made on the posterior curvature of heel...

3. Punctures should not be made deeper than 2.4 millimeters.

4. Punctures should not be made through previous puncture sites because hidden infection may be present.

\section{BESOLVNG POSSIBLE PROBLEMS}

\section{If the Hematocrit Tubes Break During Centrifugation:}

(1) Make sure centrifuge top is fastened down tight and even.

(2) Check gaskets for breaks and clay deposits.

(3) Make sure the tubes are positioned right in the centrifuge.

(4) See if there is glass present in the machine from past breaks and remove it.

\section{If Bloed Soins Out During Centrifugation:}

(1) Check gaskets.

(2) Inspect clay, it may be dirty, dry, etc. Use new clay.

(3) Make sure to twist rubes before removing thern from the clay. Do this twice if necessary.

\section{If Readings on Hematocrit Tubes Differ More Than 28:}

(1) Check finger-stick for leaving alcohol on finger, or squeezing finger too hard (milking).

(2) Check blood in tubes for bubbles. This occurs when there is not a steady flow of blood and the tube is tipped or removed from the finger, allowing air to enter.

(3) See if one tube leaked and the other did not.

(4) Did you leave tubes more than 15 minutes before reading, after centrifuge had siopped spirring? Repeat the test. 
(5) Did you use the READERCARD correctly on both readings? a) the zero line should be aligned with the point at which the red blood cells rest against the top of the clay); $b$, the 100 f line should be aligned with the top of the piasma. Make sure you are :aoking direstly down at the tube when you decide what the percent of red bicod cells is looking a: an angle may yary your reading 2-5\%.

(6) Are plasma portions fainlly red? If so, hemolysis (where red blocd cells break up ard eak into the plasma) occurred. This is usuaily a technique probien.

\section{SOLRCES DE ERROB}

(1) Excess squeezing or pressure of ninger or toe. This causes tissue fluid to come out and may dilute the sample.

(2) Failure to wipe off the first drop of biooc. The first drop of blood may be wixed ith alcohol or may contain broken red blood cells and extra plasma.

(3) Centrifuge out of calibration. This affects speed and time. Usually results in falsely hight hematocrit

(4) Rubbing fingers over the seaiant to fill in the holes. This leaves oil in the sealant and zan result in a pocr seal and leakage of red blood ceills.

(5) Wom rubber gasket of centifuge. This may resuit in breakage of tudes and red biocd ceil leakage.

(6) Air butbles in sampie (that do not "spin out" when centrifuged; small air spaces wiil probably spin out and not aftect the hematocrit).

(7) Over or uncer filling tubes.

(8) Not balancing tuobs in the centrifuge.

(9) Not running centrifuge for correct duration. Know maximum packing time of the centrifuge in your clinic. (See Nutrition Assessment \& Equipment Manual to detertine maximum pacieing ine.)

(10) Failure to record names and centrifuge channels when spinning blood samples of more than one client simultaneously. Result tray be incorrectly assigned.

(11) Reading the sample incorresly. Plasma layer strould not be included in the reacing, etc.

(12) Recording errors. Common exrors include recording hematocrit results in the hemog!obin box on the CERT form or failing to record a decimal value.

COTE: Hernoglooin vaiues (if used) are to be reconded to 1 decimal posinon. 


\section{ACTIVITY 3}

\section{COMPARING TEST RESULTS TO STANDARDS}

\section{OBIECTIVES}

\section{Knowledge}

(1) Clinical Assistant (CA) will be able to list WIC Program standards used to define nomal and abnomal hematocrit values.

(2) CA will be able to describe what the hercatocrit test tells us.

\section{Aoplication}

(1) CA will explain the purpose and procedure of the hematocrit test to eight applicants/ participants (or their parents) without error: two infants, two children, two pregnant women, two lactating women.

(2) CA will demonstrate recommended techniques for performing the hematocrit test for these eight applicants/participants (if a job responsibility) (including local health deparment's policy on handling blood).

(3) CA will deternine if these eight applicants/participants are at risk for anemia

(4) CA will accurately explain results of the hematocrit test to these eight applicants/ participants.

\section{MATERIALS AND SUPPLIES}

(1) Utah State WIC Program Nutritional Assessment and Equipment Manual

(2) Utah State Plan of Program Operations and Administration Section B (P \& P manual)

(3) Utah State WIC Protocols on Anemia and Dietary Iron

\section{GLOSSARY}

NHANES II: The Second National Health and Nutrition Examination Survey, conducted in $1977-78$ by the U.S. Public Health Service within the Deparment of Health and Human Services. The purpose of the survey was to assess the health and nutrient intakes of a population sample of 20,000 people, on the basis of a 24-hour dietary recall and extensive physical, anthropometric and biochemical analyses of health status.

Standards: Criteria used to determine the normality, adequacy, or accuracy of a value. 


\section{EILIBUULTYY CRIEERLA}

The Utah State WIC Program utilizes the hematocrit yalue as an essencial component oi certificaton, primarily to detemine progran eifgivility. It provides a valuable tricicator for ure ciben's risx of iron deñciency anemia and a basis for nutrition counseling.

The Lin WIC Program has established cut of levels for interpreting herators: ind hemogiooin vaives based on the centers for Disease Control's (CDC) criteria for aremia in. chilten and womer. adjusted to clinic aidrude (see Tables 1 \& 2 on pp 3 A.C, CDCS criera tere published in the Morbidity and Mordiry Weekly Reporn June 9, 1989 , portons of which are exceppled beiow.

The reierence vaives estabilished by CDC for children and nonpregnant worxen are derived from the most current narionally re jresenutive sample - the second Viational Health ard Nuticion Examination survey, 1976-1980 (NFALIES IT). Because representajve data are not yet availabie for pregnant women, anemia reierence $v$ values are based on the tros: curent clinical studies availabie.

\section{Anemia Cutoffs for Children}

Because hematologic vaiues change as chilicen grow older, it is necessary to use agespecinic criteria for diagnosing anemia in chiliten. The CDC hemoglobin and hematocrit cutoffs revresent the ate-specific fifth percencle values for "healthy persons" from AHA.TES I (exciuding persons who were lixely to have iron deficiency based on multople iron biochemical measures).

The Utah Program has acopted CDCs hematoctit cutoffs for iniants and chiddren, acjusted for clinic aitude. Intants and chilcren with hemoglooin or hematccrit values less than the figures given below and at risk for anemia and are eligible for WIC.

\section{Aisuce Far}

Hematcocit $\sigma_{0}$

6 mos-23 mos

$2-5$ years of age

$$
0-2099
$$

$$
3000-4990
$$

$5000-5999$

7000 or more

$33 \%$
$34 \%$$\quad 34 \%$

$$
\begin{aligned}
& 35 \% \\
& 36 \%
\end{aligned}
$$

$36 \%$

$37 \%$

Eematocit $m g^{\circ}$

6 mos-23 mos

2-5 years of age

$11.0 \mathrm{gm} \quad 11.3 \mathrm{gm}$

$11.7 \mathrm{gm}$

$11.9 \mathrm{gm}$

$12.0 \mathrm{gm}$

11.2

$11.5 \mathrm{gm}$

$12.2 \mathrm{gm}$

\section{Anemia Cutorfs During Pragnancy}

During a norwal pregnancy, 3 woman's hematologic values change substantially (discussed later in this module). For women with adequate iron nutrition, $\mathrm{Hb}$ and $\mathrm{HCT}$ values star, to decline during the early part of the first trimester, reach a low point near the end of the second trimester, then gradually rise during the third trimester. Because of the change of $\mathrm{Hb}$ and HCT during pregnancy, anemia must be characterized according to the specific stage of preznancy. 
CDC has established ane-ia cutofis for each of the three trimesiers of pregnancy, based on data from four European studies of healthy ron supolemented women. To estabiish critena for eligibility. The Utah. WIC Program adjusted CDC's figures for the second and third timesters of pregnancy and for nonpregnant women to various aititude levels. Lati's eligibility cutoff for the fist rimester are based on the fifth percentile of nomal at 8 in eess gesuzion which varies sighty from CDCs first timester yalue. (From Dieary Intake and

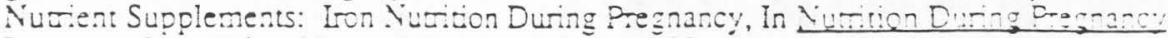
Institute of Medicine, Aational Academy Fess, 10 co.

A woman qualifies for MC on the basis of anemia if her hemataiogic values are less than the following:

\begin{tabular}{|c|c|c|c|c|}
\hline \multirow[b]{2}{*}{ Eemaroc-ic } & \multicolumn{3}{|c|}{ Altude Fre: } & \multirow[b]{2}{*}{ 7000 or trore } \\
\hline & $0-2909$ & $3000-4999$ & $5000-6900$ & \\
\hline Ist Trimesier & $35 \%$ & $36 \%$ & $37 \%$ & $38 \%$ \\
\hline 2nd Trimester & 3250 & $33 \%$ & $34 C_{0}$ & $35 \%$ \\
\hline Brd Trimester & $33 \%$ & $34 \%$ & $35 \%$ & $36 \%$ \\
\hline $\begin{array}{l}\text { Breasteeding or } \\
\text { Postpartum }\end{array}$ & $36 \%$ & $37 \%$ & $38 \%$ & $30 \%$ \\
\hline \multicolumn{5}{|l|}{ Hemaicert mger } \\
\hline 1st Tnmester & $11.5 g m$ & $11.8 \mathrm{gm}$ & $12.2 \mathrm{gm}$ & $12.5 \mathrm{gm}$ \\
\hline 2nd Trimester & $10.5 \mathrm{gm}$ & $10.8 \mathrm{gm}$ & $11.2 \mathrm{gm}$ & $11.5 \mathrm{gm}$ \\
\hline 3rd Trimester & $11.0 \mathrm{gm}$ & $11.3 \mathrm{gm}$ & $11.7 \mathrm{gm}$ & $12.0 \mathrm{gm}$ \\
\hline $\begin{array}{l}\text { Breasteeding or } \\
\text { Posparim }\end{array}$ & $12.0 \mathrm{gm}$ & $12.3 \mathrm{gm}$ & $12.7 \mathrm{gm}$ & $13.0 \mathrm{~g} \mathrm{~m}$ \\
\hline
\end{tabular}

Ltah's WIC eligibility cut off for infants and chilcren represent a level where at leas: haif ct the infants and chiicren who cualify for a low hematocrit will increase their hematocrit values during a six month cerfication period. Tnis increase indicates that iron stores in the body were low, and the low hematocnt was most likely due to an inadequate intake of dietary iron. Please note that WIC eligioulity criteria for a low hematocrit only suggests thut the client is at risk for having or developing iron deñciency anemia. WIC clinic procedures are screening :ests oniy, and do not allow one to make a diagnosis of iron deficiency anemia. Fematoctit values in the population are nomally distributed. A low hematocit value may be normal for some peopie. The low hematocrit vaiue means that the person has a greater chance of iron deficiency anemia. However, all cilients meering the low hematocrit criteria should be counseied according to the anemia and dietary protocols. If a low hematocrit does not respond to increased die:ary iron, the client shouic receive further dietary assessment and counseling and perhaps medical referral.

STOP HERE and read the Litah State WIC Protocols on Anemia and Dietary Iron. (Subject: Iron-Women, Infants \& Children. Subject: Anemia, Iron Deficiency - Infant and Children) 
TABLE 5. THE CDCNON-PREGNANT AND PRENATAL HEMATOLQGICAL CUT-FFS BY TRIMESTER

$\begin{array}{lcc}\text { Starus } & \text { Hgb }\left(g m \sigma_{0}\right) & \text { Hc: }\left(\tau_{c}\right) \\ \text { Non-pregnant } & <12.0 & <36 \\ \text { 1st trimeste: } & <11.0 & <33 \\ \text { 2nd trimeste: } & <10.5 & <32 \\ \text { 3rd trimester } & <11.0 & <33\end{array}$

\section{Altitude}

The body normally adjusts to changes in altirude by increasing hemoglobin and hematocrit values. This is because the lower oxygen concentration in the air at higher altitudes stimulates the production of red blood ceils. In other works, when there is less oxygen available to a person, she/he needs more red blood cells and hemoglobin to camy that oxygen to the cells of the body. This means that a low hematocrit is more likely to indicate anemia for a person living at a high altitude than at sea level. In other words, we expect to see higher hematocrits in peopie living at high elevations.

In FY 1991, Utah began adjusting eligibility criteria based on clinic altitude. These adjustments are applied to Table I on p 3A.

\section{TABLE 6. THE REVISED CDC ALTTTUDE ADISSTMENTS FOR HE.LATOLOGIC.AL INTERPRET ATION.}

\section{Altirude $(\mathrm{ft})$}

$$
\begin{array}{r}
0-2999 \\
3000-4999 \\
5000-6999 \\
7000+
\end{array}
$$

$\mathrm{Hgb}(\operatorname{gm} \%)$

$$
\begin{array}{r}
0.0 \\
+0.3 \\
+0.7 \\
+1.0
\end{array}
$$

$$
\begin{array}{r}
\text { Hot }(\sigma) \\
0.0 \\
+1.0 \\
+2.0 \\
+3.0
\end{array}
$$

Some clinics serve participants who actually live in a different area (e.g. Teen Mom, PKU Clinics). Please note that the altitude level used to determine eligibility for a participant is that given in Table II (pp 3B-C) for the clinic area in which he/she lives. For example, if a client lives in Summit County and attends the Teen Mom Clinic, use the altiude level given for Summit County to determine WIC eligibility. 


\section{Smoking}

Smoking aiso resuits in higher hematortis. This effect similar :o that at hign altudes. The body increases red biood cell production because the cells need to receive more oxygen. The intuence of smoking on hemoglobin and hematccti leve:s has aiso been adcressed by CDC as presented : the following table.

Table 7

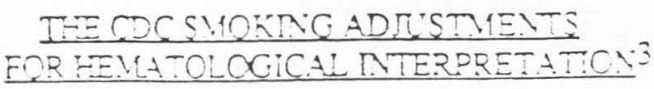

\begin{tabular}{|c|c|c|}
\hline & Hgsj(gme) & $\underline{E(c:(\tau))}$ \\
\hline Non-smoker & 0.0 & 0.0 \\
\hline $\begin{array}{l}1 / 2-1 \text { pack } \\
\text { per day smoker }\end{array}$ & +0.3 & +1.0 \\
\hline $\begin{array}{l}1 \text { - } 2 \text { paci per } \\
\text { day smoker }\end{array}$ & +0.5 & $\div 1.5$ \\
\hline $\begin{array}{l}2+\text { pack per } \\
\text { day smoker }\end{array}$ & $\div 0.7$ & +2.0 \\
\hline
\end{tabular}

Information presented in the above table can be applied to assessment ard counseling recommendations regarding the cilent's hematological status and not for eligibiity determination.

For example, a pregnant woman who smokes 1 pack per day (ppd) and has a $35 \%$ hematocti :s at higher risk for aremia than a pregnant toman with a $35 \%$ hematocit who does not smoke. When the hematocrit value of the smoker is adjusted. it can be interpreted as 33.5, (because the 1 pod smoker's hematccrit is 1.5 percent higher than it would be if she didn't smoke). She is, therefore. actuaily more anemic than is apparent.

\section{SUMMARY}

Because it is more sensitive to the fac:ors influencing hematocrit values, the information presented here is more approoriate for counseling purposes than the WIC eligibiility criteria. You will notice that the hematocrit tends to change as a child ages, and hematocrit decteases as a pregnancy progesses. Altitude influences hematocrit values in any case. As altitude or smoking increases. so does the observed hematoctit value. There is no guidance given on the additive effect of smoking and altiude at this point.

\section{LIIITATIONS}

Please note that WIC eligibility criteria for a low hematocrit oniy suggest that the client is at risk for having or developing iron deficiency anemia. However, all clients meeting the low hematccrit criteria should be icunseled according to the anemia and dietary protocols.

3 Increase in blood value associated with smoking. 
APPENDIX D: Ferritin Double Antibody Procedure (Permission to reprint granted orally by Kristine Guzman, March 15, 1993) 


\section{FERRITIN}

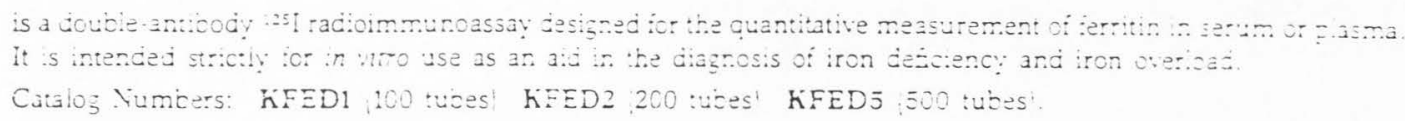

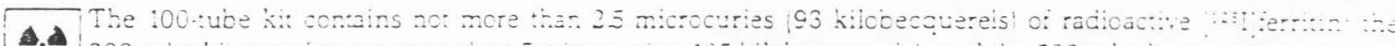

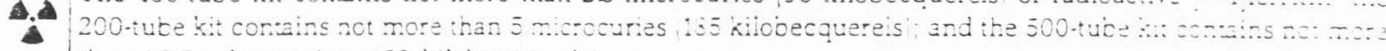
than 125 microcuries $\$ 63$ kiboeccuere:s

\section{Summary and Explanation of the Test}

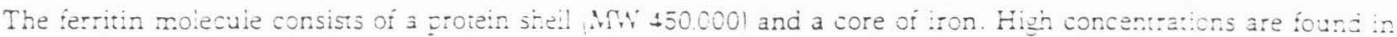
Liver cells and in erythrocre recyling centers $R E$ cellst of the liver, spleen and bone martow. In these tissues tertith serves as the bocys principal storenouse for zurpius iron, protecting against the toxic effects of excess and maintaining a readily mobilized reserie tor enthropolesis. Ferith is aiso present in human piasma wreere is concentraticn is normally a satistactor: index of bocy iron stores as measured by quantitative phlebotomy ircn jesorztion studies Lver biopsy and the mictoscopic examinaticn of bone martow aspirates tor stainable iron depos:ts

This relat:onship with iron stores can be seen in the pattern ct serum fertitin vaiues under a varten of physicicgical and pathological conditions. For ncividuals $\mathrm{n}$ zood health the median level, slightly elerated at bir:n. reaches a low of about $30 \mathrm{gg} \mathrm{mL}$ at six months. with the incease to acuit levels taking place after puberty. In máes. the redian

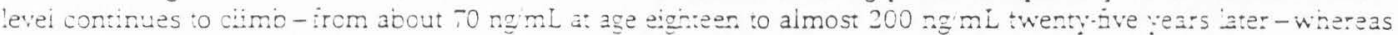
in Emales there s a plateau at $3 \equiv$ or $40 \mathrm{ngmi}$ througrout the childbearing years and a sharp lncease thereatter. For aduits in good heaith the serum ferritn evel tas been ariousiy epored :o range trom $20=10$ up to $300=$

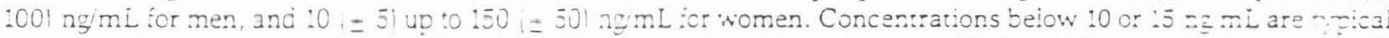

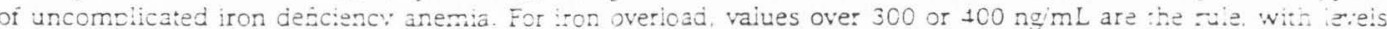
in the 1000 - $5000 \mathrm{ngmi}$ ange common :n fullblown cases of hemocnromatosis.

Clinical acplications of the serum ertitin assay have been exensivelv reviewed. It has important :o.es :o piay in the diagnosis of iron deficency and excess, and in the management of conditions and treatments posin a threat to ron balance. It has proved a valuable aid in discriminating ircn dejciency anemia trom anemias due :0 cine: causes and in exposing the disapcestance of iron reser:es before the crse: of anemia. Serial ceterminations have been emploved to monitor noninvasively, the progressive erosion of iron stores during pregnancy and in patients undergoing regular diaivsis treatment. Both in company with other coutine blood tests and on its own, the ferritin assay has been used to screen for iron deEciency in a variety of populations. ranging from blood donors to unselected hospital patients. It is also valuable in screening for frecirthotic temochromarosis and other torms of iron overioad and in rontroring patients who are receiving regular blood transtusions or iron replacement therapy and thus in danger of accumulattng excessive iron stores.

Although iron depietion appears to be the only condition associated with reductions in the serum ferritin level in creases are observed not only in the presence of increased iron stores but also in several other situations, inciuding Liver disorciers. inflammaton conditions, leukemia. Hodgkin's disease and cerain other malignancies. Here, increased levels may reflect the escape of fertitin from damaged liver ceils, impaired clearance of ferritin from the plasma sunthesis of territin ly tumor vells, or ar. expansicn of the iron storage comparment induced by ineffecure erphrop.usis. inilammation tends to rase the ferritin level, while lowering the serum iron concentration, by stimuiating increased ferritin production in RE cells, using iron that would otherwise be released to plasma transport proteins. In this condition and others, the correlation between iron stores and circulating ferritin continues to hold, but with a shift towards higher values - necessitating an adjustment in the normal range if the ferritin assay is still to be used Es disting.:- hing normal from depleted iron iserves 
2. Double Anubody Fermin

\section{Principle of the Procedure}

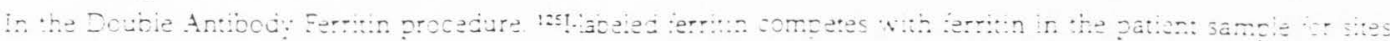

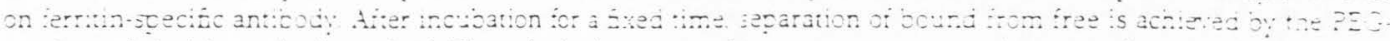

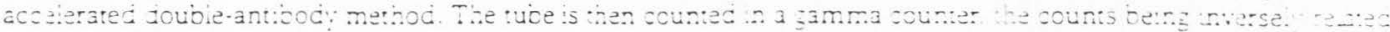
to the amount of tertiti present in the patient sample

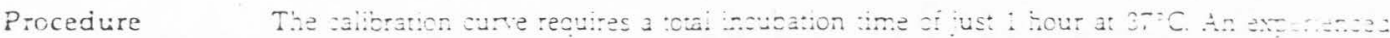

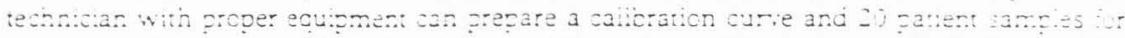

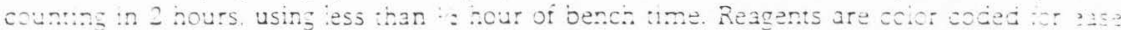
ot adiwon. The assay can aiso be pertimed at room emperature using a 3 tour ncucanon.

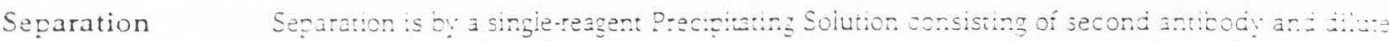
PEG. This method has been shown to yed more consisten and eproductele tesults than ather

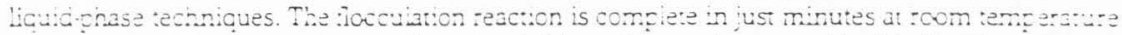

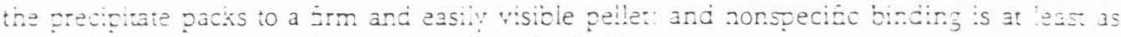
low as in separations emcioving second antibody aione

Data Reduction Conventional RIt technicues of calcutation and quaity control are appicahie. The assay has

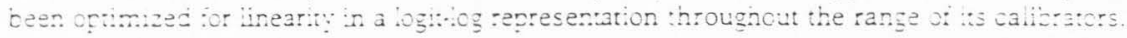

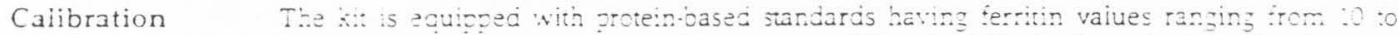
:000 ngmL. The assay is stuncardized in erms of the Word Teaith Organizations First in:erna. tional. Sundard for Ferritin buman 'iver: for Immunoassay number 80,602. The caitorators are supplied in Lquid form. ready to use.

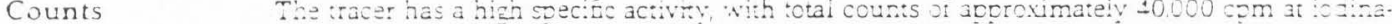
t:on Muxmum bincing is approximatey $45 \%$. Nonscectfic binding and patien blanss are nezisitie.

Precision Cis are low and uniform and no end-ot:un effect has been coserved in assays invoing up to 250 iubes. The procedure can derec: as little as $6 \mathrm{gg} \mathrm{mL}$.

Specificity The antiserum is highiy soectec tor terwh with "ery low crossreactivity to other compounds that might be present in pattent samples. Veither buirubin nor hemolysis has any ufect on the assay

Accurac: Extensive recover experments have shown that the assay is accurate over a broad ange of vaiues. its accuracy has jeen further verifed in a pat:ent comparison stucy against another weil-estuolished erritn :adicimmuroassay

Expected Vaiues The recommenced normai ranges of $: \mathrm{t}-120 \mathrm{ng} \mathrm{mL}$ for women and $25-400 \mathrm{ngmL}$ icr men are in sucstantial agreement with nocern :eterence methods.

\section{Specimen Collection}

The patient need not be fastinz, and no soecial orenarations are necessan: Collect blood by venipuncture in:o pian. heparinized or EDTA tubes, avoiding hemolvsis and noting the time of coilect:cn, and separate the serum or plasma from the ceils. The procedure calls for $100 \mu \mathrm{L}$ of serum per assay tube Lipemic samples and sample contaminated with radioactivity are unsuitable for use.

The samples may be stored retrigerated at $2-8^{\circ} \mathrm{C}$ for seven days or for longer periods of time if frozen at $-20^{\circ} \mathrm{C}$ But be sure to aliquot the sample before freezing to avoid repeated freeze thaw cycles. Before assay, allow the samples to come to room temperature and mix by gentle swirling or inversion. 


\section{Materials Supplied-Initial Preparation}

- Precautions Before opening the kit, review the paragraphs on safety: printed on the inside front cover. as they relate to the sate handling and disposal of reagents containing radioactivity human serum-derived material and sodium azide

1 Ferritin Antiserum

FED1, 5FED $1^{\dagger}$ One vial (two vials') of lyophilized ferritin antiserum. Reconstitute each vial by adding $10 \mathrm{~mL}(50 \mathrm{~mL} \dagger$ ) distilled water. Store refrigerated: stable at $2-8^{\circ} \mathrm{C}$ for at least 30 days after reconstitution. Color: biue.

2 [125I] Ferritin

FED2 One vial (two vials", five vials $\uparrow$ ) containing $10 \mathrm{~mL}$ of iodinated ferritin in liquid form, reach. to use. Store refrigerated stable at $2-8^{\circ} \mathrm{C}$ for at least 30 days after opening, or until the expiration date marked on the vial. Do not freeze Color: red.

3 Ferritin Calibrators

FED3-9

One set (two sets ${ }^{\dagger}$ ) of seven vials, labeled $A$ through $G$, of ferritin calibrators in a protein base. The zero calibrato: viai A contains $6.0 \mathrm{~mL}$; the remaining vials $B$ through $G$ each contain $2.0 \mathrm{~mL}$. Store refrigerated: stable at $2-8^{\circ} \mathrm{C}$ for at least 30 days after opening

The calibrators contain $0,10,25,100,200,500$ and 1000 nanograms of ferritin per milliliter $(\mathrm{ng} / \mathrm{mL})$ in terms of the WHO 1 st IS $80 / 602$. Intermediate calibration points can be obtained by mixing calibrators in suitable proportions.

4 Precipitating Solution

NF6, 5NF6+

One vial (two vials* +) of Precipitating Solution, containing goat anti-rabbit gamma globulin (GARGG) and dilute polyethylene glycol (PEG) in saline. The Precipitating Solution is supplied in liquid form, ready to use. Each vial contains $110 \mathrm{~mL}\left(260 \mathrm{~mL}+1\right.$. Store refrigerated: stable at $2-8^{\circ} \mathrm{C}$ for at least 30 days after opening, or until the expiration date marked on the vial. Since a fine precipitate may form after refrigeration, the Precipitating Solution should be thoroughly mixed before use, without foaming.

- Pertains to the 200-tube KFED2 kit.

$\dagger$ Pertains to the 500-tube KFED5 kit.

\section{Materials Required But Not Provided}

- Gamma counter

- Centrifuge - preferably refrigerated and capable of $3000 \times g$

Reagent Preparation:

- Distilled or deionized water

- Pipets: $10 \mathrm{~mL}$

Radioimmunoassay:

- Plain 12:75mm polvpropylene tube - available from DPC

- Micropipetio. 10r $\mu \mathrm{L}$ and $15 \mathrm{~mL}$. Fur the $100, \mu \mathrm{L}$ reagent additions a reliable repeating dispenses sichiryn, Eppendorf or equivalent) is recommended. A syringe-style dispenser (Nichiryo, Eppendorf or equivalent) accurate to within $\pm 0.1 \mathrm{~mL}$ is recommended for the $1.0 \mathrm{~mL}$ addition of Precipitating Solution.

- Vortex mixer

fortemperature

Foam decanting rack-available from DPC

- A bi-level protein haser' set of ferritin controls is available from DPC (catalog number: FECO1-2). 
$4 \cdot$ Double Antbody Ferritin

\section{Radioimmunoassay Procedure}

All components except the Precipitating Solution must be at room terperature prior to use

1 Label eighteen tubes in duplicate: T (total counts), NSB (nonspecific binding), A (maximum binding) and B through G. Label additional tubes, also in duplicate, for serum samples and controls.

\begin{tabular}{cr} 
Calibrator & $\mathrm{ng} / \mathrm{mL}$ \\
\hline A $(\mathrm{MB})$ & 0 \\
B & 10 \\
C & 25 \\
D & 100 \\
E & 200 \\
F & 500 \\
G & 1000 \\
\hline
\end{tabular}

2 Pipet $100 \mu \mathrm{L}$ of the zero calibrator $A$ into the NSB and A tubes, and $100 \mu \mathrm{L}$ of each of the remaining calibrators $\mathrm{B}$ through $\mathrm{G}$ into correspondingly labeled tubes. Pipet $100 \mu \mathrm{L}$ of each patient sample (serum or plasma) and each control into the tubes prepared. Hign samples should be diluted with the zero calibratcr.

3 Add $100 \mu \mathrm{L}$ of [125I] Ferritin to all tubes.

A repeating dispenser of the Nichiro or Eppendorf npe is recommended for this step and for the addition of antiserum at step 4. Remove the $T$ tubes for counting at step 9; they require no furher processing. All tubes should be red.

4 Add $100 \mu \mathrm{L}$ of Ferritin Antiserum to all tubes except the NSB and T tubes. Vortex.

All tubes except the NSB and T tubes should be purple. Mixcnz should cause a visible vortex in the tubes. Muitiple tube rack mixers bave been found unsuitable.

5 Incubate for 1 hour at $37^{\circ} \mathrm{C}$

The assay may also be performed using a 3-hour, room-temperature incubation

6 Add $1.0 \mathrm{~mL}$ of well-mixed, cold Precipitating Solution to all tubes. Vortex.

The Precipitatung Solution should be thoroughlv mixed just prior to use. For the $1.0 \mathrm{~mL}$ reagent addition a repeating dispenser of the Niciriryo or Eppendori type may be employed. All tubes except the T tubes should be blue.

7 Centrifuge for 15 minutes at $3000 \times g$.

The use of a refrigerated centrifuge is desirable but nor essential.

8 Decant (or aspirate) the supernatant, retaining the precipitate for counting.

Using a foam decanting rack, gently tap the tuibes an absorben paper, and blot the rims, to remove residual droplets.

9 Count each tube for 1 minute 
Double Antibody Ferntin -5

\section{Calculation of Results}

To calculate ferrin concentrations from a logit-log representation of the calibration curve, frst calculate for each pair of tubes the average NSB-corrected counts per minute.

$$
\text { Net Counts = Average CPM minus Average NSB CP.M }
$$

Then determine the binding of each pair of tubes as a percent of maximum binding (MB), with the NSB-corrected counts of the A tubes taken as $100 \%$ :

$$
\text { Percent Bound }=\frac{\text { Net Counts }}{\text { Net } 11 B \text { Counts }} \times 100
$$

Using the logit-log graph paper provided with the kit, plot Percent Bound on the vertical axis against Concentration on the horizontal axis for each of the calibrators B through $G$, and draw a straight line approximating the path of these six points. Ferritin concentrations for the unknowns may then be estimated from the line by interpolation. Although other approaches are acceptable, data reduction by the logit-log method just described has certain advantages in this context-for example, in allowing easier recognition of deviant calibration points - since the Double Antibody Ferritin procedure has been optimized for linearity in that representation.

Example: The figures tabulated below are for illustration only and should not be used to calculate results from

\begin{tabular}{|c|c|c|c|c|c|c|}
\hline Tube & $\begin{array}{c}\text { Duplicate } \\
\text { CPMA }\end{array}$ & $\begin{array}{c}\text { Average } \\
\text { CPM }\end{array}$ & $\begin{array}{c}\text { Net } \\
\text { CPM }\end{array}$ & $\begin{array}{l}\text { Percent } \\
\text { Bound }\end{array}$ & $\begin{array}{c}\text { Ferritin } \\
n g / \mathrm{mL}\end{array}$ & \\
\hline $\mathrm{T}$ & $\begin{array}{l}37,6 \div 8 \\
37,567\end{array}$ & 37,658 & & & & \\
\hline NSB & $\begin{array}{l}915 \\
915\end{array}$ & 917 & 0 & & & - \\
\hline$A(M B)$ & $\begin{array}{l}17.873 \\
17.81: \\
15.816\end{array}$ & $17,8 \div 2$ & 16,925 & $100.0 \%$ & 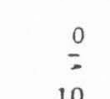 & \\
\hline B & 16,193 & 16.005 & 15,088 & $89.1 \%$ & 10 & \\
\hline C & $\begin{array}{l}14.252 \\
14.230\end{array}$ & 14,241 & 13,324 & $78.7 \%$ & 25 & \\
\hline D & $\begin{array}{l}8,908 \\
9,145\end{array}$ & 9.073 & 8,156 & $48.2 \%$ & 100 & \\
\hline$E$ & $\begin{array}{l}6,410 \\
6,469\end{array}$ & 6,440 & 5,523 & $32.6 \%$ & 200 & \\
\hline F & $\begin{array}{l}3,851 \\
3,827\end{array}$ & 3,839 & 2,922 & $17.3 \%$ & 500 & • \\
\hline G & $\begin{array}{l}2,116 \\
2,418\end{array}$ & 2,432 & 1,515 & $9.0 \%$ & 1000 & \\
\hline Unknowns: & & & & , & & \\
\hline $\mathrm{X} 1$ & $\begin{array}{l}12,204 \\
12,234\end{array}$ & 12.219 & 11,302 & 66.855 & 45 & - \\
\hline $\mathrm{X} 2$ & $\begin{array}{l}7,321 \\
7,233 \\
4,356\end{array}$ & 7,277 & 6.360 & $37.6 \%$ & 159 & \\
\hline $\mathrm{x} 3$ & $\begin{array}{r}4,356 \\
4,103 \\
\end{array}$ & 4,230 & 3,313 & $19.6 \%$ & 407 & \\
\hline
\end{tabular}
another assay.

Quality Control Parameters: 2ros Inte ceft $=395 \mathrm{ng}^{\prime} \mathrm{mi}$

$50 \%$ Intcrsent $=94 \mathrm{ng} / \mathrm{mL}$

$.80 \%$ Intercept $=22 \mathrm{ng} / \mathrm{mL}$ 
6. Double Anturiy Fentur

\section{Quality Control}

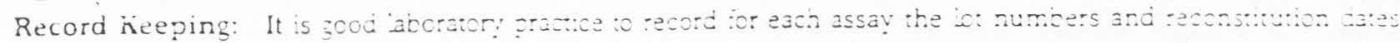
of the components used.

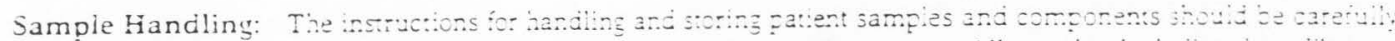

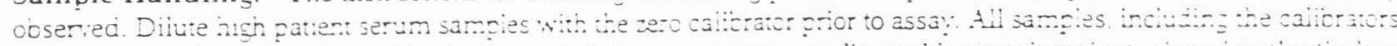

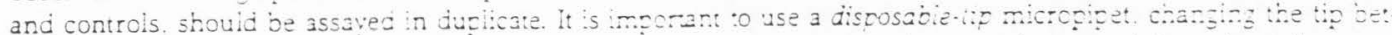
ween samples. in order to avoid carryover contaminaticn. Pairs of control tubes may be spaced throujtout the assal: to help verify the absence of signifcan drift lnspect the resuits for agreement within tube pairs and bike care to avord carrover from sample :o sample

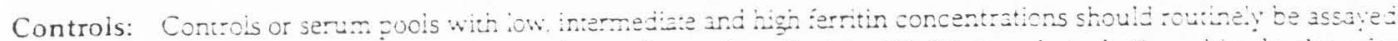
as unkrowns, and the results chared from dav to dav as descriced in J.O. Westgard et al, A rultirule chart ior quality control" Cinica! Chemistr: 27 19911 493-501. Se aiso Sianainavian joumal of Cinical and Laborator: In.

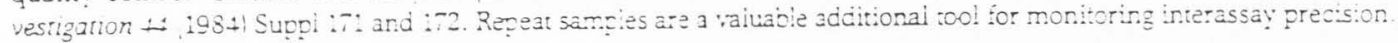

Centrifugation: The procedure cails for centrituging at $3000 \times$ g for 15 minutes. A nigh-speed retrgerated cen. trifuge is desirable jut no: essential. Use the cormulas below to calculate the acceleration of your centrifuge at a given speed, or the soeed in reviutions per minute reguired to achire a desired $g$ force.

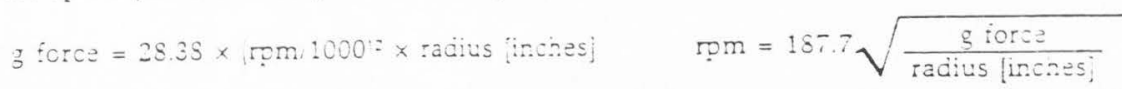

Data Reduction: It is zood practice to constuct a graph of the calibration curve as a visual check on the appropriateness of the transiormation used, even where the calculation of results is bandled by computer. See turther S.Z. Davis et ai "Racioimmunoassay data processing with a smail programmable calculator" Joumai of 'mmunoasiä i

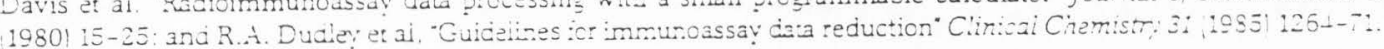

Q. C. Parameters: We recommend kegning wack of these percrmance measures:

- $T=$ Total Counts las counts per minute:

- फNSB $=100 \times$ Average NSB Counts - Totai Counts

- $5 \mathrm{MB}=100 \times[$ Average $\mathrm{MB}$ Counts minus Average NSB Coun:s! - Total Coun:s!

And the 20.50 and 30 percent "intercerts.' where

- $20 \%$ = Fertin Concentration at 20 ?ercent 3ouzd. $2: 0$

\section{Performance Characteristics}

in the sections below ferritin resuits are expressed as nanograms of ferritin per mililiter (ng/mLi. The assay has been stancardized in terms of the Worid Heaith Organizations First Internationai Standard for Fertitin for Immunoassay: number $30 / 602$.

\section{Sensitivity}

Forty zero calibrator (maximum bindingl tuces were processed in a single assay, along with a set of nonzero calibraters and controis. Mean and standard deviation were calculated for the counts per minute of the fory: zero tubes. Then.

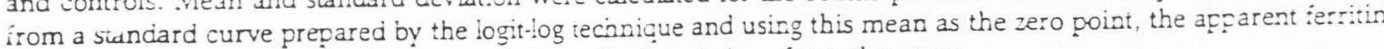
concentration was determined at increasing standard deviations from the mean.

\begin{tabular}{|c|c|c|c|c|}
\hline $\begin{array}{l}\text { Mean } \pm \text { SD of } \\
40 \mathrm{MB} \text { tubes }\end{array}$ & Mean minus & $5 \mathrm{~B} / \mathrm{B}_{3}$ & $\begin{array}{c}\text { Apparent } \\
\text { Concentration }\end{array}$ & $\begin{array}{l}\text { Approximate } \\
\text { Sensitivity }\end{array}$ \\
\hline $14.811 \pm 269$ & $\begin{array}{l}1 S D \\
2 S D \\
3 S D\end{array}$ & $\begin{array}{l}03.25 \\
06.45 \\
91.675\end{array}$ & $\begin{array}{l}1.3 \\
3.9 \\
6.2\end{array}$ & $6 \mathrm{ng} / \mathrm{mL}$ \\
\hline
\end{tabular}

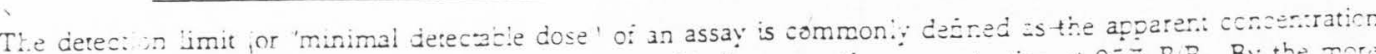
two standaru deviations jeiow the counts at maxmum bir.ting or as the concentration at $95 \% \mathrm{~B}$ B. By the more conservative dejinition, the Double Antibody Ferritin assay has a detection limit of approximately $6 \mathrm{ng} \mathrm{mL}$. 


\section{Precision}

The reliacility of the Dousle Anticody Ferritin procedure was assessed by evamining its reprocuctifity on samoles seleced to represen: a ange of ferritin leveis.

Intraassay: Statistics were calculated tor each of inree sampes from the results at iventwo pairs of tuces in a singie assay:

\begin{tabular}{cccc} 
Samse & Mean & s. & C : \\
\hline 2 & 12 & 0.9 & $7.5=3$ \\
2 & 39 & 1.3 & $45=3$ \\
3 & 130 & 3.5 & 2.7 \\
\hline
\end{tabular}

Interassay: Statistics were calculated for each of Eve same.es trom the results of pairs of tubes in $n$ diferent assays.

\begin{tabular}{ccccc} 
Samole & Mean & 52 & CV & 7 \\
\hline 1 & 13 & 1.4 & 10.85 & 51 \\
2 & 43 & 2.4 & 5.65 & 51 \\
3 & $13 !$ & $5 .-$ & 4.45 & 32 \\
4 & 143 & 5.4 & $4.5 \%$ & 50 \\
5 & 325 & $22:$ & 6.75 & 35 \\
\hline
\end{tabular}

\section{Kinetics}

To determine the efect of employing incucation times other than 1 bour, as specined on page 4 , assavs were set up in paralle! using incubations of 30 minutes, 1,2 and 3 hours. all at $37^{\circ} \mathrm{C}$. Various quaily control performance measures were monitored, inciuding: conspeciec binding and maxmum binding percent of total counts!; the correiation coeffcient rhol of the logit $\log$ line; the assay $\mathrm{Cr}$, based on the binding of the repilcates; the sensitivity of the assay concentration at $95 \% \mathrm{~B} / \mathrm{B}_{2}$ and at two standard deviations trom the couns per minute at zero binaingl; the 20,50 and 30 percent intercepts ing $\mathrm{mL}$; and the binding of the caibrators, $\omega_{0} 3 . \mathrm{B}$. tn addition, several samples were assaved as unknowns in each of the assays.

\begin{tabular}{|c|c|c|c|c|}
\hline Parameter & $30 \mathrm{~min}$ & : Sour & 2 hours & 3 hours \\
\hline $\begin{array}{l}\text { Total Counts } \\
\text { क NSB } \\
\text { कs . MB } \\
\text { rho } \\
\text { Assay CV }\end{array}$ & $\begin{array}{c}36.398 \mathrm{cpm} \\
1.5=0 \\
410 \\
-0.9002 \\
1.55\end{array}$ & $\begin{array}{l}36.710 \mathrm{cpm} \\
1.9 \sigma_{0} \\
4 \sigma_{0} \\
-0.9991 \\
1.9 \sigma_{0}\end{array}$ & $\begin{array}{c}36.779 \mathrm{cpm} \\
2.25 \\
455 \\
-0.0994 \\
1.35\end{array}$ & $\begin{array}{l}36.620 \mathrm{cpm} \\
3.6 \% \\
4.5 \\
-0.9009 \\
2.1 \%\end{array}$ \\
\hline Sensitivity: $\begin{array}{l}-2 S D \mid \\
\left.9553 / \mathrm{B}_{0}\right)\end{array}$ & $\begin{array}{l}1.7 \mathrm{ag} \mathrm{mL} \\
4.3\end{array}$ & $\begin{array}{l}1 . \pm \mathrm{ng} / \mathrm{mL} \\
4.2\end{array}$ & $\begin{array}{l}1.1 \mathrm{ng} / \mathrm{mL} \\
3.3\end{array}$ & $\begin{array}{l}0.85 \mathrm{ng} / \mathrm{mL} \\
4.0\end{array}$ \\
\hline $\begin{array}{l}\text { Intercepts: } \\
205 \mathrm{Bi} \\
50 \% \mathrm{~B}_{2} \\
805 \mathrm{Bi} \mathrm{B}_{2}\end{array}$ & $\begin{array}{l}535 n \xi / m L \\
12 S \\
2 S\end{array}$ & $\begin{array}{l}5: 5=5 / \mathrm{mL} \\
112 \\
24\end{array}$ & $\begin{array}{l}457=g / m L \\
99 \\
22\end{array}$ & $\begin{array}{l}439 \mathrm{ag} / \mathrm{mL} \\
94 \\
20\end{array}$ \\
\hline $\begin{array}{l}\text { Calibrators: } \\
\text { B }-10: \mathrm{g} / \mathrm{mL} \\
\text { C }-25 \\
D-100 \\
E-200 \\
F-500 \\
G-1000\end{array}$ & $\begin{array}{l}91 \% \\
82 \% \\
55 \% \\
40 \% \\
23 \% \\
145\end{array}$ & $\begin{array}{l}90 \sigma_{0} \\
30 \sigma_{0} \\
52 \sigma_{5} \\
37 \% \\
21 \% \\
13 \%\end{array}$ & $\begin{array}{l}895 \\
735 \\
505 \\
345 \\
195 \\
115\end{array}$ & $\begin{array}{l}895 \\
775 \\
495 \\
34 \% \\
195 \\
105\end{array}$ \\
\hline $\begin{array}{l}\text { Controls: } \\
1 \\
2 \\
3\end{array}$ & $\begin{array}{l}40 \mathrm{ag} / \mathrm{mL} \\
69 \\
285\end{array}$ & $\begin{array}{l}38 \mathrm{ng} / \mathrm{mL} \\
63 \\
295\end{array}$ & $\begin{array}{l}37 \mathrm{ag} / \mathrm{mL} \\
66 \\
277\end{array}$ & $\begin{array}{l}35 \mathrm{ng} / \mathrm{mi} \\
63 \\
280\end{array}$ \\
\hline $\begin{array}{l}\text { Samples: } \\
1 \\
2 \\
3 \\
4 \\
5 \\
6 \\
7 \\
8 \\
9 \\
10 \\
\end{array}$ & $\begin{array}{l}22 \mathrm{ng} \mathrm{mL} \\
32 \\
43 \\
60 \\
60 \\
75 \\
82 \\
188 \\
227 \\
838 \\
\end{array}$ & $\begin{array}{l}21 \mathrm{ng} / \mathrm{mL} \\
32 \\
39 \\
51 \\
51 \\
69 \\
80 \\
170 \\
206 \\
730 \\
\end{array}$ & $\begin{array}{l}22 \mathrm{ag} / \mathrm{mi} \\
30 \\
39 \\
53 \\
63 \\
72 \\
77 \\
158 \\
187 \\
718 \\
\end{array}$ & $\begin{array}{l}23 \mathrm{ng} / \mathrm{mL} \\
27 \\
36 \\
49 \\
61 \\
67 \\
73 \\
152 \\
164 \\
639 \\
\end{array}$ \\
\hline
\end{tabular}




\section{Drift}

To determine whether there is any position effect due to delays in the addition of reagents or decanting. pairs of tubes were spaced throughout a long assay for each of six samples. The resuits show no significant position or "end-of-run"! effect even in assays of more than 250 tubes.

\begin{tabular}{ccccc} 
& Tubes & Tuies & Tubes & $\begin{array}{c}\text { Tubes } \\
\text { Sample }\end{array}$ \\
$9-20$ & $95-106$ & $169-180$ & $243-254$ \\
\hline 1 & 11 & 12 & 9 & 12 \\
2 & 34 & 37 & 38 & 34 \\
3 & 40 & 36 & 42 & 40 \\
4 & 121 & 121 & 120 & 121 \\
5 & 131 & 127 & 128 & 126 \\
6 & 286 & 280 & 275 & 284 \\
\hline
\end{tabular}

\section{Specificity}

The antiserum is highly specife for liver ferritin. When different forms of ferritin found in the buman body were tested, both HeLa ferritin and Heart ferritin showed crossreactivities of less than $1 \%$ in the Double Antibody Ferritin procedure.

\section{Effect of Bilirubin and Hemolysis}

To simulate severe icterus, six serum sampies were spiked with $20 \mathrm{mg} / \mathrm{dL}$ of bilirubin. In another experiment, to simulate mild, moderate and severe hemolysis, six serum samples were spiked with 10,15 and $30 \mu \mathrm{L} / \mathrm{mL}$ of packed red biood ceils. All samples were assayed both spiked and unspiked by the Double Antibody Ferritin procedure with the following results.

\begin{tabular}{ccc} 
& & Bilirubin \\
Sample & Unspiked & $20 \mathrm{mgidL}$ \\
\hline 1 & 36 & 38 \\
2 & 112 & 122 \\
3 & 136 & 137 \\
4 & 208 & 224 \\
5 & 230 & 242 \\
6 & 296 & 286 \\
\hline
\end{tabular}

\begin{tabular}{ccccc} 
& & \multicolumn{3}{c}{ Packed Red Blood Cells $\mu \mathrm{Lim}$} \\
Sample & Unspiked & 10 & 15 & 30 \\
\hline 1 & 15 & 17 & 18 & 23 \\
2 & 38 & 43 & 44 & 46 \\
3 & 63 & 67 & 71 & 72 \\
4 & 113 & 123 & 123 & 119 \\
5 & 172 & 174 & 171 & 173 \\
6 & 228 & 225 & 226 & $22 \div$ \\
\hline
\end{tabular}

The results show that neither severe icterus (bilirubin up to $20 \mathrm{mg} / \mathrm{dL}$ ) nor gross hemolysis has any effect on the Double Antibody Ferritin procedure.

\section{Protein Effect}

To simulate various protein concentrations, experiments were performed in which $2.0 \mathrm{~mL}$ aliquots of a buman serum pool were freeze-dried and then reconstituted with várious voiumes of water. Each reconstituted aliquot was then assayed by the Double Antibody Ferritin procedure Note that aliquots reconstituted with half the criginal volume represent an extremely high protein concentration, in the order of $14 \mathrm{~g} / \mathrm{dL}$. These results indicate that even wide variations in protein have relatively little effect on the Double Antibody Ferritin assay.

\begin{tabular}{clllcccc} 
Experiment & Reconstitution & $\begin{array}{c}\text { Protein } \\
\text { Concentration }\end{array}$ & $\begin{array}{c}O \\
\text { Observed }\end{array}$ & $\begin{array}{c}E \\
\text { Expected }\end{array}$ & \% O/E \\
\hline \multirow{4}{*}{1} & $1.0 \mathrm{~mL}$ & $2.00 \times$ & $-14.0 \mathrm{~g} / \mathrm{dL}$ & 283 & 260 & $109 \%$ \\
& 1.3 & $1.50 \times$ & -10.5 & 207 & 195 & $106 \%$ \\
& 2.0 & $1.00 \times$ & -7.0 & 130 & - & $(100 \%)$ \\
& 3.0 & $0.67 \times$ & -4.7 & 98 & 87 & $113 \%$ \\
2 & $1.0 \mathrm{~mL}$ & $2.00 \times$ & $-14.0 \mathrm{~g} / \mathrm{dL}$ & 382 & 432 & $88 \%$ \\
& 1.3 & $1.50 \times$ & -10.5 & 326 & 324 & $101 \%$ \\
& 2.0 & $1.00 \times$ & -7.0 & 216 & - & $\mid 100 \%)$ \\
& 3.0 & $0.67 \times$ & -4.7 & 168 & 145 & $115 \%$ \\
\hline
\end{tabular}




\section{Effect of Anticoagulants}

To determine whether anticoagulants interfere with the assay, blood was collected from 10 volunteers into plain, heparinized and EDTA vacutainer tubes. All samples were assaved by the Double Antibody Ferritin procedure. The results were subjected to linear regression analysis.

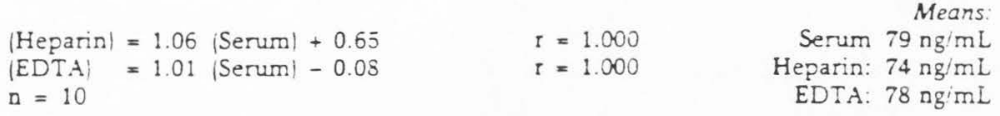

The results show that heparinized and EDTA plasma yield virtually the same results as serum in the Double Ant:body Ferritin procedure.

\section{Parallelism}

Four patient serum samples were assayed both undiluted and diluted with the zero calibrator. The observed and expected values are presented below in $\mathrm{ng} / \mathrm{mL}$.

\begin{tabular}{|c|c|c|c|c|}
\hline Sampie & Dilution & $\begin{array}{c}0 \\
\text { Observed }\end{array}$ & $\begin{array}{c}\text { E } \\
\text { Expected }\end{array}$ & $50 / E$ \\
\hline \multirow[t]{4}{*}{1} & 4 in 4 (undiluted) & 142 & & \\
\hline & 3 in 4 & 107 & 107 & 1005 \\
\hline & 2 in 4 & 69 & 71 & 975 \\
\hline & 1 in 4 & 32 & 36 & $89 \%$ \\
\hline \multirow[t]{4}{*}{2} & 4 in 4 (undiluted) & 382 & & \\
\hline & 3 in 4 & 278 & 287 & $97 \%$ \\
\hline & 2 in 4 & 178 & 191 & $93 \%$ \\
\hline & 1 in 4 & 84 & 96 & $88 \omega_{5}$ \\
\hline
\end{tabular}

\begin{tabular}{clccc} 
Sample & Dilution & $\begin{array}{c}O \\
\text { Observed Expected }\end{array}$ & $\begin{array}{c}\text { 5 } \\
\text { O O E }\end{array}$ \\
\hline 3 & 4 in 4 (undiluted) & 596 & & \\
& 3 in 4 & 422 & 447 & $94 \%$ \\
& 2 in 4 & 285 & 298 & $96 \%$ \\
4 & 1 in 4 & 139 & 149 & $93 \%$ \\
4 & 4 in 4 (undiluted) & 838 & & \\
& 3 in 4 & 594 & 629 & $94 \%$ \\
& 2 in 4 & 382 & 419 & $91 \%$ \\
1 in 4 & 196 & 210 & $93 \%$ \\
\hline
\end{tabular}

\section{Spiking Recovery}

Three spiking solutions were made using the zero calibrator as diluent. The solutions $\mid A, B$ and $C \mid$ were made to represent 1000, 2000 and $4000 \mathrm{ng} / \mathrm{mL}$, respectively. The spiking solutions were diluted in the zero calibrator and assaved by the Double Antibody Ferritin procedure.

\begin{tabular}{ccccc}
$\begin{array}{c}\text { Spiking } \\
\text { Soiution }\end{array}$ & Dilution & $\begin{array}{c}\text { O } \\
\text { Observed }\end{array}$ & $\begin{array}{c}\text { E } \\
\text { Expected }\end{array}$ & \% O/E \\
\hline A & 1 in 4 & 250 & 250 & $100 \%$ \\
B & 1 in 10 & 199 & 200 & $100 \%$ \\
C & 1 in 20 & 203 & $200 \ldots \ldots$ & $102 \%$ \\
\hline
\end{tabular}

$50 \mu \mathrm{L}$ of each of these solutions was spiked into $0950 \mathrm{~mL}$ aliquots of each of four different patient serum samples, for a spiking ratio of 1 to 19 , leaving the serum matrix of the spiked samples relatively intact. These spiked samples were then assayed by the Double Antibody Ferritin procedure. To calculate expected values, $95 \%$ of the unspiked value was added to $5 \%$ of the spiking solution concentration $(50,100$ and $200 \mathrm{ng} / \mathrm{mL}$, respectively $)$.

\begin{tabular}{ccccc} 
Sample & $\begin{array}{c}\text { Spiking } \\
\text { Solution }\end{array}$ & $\begin{array}{c}\text { O } \\
\text { Observed }\end{array}$ & $\begin{array}{c}\text { E } \\
\text { Expected }\end{array}$ & \% O/E \\
\hline 1 & - & 146 & & \\
& A & 278 & 189 & $94 \%$ \\
& B & 222 & 239 & $93 \%$ \\
2 & C & 323 & 339 & $95 \%$ \\
& - & 229 & & \\
& A & 265 & 268 & $99 \%$ \\
& C & 389 & 418 & $93 \%$ \\
\hline
\end{tabular}

\begin{tabular}{ccccc} 
Sample & Spiking & O & E & \\
Solution & Observed & Expected & \% O/E \\
\hline 3 & - & 230 & & \\
& A & 259 & 269 & $96 \%$ \\
& B & 309 & 319 & $97 \%$ \\
4 & C & 405 & 419 & $97 \%$ \\
& - & 255 & & \\
& A & 289 & 292 & $99 \%$ \\
& B & 347 & 342 & $101 \%$ \\
& C & 413 & 442 & $93 \%$ \\
\hline
\end{tabular}




\section{Method Comparison}

Fity patten serum samples were assayed by the Double Antoody Ferrtin procecure and by arother commercaily

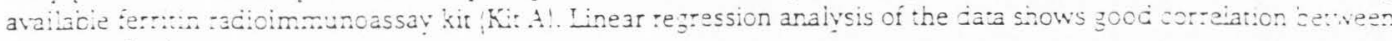
these metnods

$$
\begin{aligned}
& \angle D P C=0.9 \mathrm{~S} \text { Kit } \mathrm{A}-2.0 \mathrm{ag} \mathrm{mi} \\
& \text { Hears: } \\
& \text { DPC. } 31 \mathrm{ng} \mathrm{mi} \\
& \text { Kit A: } 95 \mathrm{ag} / \mathrm{mL}
\end{aligned}
$$

In addition, the Hour, $37^{\circ} \mathrm{C}$ and the 3 hour roomtemperature procecures were compared on :CO samedes wath the following results.

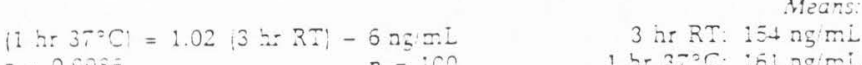

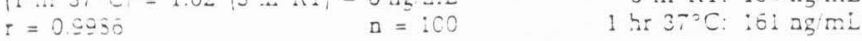

\section{Expected Values}

A norma! range sudy was getrormed in which 120 samples trom adult volunteers in good heaith were assay ed by the Double Antibody Fertin procedure. The results are summarized in the tabie below:

\begin{tabular}{lccc} 
& Median & Central $95 \bar{m}$ & $n$ \\
\hline Males & $105 \mathrm{ng} / \mathrm{mL}$ & $25-\$ 00$ & 52 \\
Eemaies & $332 \mathrm{gg} \mathrm{mL}$ & $11-120$ & $5 \delta$ \\
\hline
\end{tabular}

The normai range limits sugzested by th:s siudy should ze regarded as guideiines oniy. Because of tiforences which may exs berween laboratcries and locales with respect to population, dier, 'aboratory technicue and select:on or reference zrouss, it is imoorant for eaca laboratory to estabiish by similar means the approprateness of atcoring the normal rances suggested by this study. For further discussion. see the section Summary and Explanation of tae Test. In a furher study, sampies trom 29 patients with iron desciency anemia were assayed by the Double Antibody Ferrin procedure Diacnosis of ircn defciency was based on lacoratory fndings: decreased iron $F$ Fel and tron-binding capac:ty TIBC ancior decreased mean corpuscular volume MCV) and mean corpuscular hemoglobin (MCH). it is no: known whether the patients ¿ad "uncomplicated" iron-ceaciency anemia. Ferritin resuits for the twent-four Semales in this stucy ranged trom undetectable to $: 5 \mathrm{gg} / \mathrm{mL}$; 79 percent were below $10 \mathrm{ng} / \mathrm{mL}$. The fve nales had :erttin resuits ranging trom underectable to $16 \mathrm{gg} \mathrm{mL}$. with ail but one iess than $7 \mathrm{ag} / \mathrm{mL}$.

\section{References}

1 P. Arosio et al, Ferritin: biochemistn and methods of de:ermination” Ligand Quarteriy 4 no. 3 (Fall 19S:) 45-5:

2 J.D. Cook. "Cinical evaiuation of iron deficiency" Seminars in Hematoiogy 29 (1982) $5-17$.

3 D. Ellis, "Serum ferritin compared with other indices of iron status in children and teenagers undergoing maintenance hemodialysis' Clinical Chemistry 25 (1979) 741-44.

4 C.A. Finch and H. Huebers, "Perspectives in iron metabolism" New England Joumal of Medicine 306 (1982) $1520-28$

$=$... r Hancoc and Paline Harrison. Serum ferritin in normal individuals and in patients with malignant hymphoma and chronic renal failure riezsui: $\mathrm{d}^{-}$. th theven different commercial m.mus.o. assay techniaues" Joumal of Clinicai Pathology 35 (1982) 1204-12.
6 June Hailidav and Lawre Poweil. Tron overicad" Sem. inars in Hematoiogy $19\{1982\}+2-53$.

7 J.P. Kaitwasser. "Indikation zur Serumferritir-Bestimmung" Deutscine Medizinische Wochenschnit 05 (1980) 319-21.

8 P.E. Lundberg, G. Lindstedt et al. Increase in serum ferritin concentration isduced oy fasting" C'inical Chemistry 30 (1984) 161-63.

9 Leslie Vaiberg, Plasma furritin concentrations: their clinical signiscance and relevance to patient care Joumal of the Canadian Medical Association $222(1980)$ $1240-47$ 
Technical Assistance: If questions arise concerning the Double Antibody Ferritin reagents or for further advice on technique, data reduction, quality control or expected values, please contact DPC's Technical Services department. (213) 776-0180

(800) 678-6699

TELEX 4720518

FAX (213) 642-0192

Outside the United States, contact your National Distributor.

Double Antibody Ferritin is manufactured by EURO/DPC Ltd. and distributed in the United States by DPC.

Manufactured under a Quality System (ISO 9002/EN29002/BS 5750 part II) approved by the British Standards Institute.

EURO/DPC Ltd.

31 Station Lane

Witney, Oxfordshire OXs GAN

United Kingdom

\section{군}

Diagnostic Products Corporation

5700 West 96 th Street

Los Angeles, CA 90045

United States
Pachage Insert:

G 059

June 28, 1991 
APPENDIX E: Adjusted Ferritin Double Antibody Procedure for Small Samples 
Table A.6. Adjusted ferritin double antibody for small samples.

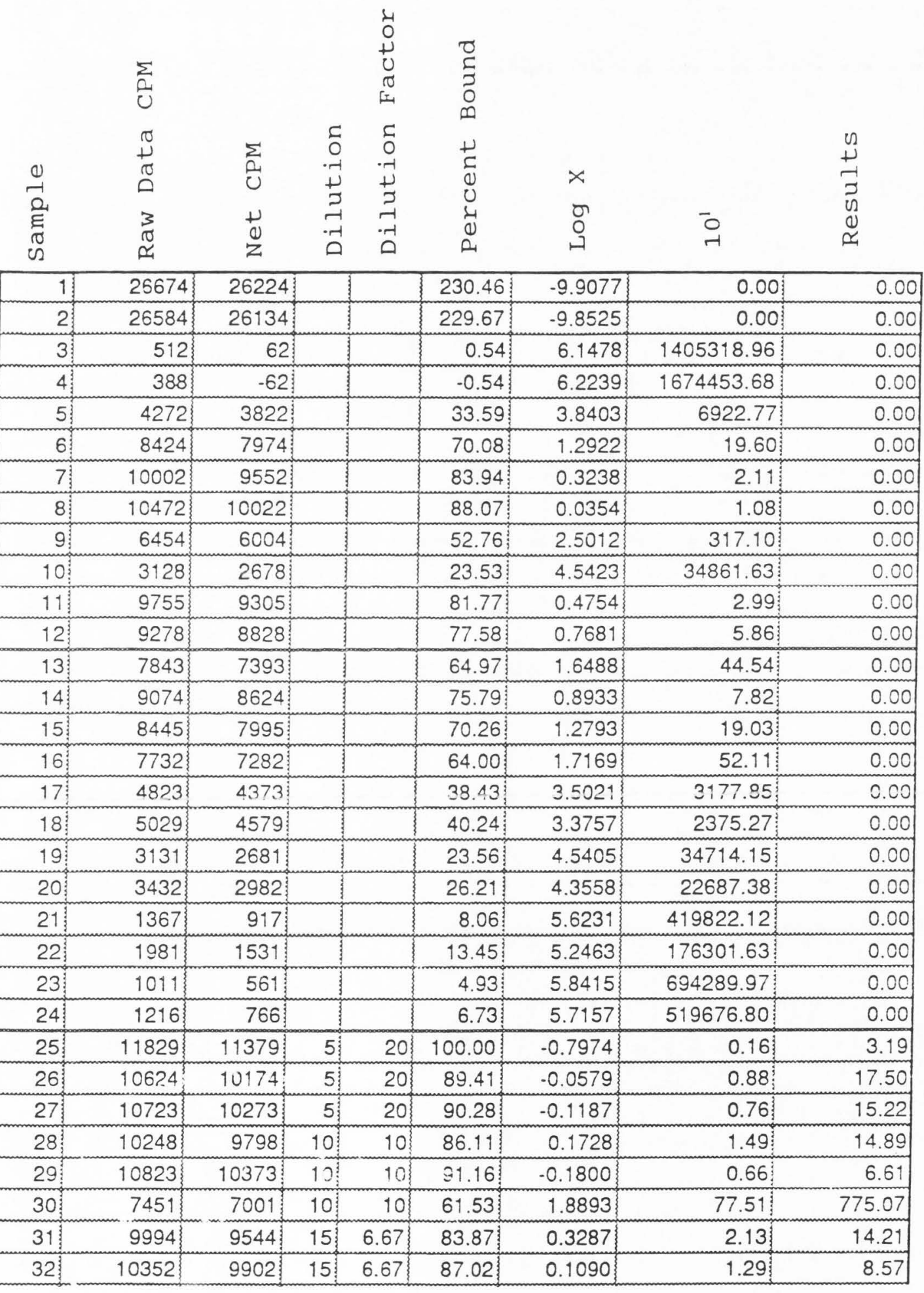


Table A.6 continued

\begin{tabular}{|c|c|c|c|c|c|c|c|c|}
\hline 33 & 10063 & 9613 & 15 & 6.67 & 84.48 & 0.2864 & 1.93 & 12.89 \\
\hline $34:$ & 9861 & 9411 & 20 & 5 & 82.70 & $0.4103\}$ & 2.57 & 12.86 \\
\hline 35 & 9761 & 9311 & 20 & 5 & 81.83 & 0.4717 & 2.96 & 14.81 \\
\hline $36:$ & 9977 & 9527 & 20 & $5\}$ & 83.72 & 0.3391 & 2.18 & 10.92 \\
\hline 37 & 9291 & 8841 & 25 & $4\}$ & 77.70 & 0.7601 & 5.76 & 23.03 \\
\hline 38 & 9918 & 9468 & 25 & $4\}$ & 83.21 & 0.3754 & 2.37 & 9.49 \\
\hline 39 & 9327 & 8877 & 25 & 4 & 78.01 & 0.7380 & 5.47 & 21.88 \\
\hline 40 & 9090 & 8640 & 30 & 3.33 & 75.93 & 0.8835 & 7.65 & 25.49 \\
\hline 41 & 9203 & 8753 & 30 & 3.33 & 76.92 & 0.8141 & 6.52 & 21.73 \\
\hline 42 & 1464 & 1014 & 30 & 3.33 & 8.91 & 5.5635 & 366047.01 & 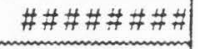 \\
\hline 43 & 9263 & 8813 & 35 & 2.86 & 77.45 & 0.7773 & 5.99 & 17.11 \\
\hline 44 & 9253 & 8803 & 35 & 2.86 & 77.36 & 0.7835 & 6.07 & 17.35 \\
\hline 45 & 8377 & 7927 & 35 & 2.86 & 69.66 & 1.3211 & 20.94 & 59.84 \\
\hline 46 & 6784 & 6334 & 100 & $1\}$ & 55.66 & 2.2987 & 198.92 & 198.92 \\
\hline 47 & 6219 & 5769 & 100 & $1\}$ & 50.70 & 2.6454 & 441.99 & 441.99 \\
\hline 48 & 6736 & 6286 & 100 & $1\}$ & 55.24 & 2.3281 & 212.88 & 212.88 \\
\hline 49 & 9319 & 8869 & 5 & 20 & 77.94 & 0.7430 & 5.53 & 110.66 \\
\hline 50 & 4614 & 4164 & 5 & $20\}$ & 36.59 & 3.6304 & 4269.69 & 85393.79 \\
\hline 51 & 3086 & 2636 & 5 & 20 & 23.17 & 4.5681 & 36993.28 & 739865.68 \\
\hline 52 & 9913 & 9463 & 10 & $10\}$ & 83.16 & 0.3784 & 2.39 & 23.90 \\
\hline 53 & 9989 & 9539 & 10 & $10\}$ & 83.83 & 0.3318 & 2.15 & 21.47 \\
\hline 54 & 8723 & 8273 & 10 & 10 & 72.70 & 1.1087 & 12.84 & 128.45 \\
\hline 55 & 10148 & 9698 & 15 & 6.67 & 85.23 & 0.2342 & 1.71 & 11.43 \\
\hline 56 & 9380 & 8930 & 15 & 6.67 & 78.48 & 0.7055 & 5.08 & 33.84 \\
\hline 57 & 8349 & 7899 & 15 & 6.67 & 69.42 & 1.3382 & 21.79 & 145.26 \\
\hline 58 & 9221 & 8771 & 20 & $5\}$ & 77.08 & 0.8031 & 6.35 & $\begin{array}{r}31.77 \\
\end{array}$ \\
\hline 59 & 972 & 522 & 20 & $5\}$ & 4.59 & 5.8655 & 733626.50 & 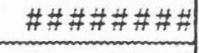 \\
\hline 60 & 9581 & 9131 & 20 & $5\}$ & 80.24 & 0.5822 & 3.82 & $\begin{array}{r}19.10 \\
\end{array}$ \\
\hline 61 & 481 & 31 & 25 & 4 & 0.27 & 6.1668 & 1468248.16 & \#\#\#\#\#\#\# \\
\hline 62 & 7981 & 7531 & 25 & $4\}$ & 66.18 & 1.5641 & 36.65 & 146.60 \\
\hline 63 & 9583 & 9133 & 25 & 4 & 80.26 & 0.5809 & 3.81 & 15.24 \\
\hline 64 & 8451 & 8001 & 30 & 3.33 & 70.31 & 1.2756 & 18.86 & 62.88 \\
\hline 65 & 6664 & 6214 & 30 & 3.33 & 54.61 & 2.3723 & 235.68 & 785.60 \\
\hline 66 & 7791 & 7341 & 30 & 3.33 & 64.51 & 1.6807 & 47.94 & 159.80 \\
\hline 67 & 8691 & 8241 & 35 & 2.86 & $72.4 ?$ & 1.1284 & 13.11 & 38.40 \\
\hline 68 & 8783 & 8333 & 35 & 2.86 & 73.23 & 1.0719 & 11.80 & 33.72 \\
\hline 69 & 2299 & 1849 & 35 & 2.86 & 16.25 & 5.0511 & 112486.70 & 321390.58 \\
\hline $70 !$ & $6068\}$ & $5 \in 1 \varepsilon$ & 100 & $\therefore$ & $A 0 \quad 27$ & 2.7381 & 547.12 & 547.12 \\
\hline 71 & 5083 & 5633 & 100 & 13 & 49.50 & 2.7289 & 535.65 & 535.65 \\
\hline 72$\}$ & 5770 & 5320 & 100 & 13 & 46.15 & 2.9210 & 833.61 & 833.61 \\
\hline
\end{tabular}


CURRICULUM VITAE

Nedra K. Christensen

\author{
Assistant Director of Coordinated \\ Dietetic Program \\ Dept. of Nutr. \& Food Sciences \\ Utah State University \\ Logan, UT 84322-8700 \\ (801) 750-2126
}

\section{Education}

University of Utah Salt Lake City, UT B.A. 1975

Utah state University Dietetics Logan, UT Nutrition M.S. $\quad 1980$

Previous Employment

1975-1976 Internship Program, New England Deaconess Hospital, Boston, Massachusetts.

1976 Clinical Dietitian, New England Deaconess Hospital, Boston, Massachusetts.

1977-1978 Clinical Dietitian, Joslin Diabetes Treatment Unit, New England Deaconess Hospital, Boston Massachusetts.

1980-1984 Nutrition Coordinator, Diabetes Research and Training Center, Vanderbilt University.

1984-1985 Nutrition Coordinator, Salt Lake City/County Health Department/WIC, Salt Lake City, Utah.

1984-1988 Nutrition Coordinator, Utah State Department of Health/WIC, Salt Lake City, Utah.

1988-date Assistant Director of Coordinated Dietetic Program, Department of Nutrition and Food Sciences, Utah State University, Logan, Utah.

\section{Honors and Activities}

Board Member of Utah Dietetic Association, Nominating Chair, 1990 - 1991

Coordinator of Semiannual Nutrition Workshops for public health dietitians and nurses september 1985 - September 1988

Speaker, Alabama's Annual Diabetes Association Meeting, "Update on Diet", October 1983

Speaker, Tennessee Annual Diabetes Association Meeting, "Diet Adherence" and "Fiber", May 1982

Chairman, Council on Practice Division of Education, Nashville District Dietetic Association, 1981-82

Chairman, Council on Practice Division of Community Nutrition, Nashville District Dietetic Association, 198283 and 1983-84

Co-Chairman of Workshop, "Nutritional Counseling for the Home Health Nurse", 1982 
Instructor, Food Biochemistry Course for Layman, Cambridge Center of Adult Education, 1978-1979

\section{Memberships}

American Dietetic Association,

American Diabetes Association

\section{Publications}

Srinivasan, V., Christensen, N.K., Wyse, B.W., Hansen, R.G.: Pantothenic Acid Nutritional status in the Elderly Institutionalized and Non-institutionalized. American Journal of Clinical Nutrition 34: 1736-1742, September 1981 .

Christensen, N.K., Terry, R.D., Wyatt, S., Pichert, J.W., and Lorenz, R.A.: Quantitative Assessment of Dietary Adherence in Patients with Insulin Dependent Diabetes Melitus. Diabetes Care 6(3):245, May-June, 1983.

Lorenz, R.A., Christensen, N.K., Pichert, J.W.: Diet Related Knowledge, Skill, and Adherence Among Children With Insulin Dependent Diabetes Mellitus. Pediatrics 1985, $75: 872$.

Christensen, N., Lorenz, R.: Nutrition Educational Needs of Children with Insulin Dependent Diabetes Melitus. Diabetes 32 (Suppl. 1):6A\#23, 1983 (abstract).

Christensen, N., Heins, J., and Thompson, J: Nutrition Surveillance Information: A Tool to Assure Quality Nutrition Education Intervention. JADA 1986, Abstracts p. 70 . 